RM12-2798 High-Efficiency Rooftop Unit Replacement

\title{
Hawaii and Guam Energy Improvement Technology Demonstration Project
}

Ian Doebber and Gene Holland National Renewable Energy Laboratory

NREL Technical Monitor: Steve Gorin

Produced under direction of the Naval Facilities Engineering Command (NAVFAC) by the National Renewable Energy Laboratory (NREL) under Interagency Agreement 11-01829.

NREL is a national laboratory of the U.S. Department of Energy Office of Energy Efficiency \& Renewable Energy Operated by the Alliance for Sustainable Energy, LLC

This report is available at no cost from the National Renewable Energy Laboratory (NREL) at www.nrel.gov/publications.

Strategic Partnership Project Report NREL/TP-7A40-71508

July 2018

Contract No. DE-AC36-08G028308 


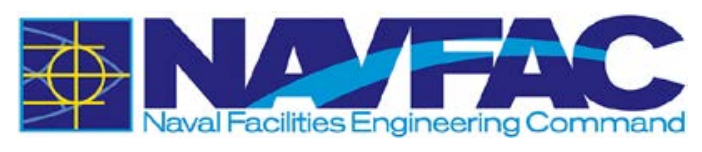

\title{
RM12-2798 High-Efficiency Rooftop Unit Replacement
}

\section{Hawaii and Guam Energy Improvement Technology Demonstration Project}

\author{
Ian Doebber and Gene Holland \\ National Renewable Energy Laboratory \\ NREL Technical Monitor: Steve Gorin
}

\section{Suggested Citation}

Doebber, lan, Gene Holland. 2018. RM12-2798 High-Efficiency Rooftop Unit Replacement: Hawaii and Guam Energy Improvement Technology Demonstration Project. Golden, CO: National Renewable Energy Laboratory. NREL/TP-7A40-71508. https://www.nrel.gov/docs/fy18osti/71508.pdf.

NREL is a national laboratory of the U.S. Department of Energy Office of Energy Efficiency \& Renewable Energy Operated by the Alliance for Sustainable Energy, LLC

This report is available at no cost from the National Renewable Energy Laboratory (NREL) at www.nrel.gov/publications.

National Renewable Energy Laboratory 15013 Denver West Parkway Golden, CO 80401

303-275-3000 • www.nrel.gov
Strategic Partnership Project Report NREL/TP-7A40-71508

July 2018

Contract No. DE-AC36-08GO28308 


\section{NOTICE}

This work was supported by the U.S. Department of Energy under Contract No. DE-AC36-08G028308 with Alliance for Sustainable Energy, LLC, the Operator of the National Renewable Energy Laboratory, and the Naval Facilities Engineering Command (NAVFAC) under Interagency Agreement 11-01829. The views expressed in the article do not necessarily represent the views of the DOE or the U.S. Government.

This report is available at no cost from the National Renewable Energy Laboratory (NREL) at www.nrel.gov/publications.

U.S. Department of Energy (DOE) reports produced after 1991 and a growing number of pre-1991 documents are available free via www.OSTI.gov.

NREL prints on paper that contains recycled content. 


\section{Acknowledgments}

The authors wish to acknowledge Joint Base Pearl Harbor-Hickam (JBPHH) personnel for hosting this demonstration and providing key support from initial design to project completion. We thank Robert Cabreros and David Stiner from Naval Facilities Engineering Command (NAVFAC) Pacific; Peter Yuen and Chelsea Goto of the NAVFAC Hawaii energy team; Captain Jeffrey W. James, joint base commander; and Colonel David Kirkendall, deputy base commander.

The project could not have met success without the coordination and oversight from Florence Ching, Wah-Cheong Sze, James Low, April Teekell, and Susan Kim with NAVFAC Pacific and Hawaii.

We also thank Kevin Hurley of NAVFAC Headquarters for his guidance and administration of the demonstration program.

Numerous contributors at the U.S. Department of Energy's National Renewable Energy Laboratory (NREL), Transformative Wave (TW), ClimaCheck, Emerging Energy Solutions, and Daikin Applied should be acknowledged. At NREL, contributors include Jeff Dominick, John Nangle, Mike Heaney, Michael Deru, Eric Kozubal, and Melissa Butheau. At TW, who managed the construction, Web-based building management system, and remote monitoring, we wish to thank Justin Sipe, Danny Miller, Jerry Scott, and Ken Hellewell. At ClimaCheck and Emerging Energy Solutions, who provided the detailed submetering on each refrigeration circuit, we wish to thank Klas Berglof, Sean McCaffery and Joel Klobas. At Daikin Applied who provided Rebel technical support, we wish to thank Brett Gist, Gregory Durant, and Brad Hassing. 


\section{List of Abbreviations and Acronyms}

AFDD automated fault detection and diagnostics

AHJ authority having jurisdiction

AHRI Air-Conditioning, Heating, \& Refrigeration Institute

ANSI American National Standards Institute

ASHRAE American Society of Heating, Refrigerating and Air-Conditioning Engineers

Btuh British thermal units per hour

cfm cubic feet per minute

$\mathrm{CO}_{2} \quad$ carbon dioxide

COP coefficient of performance

CVRMSE coefficient of variation of the root mean squared error

DAT discharge air temperature

DCV demand-controlled ventilation

DOD U.S. Department of Defense

DOE U.S. Department of Energy

DX direct expansion

ECM electronically commutated motor

EER energy efficiency ratio

FEMP Federal Energy Management Program

$\mathrm{ft}^{2} \quad$ square feet

fpm flow per minute

HVAC heating, ventilation, and air conditioning

IEER integrated energy efficiency ratio

JBPHH Joint Base Pearl Harbor-Hickam

kW kilowatt 


\begin{tabular}{|c|c|}
\hline $\mathrm{kWh}$ & kilowatt-hour \\
\hline MWh & megawatt-hours \\
\hline NAVFAC & Naval Facilities Engineering Command \\
\hline NEMA & National Electrical Manufacturers Association \\
\hline NREL & National Renewable Energy Laboratory \\
\hline OA & outdoor air \\
\hline $\mathrm{O} \& \mathrm{M}$ & operation and maintenance \\
\hline PAC & Pacific (NAVFAC PAC) \\
\hline PI & proportional-integral \\
\hline $\mathrm{RH}$ & relative humidity \\
\hline ROI & return on investment \\
\hline RTU & packaged air conditioning rooftop unit \\
\hline SEER & seasonal energy efficiency ratio \\
\hline SHGC & solar heat gain coefficient \\
\hline SZVAV & single-zone variable-air volume \\
\hline TAB & (HVAC) testing, adjusting, and balancing \\
\hline TMY3 & typical meteorological year 3 \\
\hline TWT & Transformative Wave Technologies \\
\hline UFC & Unified Facilities Criteria \\
\hline UFGS & Unified Facilities Guide Specifications \\
\hline $\mathrm{W}$ & Watt \\
\hline WC & water column \\
\hline
\end{tabular}




\section{Executive Summary}

As part of its overall strategy to meet its energy goals, NAVFAC partnered with NREL to rapidly demonstrate and deploy cost-effective renewable energy and energy efficiency technologies. This was one of several demonstrations of new and underutilized commercial energy efficiency technologies. The common goals were to demonstrate and measure the performance and economic benefits of the system and to monitor any ancillary impacts related to standards of service and operation and maintenance (O\&M) practices. In short, these demonstrations simultaneously evaluated the benefits and compatibility of the technologies with the U.S. Department of Defense (DOD) mission, and with NAVFAC's design, construction, and O\&M practices.

A wide variety of DOD buildings, such as offices, warehouses, gymnasiums, commissaries, exchange stores, and hangars, are ventilated, cooled, and heated with packaged rooftop air conditioning units (RTUs). The term RTU refers to a pre-engineered unitary system that houses all the components of a heating, ventilation, and air conditioning (HVAC). Most RTUs are located on a roof but can also be located on concrete pads next to the building they serve. In Hawaii, RTUs provide only space cooling and outdoor air (OA) for ventilation, as no heating is needed. RTUs are popular for three reasons: (1) minimal engineering design and specifications; (2) low first costs compared to built-up systems (e.g., chillers with air handling units); and (3) quick installation. Unfortunately, RTUs have historically been one of the lowest efficiency HVAC systems on the market.

DOE issued the High-Performance Rooftop Unit Challenge in January 2011 to: ${ }^{1}$

catalyze the market introduction of cost-effective, energy-saving RTUs that would significantly outperform any models that were currently available. RTUs built according to this specification are expected to reduce energy use by as much as 50\% compared to the current ASHRAE 90.1 Standard, depending on location and facility type.

In May 2012, ${ }^{2}$ the Daikin Applied Rebel $^{3}$ was the first commercially available RTU to meet the DOE RTU challenge specification. The Rebel met the comprehensive RTU challenge requirements with: an integrated energy efficiency ratio (IEER) exceeding18.0, a variable-speed supply fan, direct digital controls, and automated fault detection and diagnostics (AFDD). This field demonstration evaluated the energy savings and thermal comfort benefits of the Rebel compared to a code-minimum RTU. The baseline RTU met the ASHRAE 90.1-2010 minimum performance requirements per the United Facilities Guide Specification (UFGS) 2381000020. Both the Rebel and baseline RTUs served a small office located on JBPHH.

The field demonstration was designed to provide a true apples-to-apples comparison between the Rebel RTU and baseline RTU. Based on an extensive investigation of existing RTUs at JBPHH, NAVFAC and NREL chose to replace two 10-ton, 15-year-old RTUs serving a 5,000-ft ${ }^{2}$ office.

\footnotetext{
1 “DOE Facilitates Market-Driven Solutions to Develop and Deploy New High-Efficiency Commercial Air Conditioners.” U.S. Department of Energy, Office of Energy Efficiency \& Renewable Energy, February 3, 2011.

2 "Energy Department Announces First Product to Meet the Commercial Rooftop Air Conditioner Challenge.” U.S. Department of Energy, Office of Energy Efficiency \& Renewable Energy, May 24, 2012.

3 “Rebel Overview.” Daikin Applied, 2014. http://www.daikinapplied.com/rooftop-rebel.php.
} 
The RTU serving the southern half of the space was replaced with a Rebel; the RTU serving the northern half of the space with the baseline. Table ES-1 compares their rated performances and highlights the high-efficiency components of the Rebel.

Table ES-1. Daikin Applied Rebel and Baseline RTU Rated Performance

\begin{tabular}{|c|c|c|}
\hline & Baseline RTU ${ }^{1}$ & $\begin{array}{l}\text { Daikin Applied Rebel } \\
\text { Model DPS010A }\end{array}$ \\
\hline $\begin{array}{l}\text { Energy } \\
\text { Efficiency Ratio } \\
\left(\text { EER) }{ }^{2} / \text { IEER }^{3}\right.\end{array}$ & $11.3 / 11.8$ & $12.5 / 19.4$ \\
\hline $\begin{array}{l}\text { Net Rated } \\
\text { Cooling }\end{array}$ & 10 tons & 10 tons \\
\hline Supply Fan & $\begin{array}{l}\text { Constant-speed/belt-driven/ } \\
\text { National Electrical Manufacturers } \\
\text { Association (NEMA) standard } \\
\text { efficiency motor }\end{array}$ & $\begin{array}{l}\text { Variable-speed/direct drive/electronically } \\
\text { commutated motor (ECM) }\end{array}$ \\
\hline Compressors & $\begin{array}{l}2 \text { constant speed scrolls on } 2 \\
\text { separate direct expansion (DX) } \\
\text { circuits }\end{array}$ & $\begin{array}{l}1 \text { variable-speed scroll and } 1 \text { constant-speed } \\
\text { scroll on a single DX circuit }\end{array}$ \\
\hline OA Damper & $\begin{array}{l}\text { Fixed parallel blade; } \\
\text { No edge/jamb seals }\end{array}$ & $\begin{array}{l}\text { Actuator/linkage-driven opposing blade damper; } \\
\text { Low-leakage damper with edge/jamb seals }\end{array}$ \\
\hline Cabinet Casing & Single-wall with no insulation & Double-wall with foam insulation \\
\hline \multicolumn{3}{|c|}{$\begin{array}{l}\text { Notes: (1) Per UFGS-23 } 8100.00 \text { 20, the baseline is a code-minimum RTU meeting ASHRAE Standard 90.1-2010 } \\
\text { prescriptive performance requirements of } 11.2 \text { EER and } 11.4 \text { IEER based on Table 6.8.1A for air conditioners } \\
\geq 65,000 \text { British thermal units per hour (Btuh) (5.4 tons) and }<135,000 \text { Btuh ( } 11.3 \text { tons). The baseline RTU has basic } \\
\text { thermostatic control - fan (G), cooling stage } 1 \text { (Y1), cooling stage } 2 \text { (Y2). (2) EER rated conditions are at an } \\
\text { ambient dry-bulb of } 95^{\circ} \mathrm{F} \text { and a mixed-air dry-bulb of } 80^{\circ} \mathrm{F} \text { and wet-bulb of } 67^{\circ} \mathrm{F} \text { per the Air-Conditioning, Heating, } \\
\text { \& Refrigeration Institute (AHRI) Standard } 340 / 360-2007 \text {. (3) IEER rating incorporates the part load performance of } \\
\text { an RTU per AHRI Standard 340/360-2007. }\end{array}$} \\
\hline
\end{tabular}

NREL stipulated a true apples-to-apples RTU comparison must meet two requirements: (1) both RTUs provide the same amount of cooling to achieve the same duty cycle and (2) both RTUs maintain their respective temperature sensors to $\pm 1^{\circ} \mathrm{F}$ of a $76^{\circ} \mathrm{F}$ set point. While operating the RTUs simultaneously during the first month of the demonstration period (October 2013), the monitored data clearly showed that the first parameter was not achievable. Even though the RTUs were conditioning different sides of an open office space, the Rebel RTU was providing more than $70 \%$ of the cooling and, consequently, was consuming more energy.

The Rebel provided more cooling because of its single-zone variable-air volume (SZVAV) control logic. The Rebel ramps the supply fan from 40\%-100\% based on the space temperature versus set point error. The Rebel then modulates the compressors to maintain a user-specified discharge air temperature (DAT). The Rebel would essentially stay on for most of the occupied hours, nimbly adjusting its compressor capacity to maintain more gradual temperature changes within its $\pm 1^{\circ} \mathrm{F}$ deadband. In contrast, the baseline maintained a constant supply airflow and could only control its cooling to either $50 \%$ (first stage) or 100\% (second stage) capacity. 
Therefore, NREL shifted tactics. For the remainder of the demonstration period, from November 2013 through January 2014, NREL alternated baseline and Rebel operation weekly. The demonstration data were then used to develop calibrated models of both RTUs. The baseline model was calibrated against 36 days of baseline-only operation. The Rebel model was calibrated against 35 days of Rebel-only operation. Oahu's weather year-round is consistent such that this limited dataset was sufficient to capture the performance of both RTUs across the year.

Each calibrated model was then simulated across an entire year using Honolulu typical meteorological year (TMY3) weather data. The baseline model was simulated as if two baseline RTUs were conditioning the entire office space. Similarly, the Rebel model was simulated with the entire office space being conditioned by two Rebel RTUs. Both baseline and Rebel models incorporated identical building envelope, infiltration, and internal loads.

The Rebel RTU model provided ventilation that met ASHRAE 62.1-2010 requirements according to its testing, adjusting, and balancing (TAB) report. The demand-controlled ventilation (DCV) capability of the Rebel was not modeled because it is not common on NAVFAC facilities. The Unified Field Criteria (UFC) 3-410-01stipulates DCV must receive approval from the authority having jurisdiction (AHJ) because of NAVFAC's concern about the carbon dioxide sensors maintaining calibration over time.

The baseline RTU was found to have an extremely leaky OA damper based on its TAB report. Even a fixed 5\% OA damper position resulted in a ventilation rate over three times the ASHRAE 62.1-2010 minimum requirement. NREL found typical RTU OA dampers ranging from 5\%-20\% fixed positions based on site visits to more than 30 RTUs throughout JBPHH. Therefore, NREL compared the Rebel model versus the baseline model with (1) a fixed 5\% OA damper, (2) a fixed 20\% OA damper, and (3) a ventilation rate exactly meeting the ASHRAE 62.1-2010 minimum requirements.

Table ES-2 compares a single 10-ton Rebel RTU to a single 10-ton baseline RTU with a fixed 5\% OA damper configuration. Accounting for the power measurement and model uncertainties, the annual energy savings of 3,862 kilowatt-hours ( $\mathrm{kWh})$ has a $\pm 27 \%$ uncertainty $( \pm 1,042 \mathrm{kWh})$ based on a $95 \%$ confidence interval. Compared to a 10-ton baseline RTU with a fixed 20\% OA damper, the Rebel saved 4,552 kWh (37\%). Compared to a 10-ton baseline RTU exactly providing ASHRAE 62.1 ventilation rates, the Rebel saved 3,034 kWh (29\%).

In summary, a 10-ton Rebel RTU serving a small office at JBPHH will save 34\%-37\% compared to a code-minimum, baseline RTU with a typical OA damper set to a $5 \%-20 \%$ position. If the baseline RTU is specified with a low leakage damper at least meeting leakage class 2 per Air Movement and Control Association Standard 511, the Rebel saves 29\% for a small office at JBPHH. These savings are based on operating the RTUs only during NAVFAC Pacific approved HVAC times (see footnote ${ }^{\mathrm{a}}$ in Table ES-2). 
Table ES-2. Model Energy Usage of One 10-Ton Rebel Versus One 10-Ton Baseline Serving an Office Space in JBPHH

\begin{tabular}{llll}
\hline & $\begin{array}{l}\text { Baseline RTU 10-Ton } \\
\text { Fixed 5\% OA Damper }\end{array}$ & $\begin{array}{l}\text { Rebel RTU } \\
\text { 10-Ton }^{\mathbf{a}, \mathbf{b}}\end{array}$ & Savings \\
\hline $\begin{array}{l}\text { Supply Fan } \\
\text { Compressors \& }\end{array}$ & $2,607 \mathrm{kWh}$ & $1,268 \mathrm{kWh}$ & $\begin{array}{l}1,339 \mathrm{kWh} \\
(51 \%)\end{array}$ \\
Condenser Fan(s) & $8,855 \mathrm{kWh}$ & $6,332 \mathrm{kWh}$ & $\begin{array}{l}2,523 \mathrm{kWh} \\
(28 \%)\end{array}$ \\
Total RTU & $11,462 \mathrm{kWh}$ & $7,600 \mathrm{kWh}$ & $\begin{array}{l}3,862 \mathrm{kWh}^{\mathrm{c}} \\
(34 \%)\end{array}$ \\
\hline
\end{tabular}

${ }^{a}$ Models controlled the baseline and Rebel RTUs to operate only during NAVFAC Pacific approved hours of 06001530 for summer weekdays (May 1-October 31) and 0800-1530 for winter weekdays (November 1-April 30). This yields 1,950 operational hours annually. RTUs are turned-off outside these hours.

${ }^{\mathrm{b}}$ Rebel provided the minimum ventilation rate per ASHRAE 62.1-2010; DCV capability was not enabled.

${ }^{\mathrm{c}} \pm 27 \%$ total uncertainty $( \pm 1,042 \mathrm{kWh})$ based on a $95 \%$ confidence interval

In 2018, the Rebel model was rerun with a lower fan pressure drop. When the demonstration was completed in 2014, Daikin Applied only provided a downward discharge configuration. To integrate with the existing ductwork, the installation at the small office used a roof curb to transition the airflow from downward to horizontal, resulting in an additional inch of static pressure. The Rebel now has a horizontal discharge option. Table ES-3 shows the fan savings increased to $71 \%$ over the baseline. Across the three baseline damper configurations, the energy savings ranged from $33-42 \%$.

Table ES-3. Updated Model Energy Usage Account for the Rebel Having a Lower Pressure Drop

\begin{tabular}{|c|c|c|c|}
\hline & $\begin{array}{l}\text { Baseline RTU 10-Ton } \\
\text { Fixed 5\% OA Damper }\end{array}$ & $\begin{array}{l}\text { Rebel RTU } \\
\text { 10-Tona,b }\end{array}$ & Savings \\
\hline Supply Fan & $2,607 \mathrm{kWh}$ & $767 \mathrm{kWh}$ & $\begin{array}{l}\text { 1,840 kWh } \\
(71 \%)\end{array}$ \\
\hline $\begin{array}{l}\text { Compressors \& } \\
\text { Condenser Fan(s) }\end{array}$ & $8,855 \mathrm{kWh}$ & 6,332 kWh & $\begin{array}{l}2,523 \mathrm{kWh} \\
(28 \%)\end{array}$ \\
\hline Total RTU & $11,462 \mathrm{kWh}$ & 7,099 kWh & $\begin{array}{l}4,363 \mathrm{kWh}^{\mathrm{c}} \\
(38 \%)\end{array}$ \\
\hline
\end{tabular}

In addition to energy savings, the Rebel improves thermal comfort compared to the baseline RTU. The variable speed fan and variable capacity cooling maintain a smoother, more constant space temperature throughout the day. The Rebel also maintains a drier space-lower relative humidity (RH) and dew point. By controlling to a constant DAT, the Rebel achieves a consistently lower discharge air dew point. The modeling results showed that during operational hours, the Rebel maintained a 53\% annual average space RH compared to the $61 \%$ annual average space RH for the baseline RTU with a 5\% fixed OA damper.

Based on the energy savings from Table ES-2 and the additional cost of the Rebel, NREL estimates a total discounted operational savings of $\$ 18,000$ over a 15 -year operational life, with a simple payback occurring in the ninth year of operation. Just using the RTU-only cost difference between the Rebel versus the baseline - excluding the Rebel's larger incremental costs for the cabinet coating, condenser coil coating, extended 5-year parts and compressor warranties, and roof curb - the same energy savings yields a simple payback in the fifth year of operation. No utility incentives are included in these paybacks. 
During site inspections, NREL found most office buildings not abiding by the NAVFAC Pacific mandated operating hours. Building occupants are over-riding thermostats, enabling cooling from typically 0600 to 1800 . Therefore, NREL re-calculated the 10-ton Rebel's annual energy savings to be 7,426 kWh based on weekday operation of 0600 to 1800 . The baseline had a fixed $5 \%$ damper position. This yielded a simple payback in the fifth year including all incremental costs. When excluding these incremental costs, the simple payback was in the third year.

For next steps, NREL recommends NAVFAC expand the sample size of measured energy savings for high-efficiency RTUs, leveraging the DOE-sponsored field demonstrations that will be completed in spring 2015. If NAVFAC begins to invest in high-efficiency RTUs, NAVFAC service technicians should receive formal training to provide the same level of service they currently provide for typical RTUs. Local distributors of high-efficiency RTUs can provide onsite training. Some manufacturers of high-efficiency RTUs provide multiday, formalized training at their facilities. These trainings will be crucial for NAVFAC to ensure proper control of the advanced features of these high-efficiency RTUs, as well as utilizing the enhanced troubleshooting capabilities of the AFDD features. 


\section{Table of Contents}

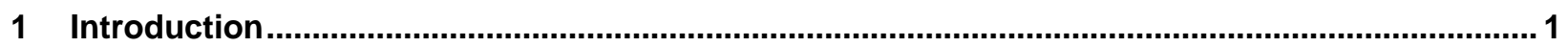

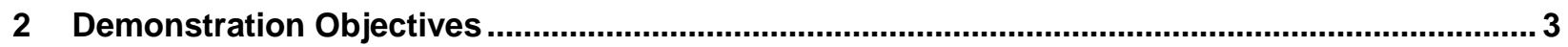

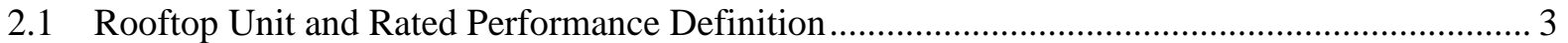

2.2 High-Efficiency Rooftop Unit Technology Description .......................................................... 4

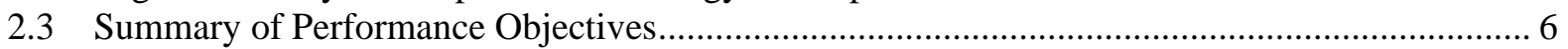

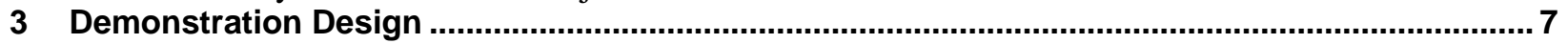

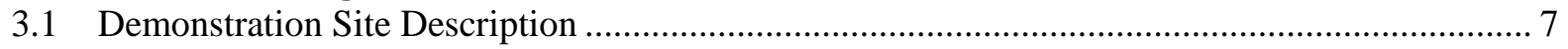

3.2 Baseline Rooftop Unit Description ...................................................................................... 9

3.2.1 ENERGY STAR/Federal Energy Management Program Rooftop Unit Performance

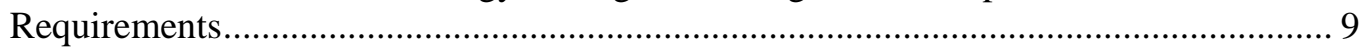

3.2.2 ASHRAE 90.1-2010 Rooftop Unit Performance Requirements .................................... 9

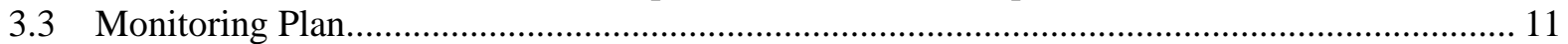

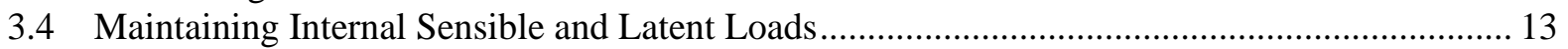

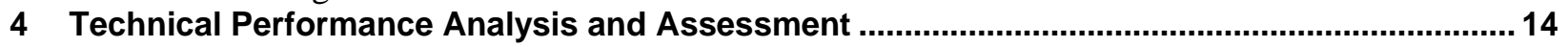

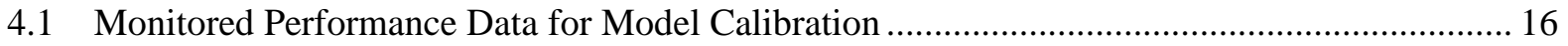

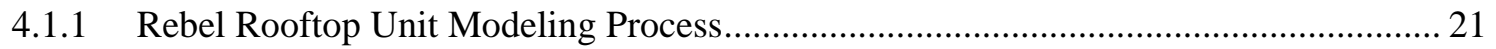

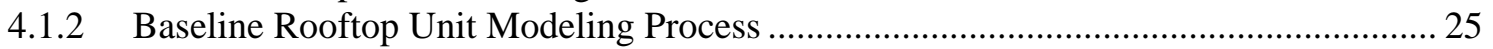

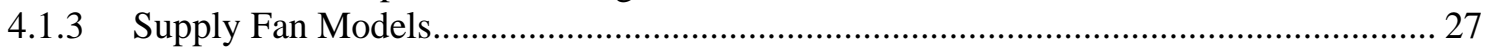

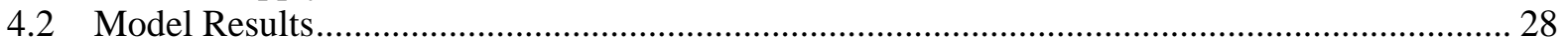

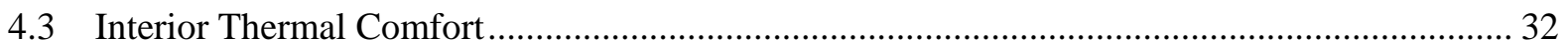

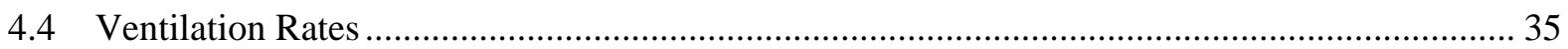

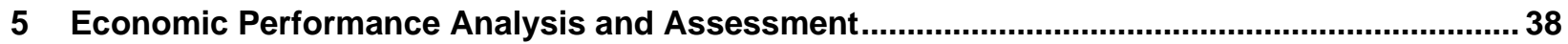

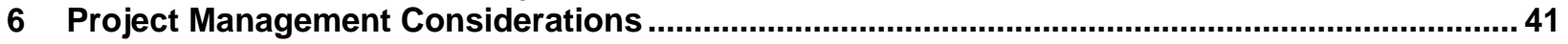

6.1 Site Approval, National Environmental Policy Act, and DD1391 ............................................ 41

6.2 Contracts and Procurement ................................................................................................. 41

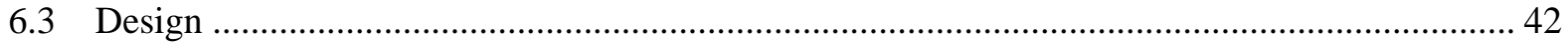

6.4 Installation and Construction (includes permitting, interconnect agreements, factory acceptance

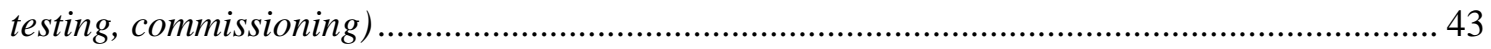

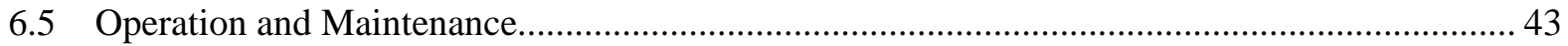

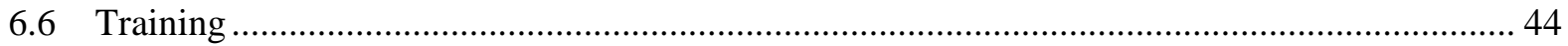

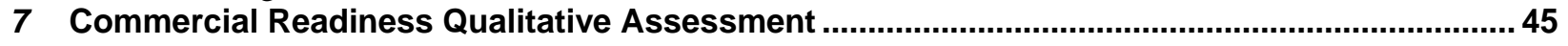

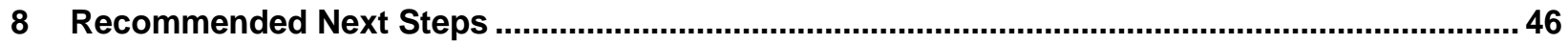

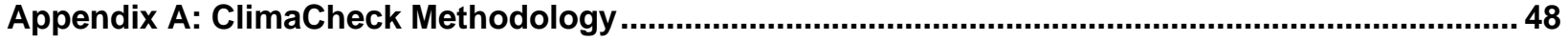

Appendix B: Model Geometry, Envelope, and Internal Loads ........................................................5 50

Appendix C: Rebel Model Summary

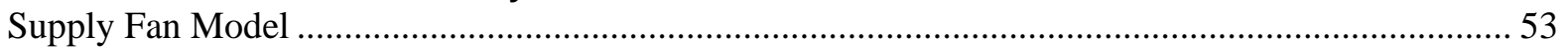

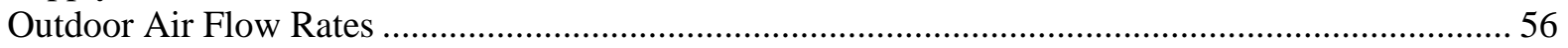

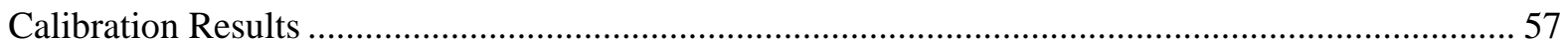

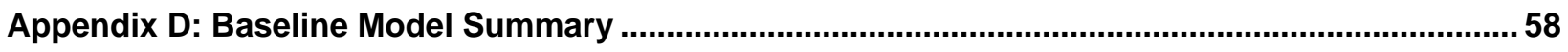

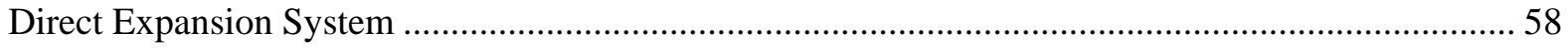

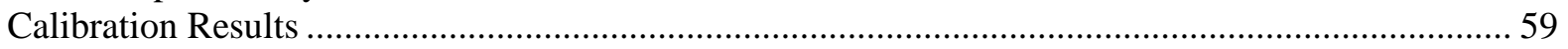

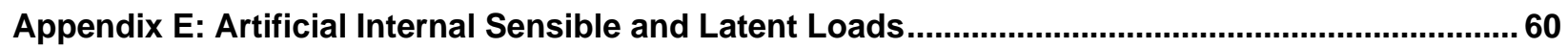

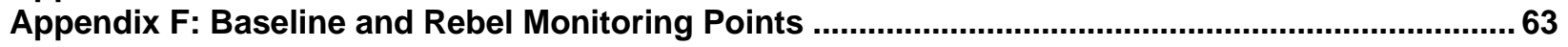

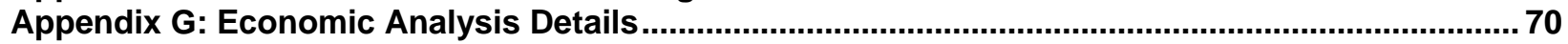

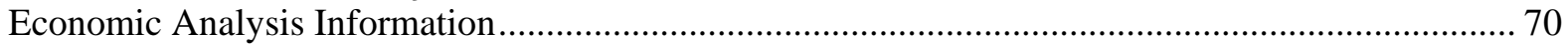

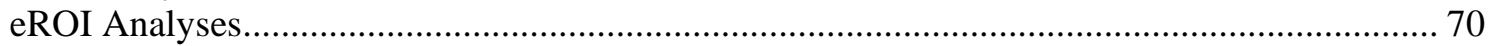

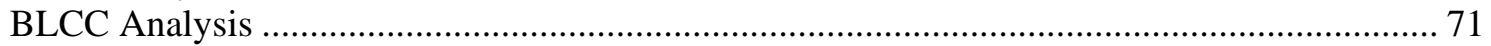

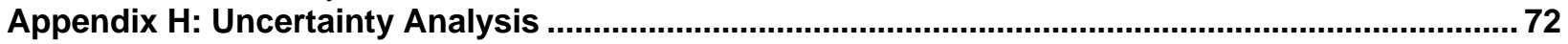

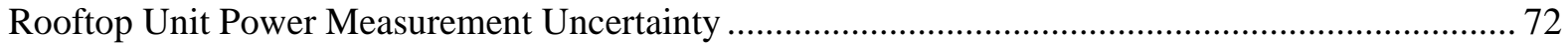

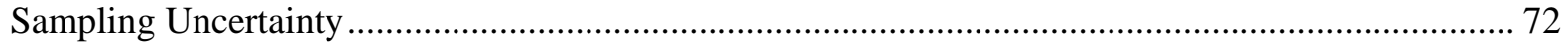




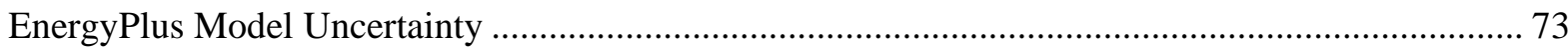
Appendix I: Naval Facilities Engineering Command Routine Rooftop Unit Maintenance Procedures

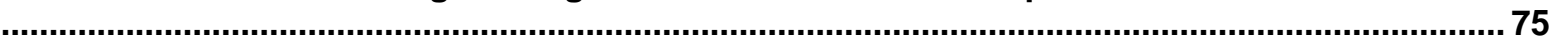




\section{List of Figures}

Figure 1. RTU schematic showing basic component operation........................................................... 3

Figure 2. Technologies incorporated into the Daikin Applied Rebel RTU ................................................ 4

Figure 3. (a) Location of building 550 in NAVFAC PAC (Rebel = RTU \#1; Baseline = RTU \#2) (b)

Google map satellite image of building 550 ...................................................................... 7

Figure 4. Roof of building 550 showing the existing two Trane TCH120 RTUs ....................................... 8

Figure 5. Roof of building 550, which shows the Daikin Applied Rebel and baseline RTU ..................... 8

Figure 6. Unitary air-conditioning equipment (RTUs) efficiency requirements per UFGS 238100.00 20,

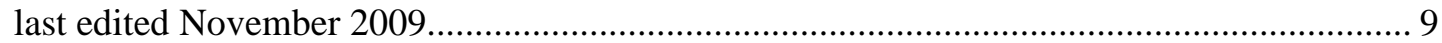

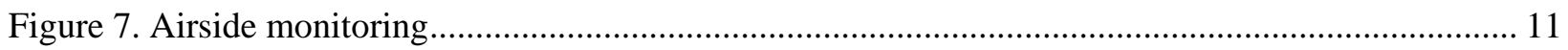

Figure 8. ClimaCheck methodology to measure temperatures, pressure, and power of the DX circuit to calculate real-time cooling capacity and COP …................................................................. 12

Figure 9. Rebel and baseline RTU simultaneous operation on October 28, 2013: (a) space temperature measured by each RTU's temperature sensor (b) total DX cooling by each RTU ................ 14

Figure 10. Histogram of monitored baseline and Rebel operational cooling capacities ............................. 18

Figure 11. Rebel DX power regression modeled versus measured, including uncertainty based on

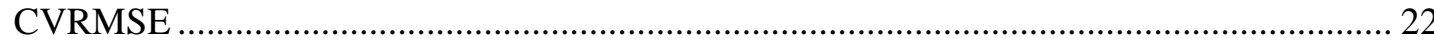

Figure 12. Using DX power regression model to calculate DX cycle performance (EER) for a range of

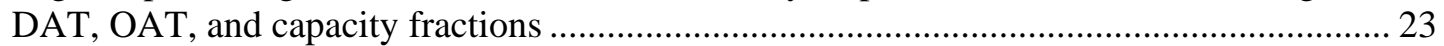

Figure 13. Rebel RTU model versus measured daily RTU energy usage................................................. 24

Figure 14. Baseline RTU DX power regression (including compressors and condenser fans) ................... 26

Figure 15. Baseline RTU model versus measured daily DX energy usage ...............................................2

Figure 16. Baseline and Rebel annual operating hours at different capacity bins ..................................... 30

Figure 17. Baseline and Rebel daily energy usage versus daily average dry-bulb temperature .................. 30

Figure 18. Office space dry-bulb temperature histogram comparing the Rebel model versus the baseline model with a fixed 5\% OA damper position.............................................................................. 33

Figure 19. Measured (not modeled) space temperature fluctuation across the day between the Rebel RTU

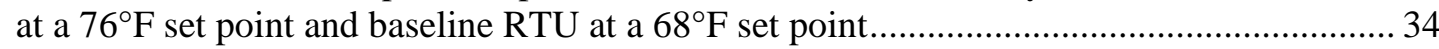

Figure 20. Office space RH histogram comparing the Rebel model versus the baseline model with a 5\%

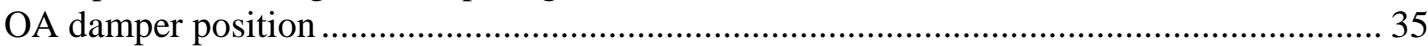

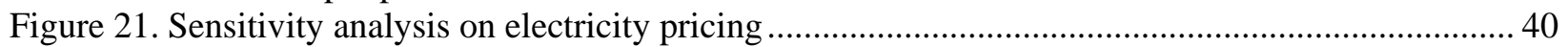

Figure A-1. Rebel refrigerant-side monitoring (instance December 10, 2013 6:40) .............................. 48

Figure A-2. Baseline refrigerant-side monitoring (instance December 4, 2013 13:00).......................... 49

Figure B-1. Southeast view of building 550 model .......................................................................... 50

Figure C-1. Correlation between supply fan controller speed setting and supply air flow rate based on TAB 53

Figure C-2. (a) Regression model of supply fan pressure and efficiency as a function of flow fraction (b)

EnergyPlus model of supply fan power based on flow fraction............................................5 54

Figure C-3. Projected error timeline from MicroTech III unit controller operation manual ...................... 56

Figure C-4. OA flow rates based on the supply air flow rate (a) shows flow rates in cfm and (b) shows regression equations relating OA mass flow rates to supply air mass flow rates used in the

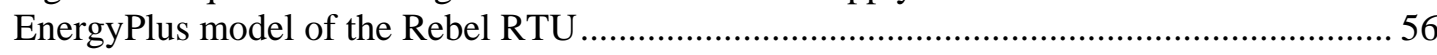

Figure C-5. Rebel RTU model versus measured daily RTU energy usage............................................5 57

Figure C-6. Rebel RTU model versus measured space dry-bulb and dew point ......................................5 57

Figure D-1. Baseline RTU model versus measured daily DX energy usage ........................................... 59

Figure D-2. Baseline RTU model versus measured space dry-bulb and dew point.................................59

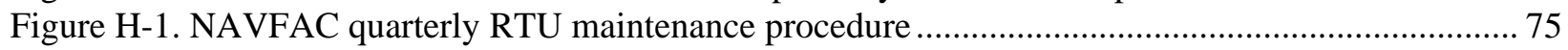




\section{List of Tables}

Table ES-1. Daikin Applied Rebel and Baseline RTU Rated Performance ...........................................viii

Table ES-2. Model Energy Usage of One 10-Ton Rebel Versus One 10-Ton Baseline Serving an Office Space in JBPHH..... $\mathrm{x}$

Table ES-3. Updated Model Energy Usage Account for the Rebel Having a Lower Pressure Drop ........... x Table 1. Performance Objectives Defining How the Daikin Applied Rebel RTU Was Compared Against

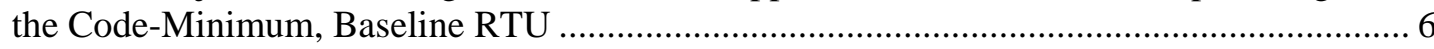

Table 2. Performance and Component Comparison Between the Baseline RTU and the Daikin Applied

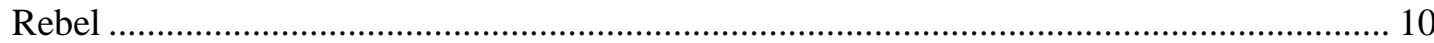

Table 3. Artificial Internal Sensible and Latent Loads Established to Represent a Typical Office Space. 13

Table 4. Performance Comparison Between Baseline and Rebel RTUs on October 28, 2013................... 15

Table 5. Summary of Performance Data Used to Develop and Calibrate the Baseline and Rebel Energy Models Across Dates November 10, 2013, through January 26, 2014 .................................. 15

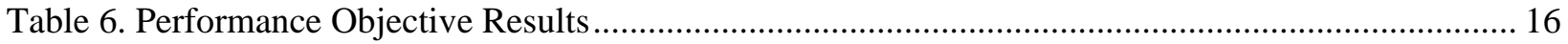

Table 7. Rebel and Baseline Control Parameters During Demonstration Period ....................................... 17

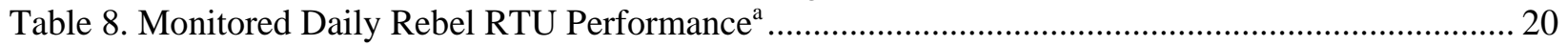

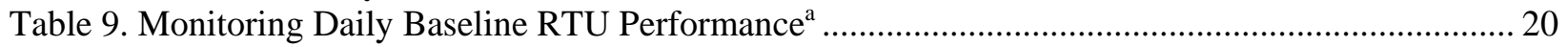

Table 10. Rebel RTU DX Power Regression Model Parameters .......................................................... 23

Table 11. Baseline RTU DX Power Regression Parameters (including Compressors and Condenser Fans)

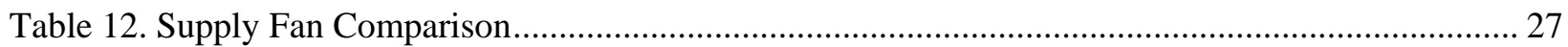

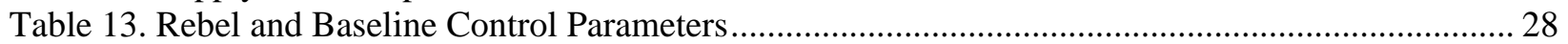

Table 14. Modeled Annual Energy Consumption and Savings Between One 10-Ton Rebel RTU Versus One 10-Ton Baseline RTU Serving the Building 550 Small Office Space ............................ 29

Table 15. Modeled Rebel Savings Over the Baseline RTU Maintaining Different Ventilation Flow Rates

Table 16. Office Minimum Ventilation Rates per ASHRAE Standard 62.1-2010 ................................... 36

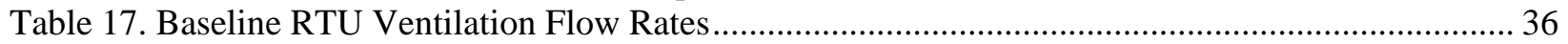

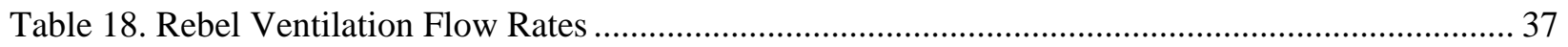

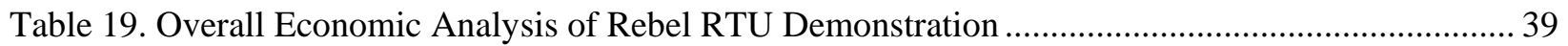

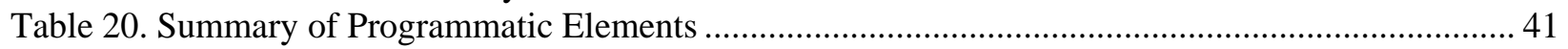

Table 21. Applicable Division 01, General Requirements ...................................................................... 42

Table 22. UFGS Facility Construction/Technical Design Specifications Used in the Construction Activity

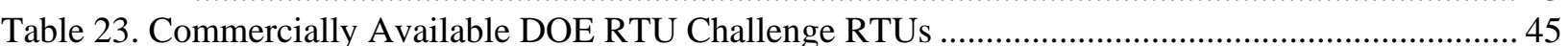

Table B-1. Summary of Building Envelope and Internal Load Parameters............................................. 51

Table C-1. Rebel RTU Supply Fan Performance Based on TAB Report ................................................ 53

Table C-2. Fan Operational Sequence Based on Startup ................................................................... 55

Table D-1. Baseline RTU Cooling Capacity Regression Parameters ..................................................... 58

Table E-1. Overhead Lighting Power and Schedule Maintained During the Demonstration Period .......... 60

Table E-2. NREL Installed Heat Lamps to Represent the Sensible Loads from Occupants and Plug Loads

Table E-3. Total Internal Sensible Heat Gain from Overheat Lighting and NREL’s Installed Heat Lamps

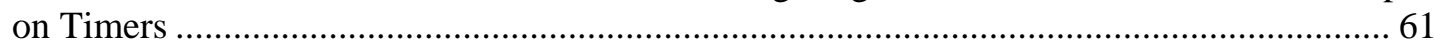

Table E-4. NREL Set Up Humidifiers on Timers to Represent the Total Internal Latent Heat Gain from

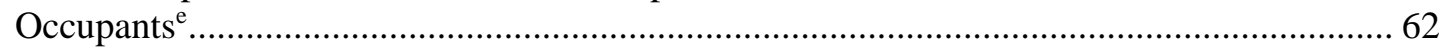

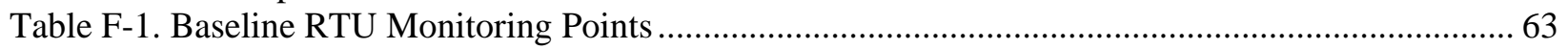

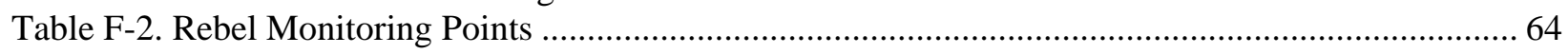

Table G-1. Summary of Key Information Regarding the eROI Analyses Developed for This Project...... 70 
Table G-2. Summary of Key Information Regarding the Building Life-Cycle Cost Analyses Developed

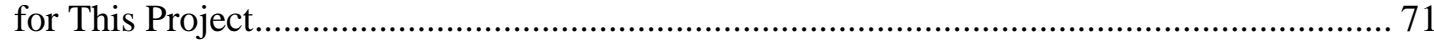




\section{Introduction}

To meet its energy goals, the Naval Facilities Engineering Command (NAVFAC) partnered with the U.S. Department of Energy's (DOE) National Renewable Energy Laboratory (NREL) to rapidly demonstrate and deploy cost-effective renewable energy and energy efficiency technologies. This is one of several demonstrations of new or underutilized energy technologies. The common goal is to demonstrate and measure the energy savings and return on investment (ROI) of the system while monitoring any ancillary impacts to related standards of service and operation and maintenance $(\mathrm{O} \& \mathrm{M})$ practices.

The standards of service may include acceptable temperature and relative humidity $(\mathrm{RH})$ ranges, power quality, allowable setbacks, noise criteria, air quality parameters, light levels, and other related factors. In short, demonstrations at U.S. Department of Defense (DOD) facilities simultaneously evaluate the benefits and compatibility of the technology with the DOD mission, and with its design, construction, and O\&M practices.

The consistent year-round demand for cooling and dehumidification in Hawaii and Guam provide ideal locations for realizing significant energy savings from high-efficiency heating, ventilation, and air conditioning (HVAC) systems. Many of NAVFAC's small- to medium-size facilities are conditioned by packaged roof top units (RTUs). These facilities include offices, warehouses, gymnasiums, commissaries, exchange stores, and hangars.

The term packaged RTU refers to a pre-engineered unitary system that houses all the components of an HVAC system. For Hawaii and Guam, RTUs need to provide cooling and ventilation only. Therefore, the DOD has a significant amount of conditioned square footage that can leverage high-efficiency RTUs to reduce energy usage while improving thermal comfort.

The performance range from code-minimum to the highest efficiency RTUs was not that significant until the past couple years. To help incentivize manufacturers to build higher performance RTUs, DOE issued the High-Performance Rooftop Unit Challenge in January 2011 to: ${ }^{4}$

catalyze the market introduction of cost-effective, energy-saving RTUs that would significantly outperform any models that were currently available. RTUs built according to the specification are expected to reduce energy use by as much as $50 \%$ compared to the current ASHRAE 90.1 Standard, depending on location and facility type.

To achieve the DOE RTU Challenge status, RTUs that range from 10 to 20 tons must meet a comprehensive specification codeveloped by DOE national labs, including NREL, and private sector building owners with large building portfolios (i.e., Target, Walmart). ${ }^{5}$ The primary specification requirements include a minimum integrated energy efficiency ratio (IEER) of 18.0,

\footnotetext{
4 “DOE Facilitates Market-Driven Solutions to Develop and Deploy New High-Efficiency Commercial Air Conditioners.” U.S. Department of Energy, Office of Energy Efficiency \& Renewable Energy, February 3, 2011. http://apps1.eere.energy.gov/news/news_detail.cfm/news_id=16696.

5 "Install units produced by the High-Performance Rooftop Unit Challenge that meet the high-performance rooftop unit specification.” U.S. Department of Energy, Office of Renewable Energy \& Energy Efficiency, undated.
} 
a variable- or multispeed supply fan, direct digital controls, and automated fault detection and diagnostics (AFDD).

In May 2012, ${ }^{6}$ the Daikin Applied Rebel $^{7}$ was the first commercially available RTU to meet the DOE High Performance Rooftop Unit Challenge. The following field demonstration compared the performance of the Daikin Applied Rebel against a code-minimum, baseline RTU serving a small office building on NAVFAC Pacific (PAC).

\footnotetext{
6 “Energy Department Announces First Product to Meet the Commercial Rooftop Air Conditioner Challenge.” U.S. Department of Energy, Office of Renewable Energy \& Energy Efficiency, May 24, 2012.

http://apps1.eere.energy.gov/news/progress_alerts.cfm/news_id=20367.

7 “Rebel Overview.” Daikin Applied, 2014. www.go.Rebel.com/rebel.
} 


\section{Demonstration Objectives}

The demonstration objectives were to evaluate the energy savings, ROI, and thermal comfort impact of the Daikin Applied Rebel against a code-minimum, baseline RTU.

\subsection{Rooftop Unit and Rated Performance Definition}

To better understand the basic function of an RTU, Figure 1 shows the components and airstreams. An RTU uses a supply fan to draw in return air from the conditioned space along with a controlled amount of outdoor air (OA) needed to ventilate the space. The mixed air is then cooled as it passes through a direct expansion (DX) evaporator coil. For the humid Hawaiian climate, the DX coil also dehumidifies by condensing moisture out of the mixed air stream. For maintaining space comfort in Hawaii and Guam, dehumidifying the air (latent cooling) is as important as sensible cooling. Sometimes, RTUs include exhaust fans that push some of the return air outside, although neither of the RTUs in this demonstration included exhaust fans.

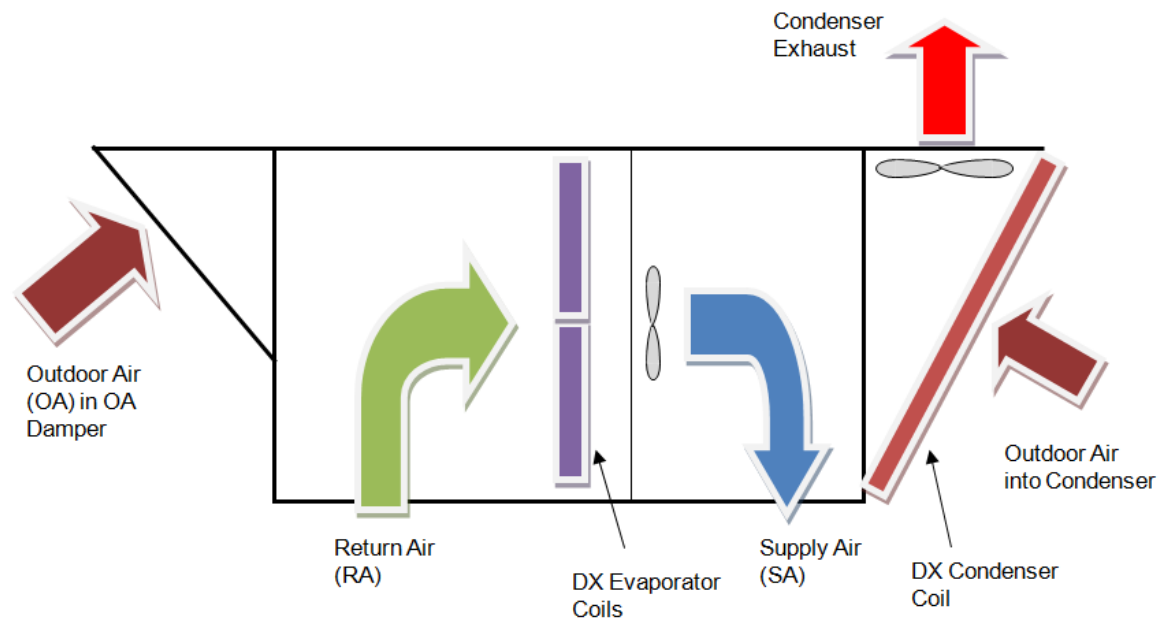

Figure 1. RTU schematic showing basic component operation

(Credit: Eric Kozubal, NREL)

The refrigerant in the evaporator coil is pumped by the compressor to the condenser coil. Here, the DX cycle rejects the heat by blowing OA across the condenser coil. RTUs with 10 tons of cooling operate with two compressors that can be "staged", operating one or two at a time.

RTU-rated performance is based on the applicable American National Standards Institute (ANSI)/Air-Conditioning, Heating, \& Refrigeration Institute (AHRI) standards. For RTUs lower than 65,000 British thermal units per hour (Btuh) (5.4 tons), ANSI/AHRI 210/240-2008 defines an energy efficiency ratio (EER) to characterize peak operational performance and a seasonal energy efficiency ratio (SEER) to represent cooling season average performance. Larger RTUs adhere to ANSI/AHRI 340/360-2007, which also uses EER to define peak performance but defines a separate IEER to represent cooling season average performance. Compared to EER, the seasonal performance ratings, SEER and IEER, provide a better indication of annual energy usage. Consequently, the DOE RTU challenge mandated a minimum 18.0 IEER rating, rather than stipulating an EER rating because annual energy savings was the goal. 


\subsection{High-Efficiency Rooftop Unit Technology Description}

The Daikin Applied Rebel exceeds the 18.0 IEER by packaging multiple advanced technologies and control capabilities. These include a variable-speed direct-drive supply fan, variable-speed condenser fans, and a variable-speed first-stage compressor (second-stage compressor is constant speed). A sophisticated programmable logic controller (PLC) controls all the components and includes AFDD along with open protocol communication (BACnet IP, BACnet MSTP, and LonMark).

As Hawaii does not need heating, the Rebel unit demonstrated did not have gas heating. Yet, because of an ordering mix-up, the Rebel delivered was a heat pump RTU. The heat pump operational mode was never utilized during the demonstration. The marketing schematic developed by Daikin Applied, shown in Figure 2, highlights these advanced components and control features of the Rebel.

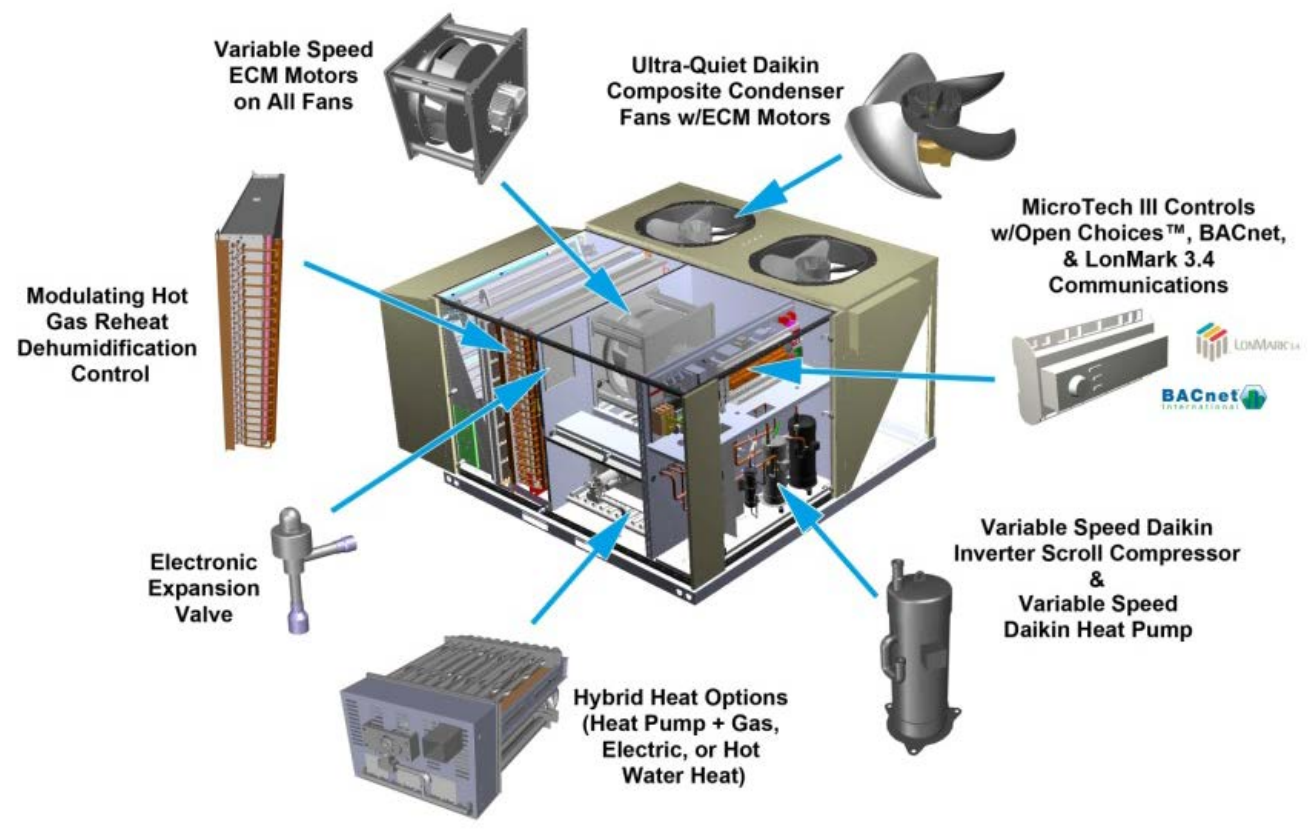

Figure 2. Technologies incorporated into the Daikin Applied Rebel RTU

Source: Daikin Applied 
The Daikin Applied Rebel achieves improved energy and thermal comfort performance over a code-minimum, baseline RTU by incorporating the following technologies:

Direct-drive, variable-speed supply fan. RTUs are typically configured with a constantspeed supply fan that moves more air than necessary for most of the year. These constant flow rates are sized to meet the worst-case design condition. These worst-case design conditions typically represent fewer than 100 hours of the year. The Rebel uses a variablespeed electronically commutated motor (ECM) to directly drive the supply fan, eliminating the need for a fan belt. The Rebel supply fan can be controlled in three ways:

o Duct static pressure control for standard variable air volume (VAV) applications,

o Constant air volume (CAV) and

o Single-zone variable-air volume (SZVAV).

NREL configured the Rebel for SZVAV control, which changes the fan speed based on the space temperature relative to the temperature set point. See Appendix $C$ for a detailed summary of the supply fan proportional-integral [PI] control sequence. Consequently, the supply fan will move only enough air as necessary, based on the space demands.

Variable refrigerant flow. Daikin Applied packaged its variable-refrigerant flow technology into the Rebel's DX system. The lead compressor is an inverter-driven scroll. Rebels larger than 5 tons have a second-stage, constant-speed compressor. Both variable- and fixed-speed compressors are part of the same DX circuit. By ramping the variable-speed lead compressor, the Rebel provides the proper amount of cooling to meet the space's needs whether at part load or extreme design conditions. Comparatively, code minimum RTUs achieve cooling load control based on the number of separate compressor stages. The Rebel also leverages electronic expansion valves to achieve improved refrigerant flow control (i.e., tight superheat) compared to standard thermostatic expansion valves.

In addition to greater control of space temperature and $\mathrm{RH}$, the variable-refrigerant flow technology improves the refrigeration cycle efficiency because the full-load heat transfer surface area on the evaporator and condenser coils is available for low-load conditions. The improved part-load efficiency is reflected in the 10-ton Rebel's 19.4 Btuh/W ${ }^{8}$ IEER. For context, a 10-ton code-minimum RTU is 11.4 IEER, according to ASHRAE 90.1-2010.

Variable-speed condenser fans. The Rebel's two condenser fans are variable speed, which are controlled to maintain the refrigerant saturated condensing temperature (discharge pressure) a specified delta-T above ambient dry-bulb. For this demonstration, the condenser fan speeds were controlled to maintain a $10^{\circ} \mathrm{F}$ delta-T. Compared to constant-speed condenser fans, the Rebel can achieve improved refrigerant discharge pressure and subcooling control to enhance performance at part-load conditions.

Low-leakage OA damper. Standard RTU OA dampers are notoriously leaky and typically not certified under Air Movement and Control Association Standard 511. The Rebel has vinyl gasket, motorized blade dampers that maintain low leakage.

\footnotetext{
${ }^{8}$ Based on AHRI Certified Reference Number 5056846.
} 
Demand-controlled ventilation (DCV). RTUs are typically configured with an OA flow rate based on the expected maximum number of occupants. Yet most spaces typically experience occupancy rates well below this number throughout most of the year. The Rebel has DCV capability in which, based on the return air carbon dioxide $\left(\mathrm{CO}_{2}\right)$ concentration, the OA damper will open beyond a set minimum OA flow rate to meet the ventilation needs of the space. However, Unified Facilities Criteria (UFC) 3-410-01 Section 401.1 (dated July 1, 2013) states "Use of $\mathrm{CO}_{2}$ sensors for ventilation control is prohibited unless approved by AHJ" Based on this requirement, NREL did not demonstrate the Rebel enabled with DCV.

Dual enthalpy economizing. In many U.S. climates, during cooling demands, the OA temperature and RH may be low enough to use in lieu of — or in conjunction withcompressor-based cooling. The Rebel's advanced controller has the ability to leverage multiple economizer control sequences, including fixed dry-bulb, dual dry-bulb, and dual enthalpy. However, Hawaii has such a humid climate that none of the economizing features of the Rebel were initiated for the demonstration.

\subsection{Summary of Performance Objectives}

NREL developed a list of performance objectives to evaluate the Daikin Applied against the baseline RTU. Table 1 defines each performance objective, the data required, and how success was defined.

Table 1. Performance Objectives Defining How the Daikin Applied Rebel RTU Was Compared Against the Code-Minimum, Baseline RTU

\begin{tabular}{|c|c|c|c|}
\hline $\begin{array}{l}\text { Performance } \\
\text { Objective }\end{array}$ & Metric & Data Requirements & Success Criteria \\
\hline $\begin{array}{l}\text { 1. Annual } \\
\text { energy } \\
\text { savings }\end{array}$ & $\begin{array}{l}\text { Annual kilowatt-hour } \\
\text { savings }\end{array}$ & $\begin{array}{l}\text { Calibrated energy models of } \\
\text { the baseline and Rebel RTUs, } \\
\text { based on measured } \\
\text { performance data }\end{array}$ & $\begin{array}{l}\text { Rebel reduces energy } \\
\text { usage by at least } 30 \% \\
\text { compared to the Baseline } \\
\text { RTU }\end{array}$ \\
\hline $\begin{array}{l}\text { 2. Interior } \\
\text { thermal } \\
\text { comfort } \\
\text { improvement }\end{array}$ & $\begin{array}{l}\text { Space temperature } \\
\text { and } \mathrm{RH} \text { during } \\
\text { occupied hours }\end{array}$ & $\begin{array}{l}\text { Measurements of space } \\
\text { temperature and RH; } \\
\text { calibrated energy models of } \\
\text { the baseline and Rebel RTUs, } \\
\text { based on measured } \\
\text { performance data }\end{array}$ & $\begin{array}{l}\text { Rebel maintains a narrower } \\
\text { temperature band and } \\
\text { lower annual average } \mathrm{RH} \\
\text { by at least } 5 \%\end{array}$ \\
\hline $\begin{array}{l}\text { 3. Proper } \\
\text { ventilation } \\
\text { rates and } \\
\text { reduced OA } \\
\text { damper } \\
\text { leakage }\end{array}$ & $\begin{array}{l}\text { Leakage flow rates } \\
\text { while OA damper is } \\
\text { closed; Proper } \\
\text { ventilation flow rates } \\
\text { maintained during } \\
\text { occupied hours per } \\
\text { ASHRAE Standard } \\
\text { 62.1-2010 }\end{array}$ & $\begin{array}{l}\text { Testing, adjusting, and } \\
\text { balancing (TAB) OA flow rates } \\
\text { measured at different OA } \\
\text { damper positions and fan } \\
\text { speeds }\end{array}$ & $\begin{array}{l}\text { Rebel reduces OA damper } \\
\text { leakage by } 30 \% \text { compared } \\
\text { to the baseline RTU; Rebel } \\
\text { maintains proper ventilation } \\
\text { rates during occupied hours }\end{array}$ \\
\hline
\end{tabular}




\section{Demonstration Design}

The performance benefits of the Daikin Applied Rebel were compared against a code-minimum baseline RTU that the Navy would typically purchase adhering to Unified Facilities Guide Specifications (UFGS) and UFC requirements. After evaluating potential demonstration sites across Joint Base Pearl Harbor-Hickam (JBPHH) and NAVFAC PAC, NAVFAC and NREL determined building 550 NAVFAC PAC Public Works was an ideal configuration with two identically sized RTUs serving a typical small office space. The following section summarizes building 550 characteristics and thermal loads, the baseline RTU, thermostat set point schedules, and the calibrated energy models.

\subsection{Demonstration Site Description}

Building 550, NAVFAC PAC Public Works, is a two-story building built in 1946, which is broken up into four separate facilities. Figure 3 shows how the Rebel and baseline RTUs serve one of these facilities, a 4,976- $\mathrm{ft}^{2}$ office space on the second floor. Figure 3 shows the location of building 550 inside NAVFAC PAC and details the location of the second-floor office space on the northern side of the building. Based on NAVFAC's property record (iNFAD) report, building 550 has a total of 26,313 $\mathrm{ft}^{2}$. Therefore, the second-floor office space comprises $19 \%$ of the total floor area. Figure 4 shows the roof of building 550 with the two 17-year-old (built in 1996) 10ton Trane RTUs that were replaced. Figure 5 shows the Daikin Applied Rebel and baseline RTU on the roof of building 550 .

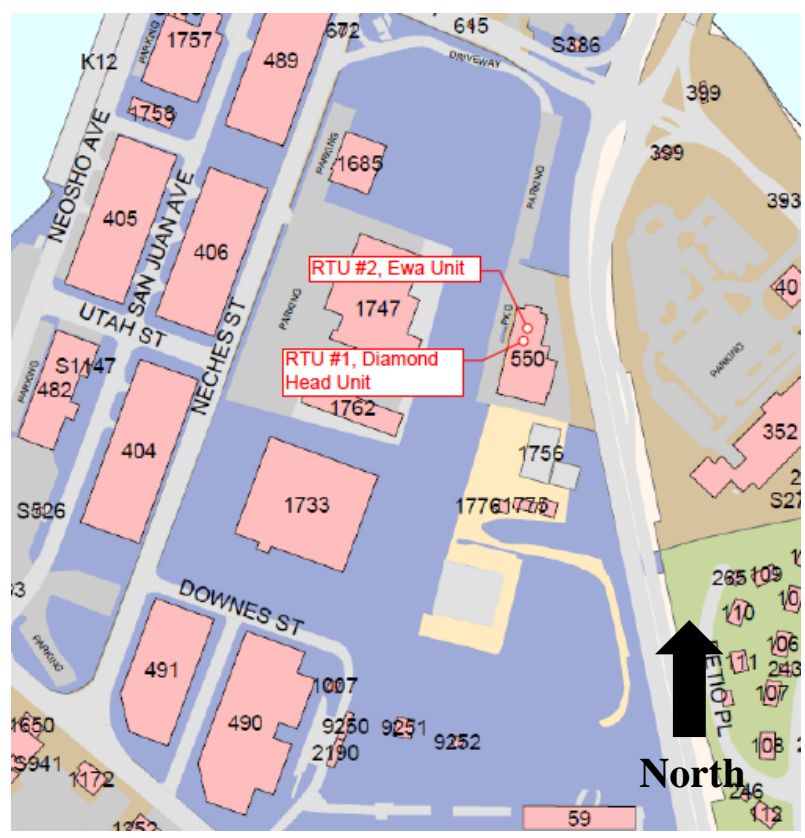

(a)

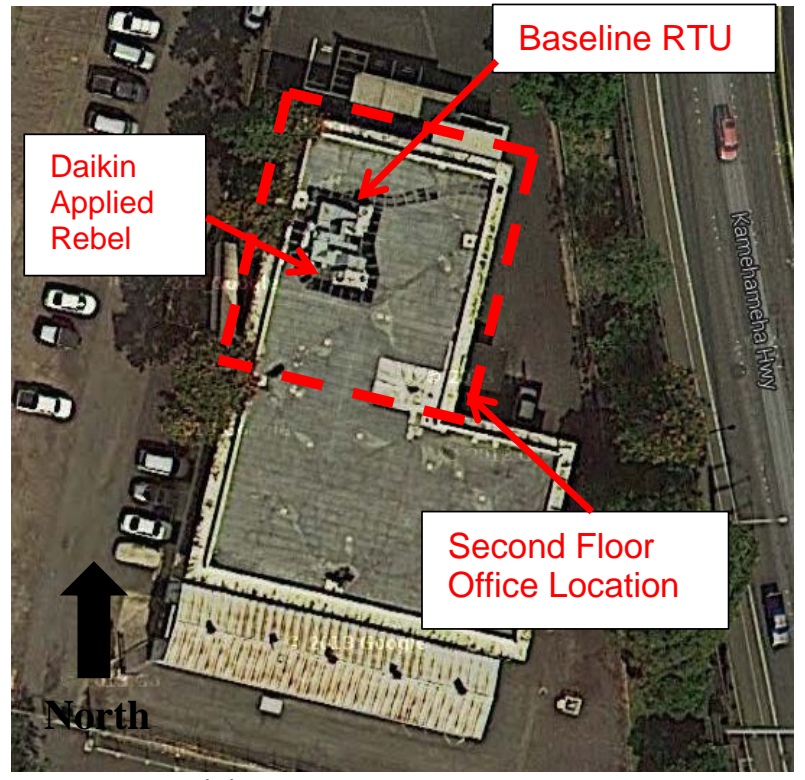

(b)

Figure 3. (a) Location of building 550 in NAVFAC PAC (Rebel = RTU \#1; Baseline = RTU \#2) (b) Google map satellite image of building 550

Source: (a) JBPHH Building Site Map provide by NAVFAC (b) Google Earth 


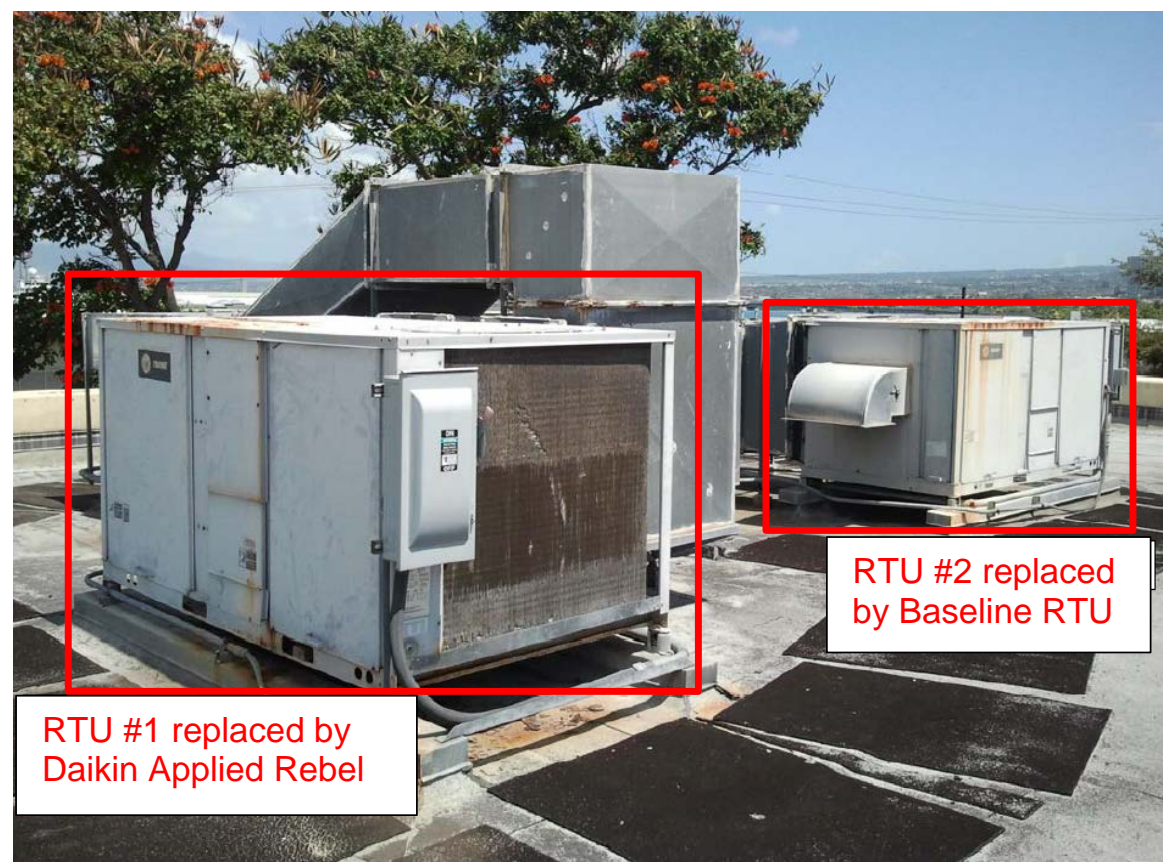

Figure 4. Roof of building 550 showing the existing two Trane TCH120 RTUs

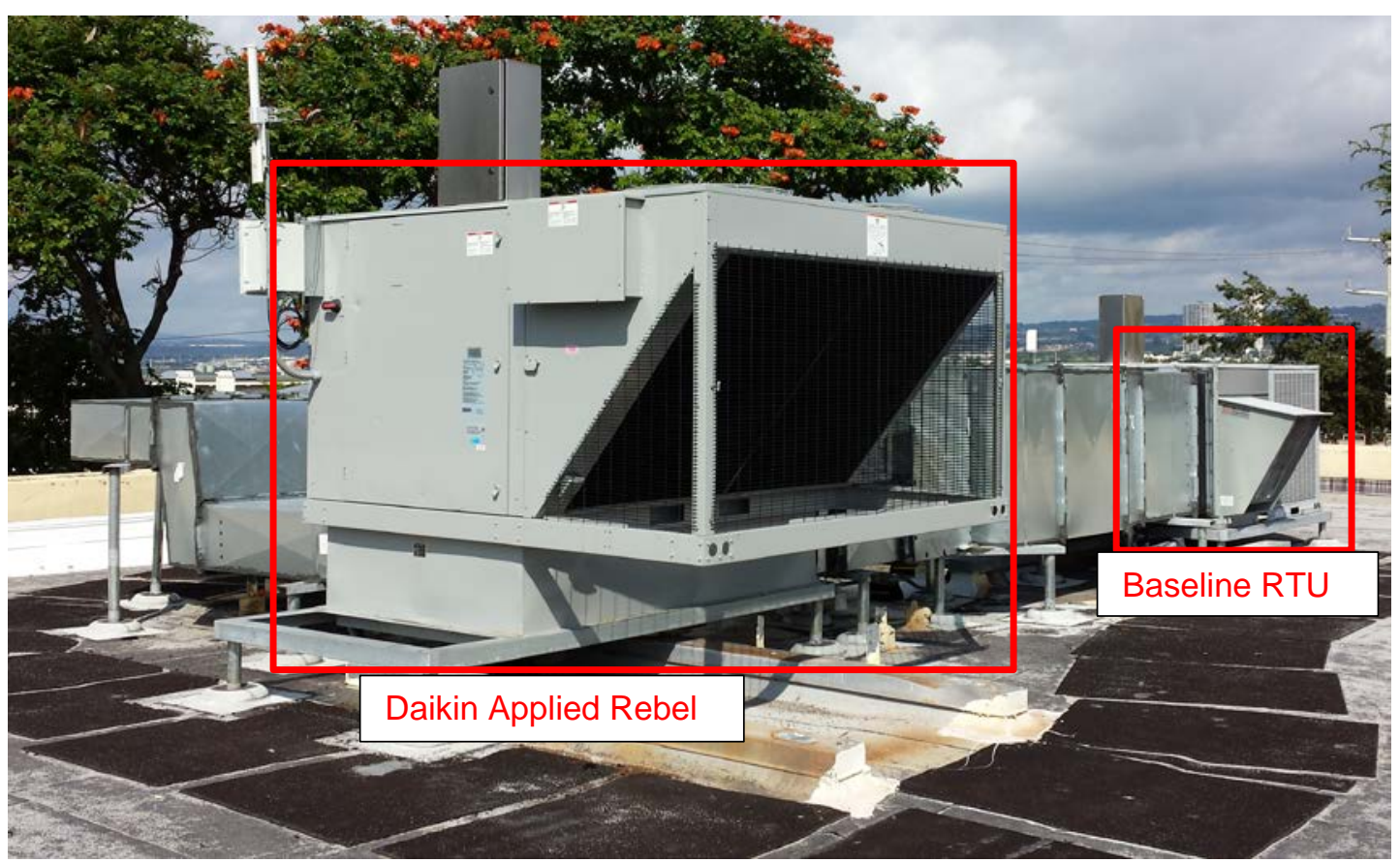

Figure 5. Roof of building 550, which shows the Daikin Applied Rebel and baseline RTU 


\subsection{Baseline Rooftop Unit Description}

The Daikin Applied Rebel was compared against a baseline code-minimum RTU meeting UFC 3-410-01 ${ }^{9}$ Heating, Ventilating, and Air Conditioning Systems (dated July 1, 2013) and UFGS$238100.0020^{10}$ Unitary Air Conditioning Equipment. Per Part 2 of UFGS 238100.0020 (shown in Figure 6), RTUs must exceed the minimum performance requirements of ASHRAE Standard 90.1-2010, ENERGY STAR ${ }^{\circledR}$, and the Federal Energy Management Program (FEMP). Therefore, these three references were evaluated to confirm the baseline RTU met the most stringent requirements.

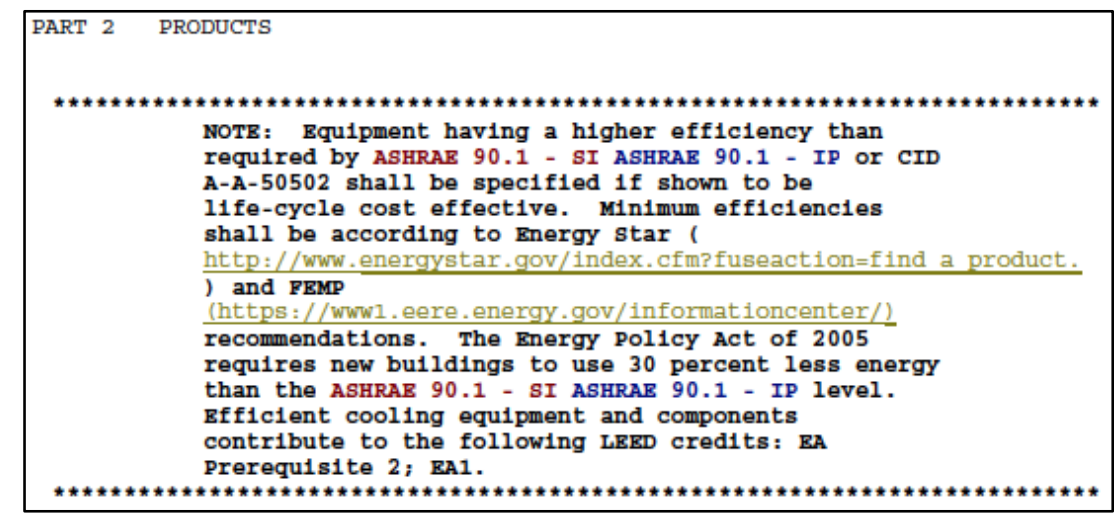

Figure 6. Unitary air-conditioning equipment (RTUs) efficiency requirements per UFGS 238100.00 20, last edited November 2009

\subsubsection{ENERGY STAR/Federal Energy Management Program Rooftop Unit Performance Requirements}

FEMP requirements ${ }^{11}$ state "Federal purchases of light commercial heating and cooling equipment must be ENERGY STAR qualified.” The ENERGY STAR website reveals RTUs lower than 65,000 Btuh (approximately 5 tons) must meet a minimum 11.0 EER and 14.5 SEER. ${ }^{12}$ Because this demonstration was for a 10-ton RTU, the FEMP/ENERGY STAR requirements did not apply.

\subsubsection{ASHRAE 90.1-2010 Rooftop Unit Performance Requirements}

Based on ASHRAE Standard 90.1-2010, Table 6.8.1A stipulates for nominal tonnages $\geq 65,000$ Btuh and < 135,000 Btuh, RTUs must exceed 11.2 EER and 11.4 IEER. Consequently, NREL specified a baseline RTU that just exceeds the ASHRAE Standard 90.1-2010 requirements to represent the baseline, code-minimum RTU (Table 2). Beyond the EER and IEER performance requirements, the baseline represents a typical RTU installed today at JBPHH with a constant-

\footnotetext{
${ }^{9}$ National Institute of Building Sciences, Whole Building Design Guide, Unified Facilities Criteria 3-410-01: www.wbdg.org/ccb/browse_cat.php?c=4.

${ }^{10}$ National Institute of Building Sciences, Whole Building Design Guide, Unified Facilities Guide Specifications 23 8100.00 20: www.wbdg.org/ccb/browse_cat.php?c=3.

11 “Covered Product Category: Light Commercial Heating and Cooling.” U.S. Department of Energy, Office of Energy Efficiency \& Renewable Energy, April 24, 2014. http://energy.gov/eere/femp/covered-product-categorylight-commercial-heating-and-cooling.

12 “Air-Source Heat Pumps and Central Air Conditioners Key Product Criteria.” ENERGY STAR, April $24,2014$. www.energystar.gov/index.cfm?c=airsrc heat.pr_crit_as_heat_pumps.
} 
speed fan and standard thermostatic control. Although the OA damper can modulate, for this demonstration it was controlled to be fixed at a specified position.

Table 2. Performance and Component Comparison Between the Baseline RTU and the Daikin Applied Rebel

\begin{tabular}{|c|c|c|}
\hline & Baseline RTU 1 & $\begin{array}{l}\text { Daikin Applied Rebel } \\
\text { Model DPS010A }\end{array}$ \\
\hline $\begin{array}{l}\text { EER } 2 \\
\text { (note ASHRAE 90.1-2010= } \\
11.2 \text { EER) }\end{array}$ & 11.3 & 12.5 \\
\hline $\begin{array}{l}\text { IEER } 3 \\
\text { (note ASHRAE 90.1-2010= } \\
11.4 \text { IEER) }\end{array}$ & 11.8 & 19.4 \\
\hline $\begin{array}{l}\text { Gross Cooling Capacity at } \\
\text { EER-rated conditions [Btuh] }\end{array}$ & 124,700 Btuh & 122,000 Btuh \\
\hline $\begin{array}{l}\text { Gross Cooling Capacity at } \\
\text { EER-rated conditions (tons) }\end{array}$ & 10.4 tons & 10.2 tons \\
\hline Supply Fan & $\begin{array}{l}\text { Constant speed/belt } \\
\text { driven/National Electrical } \\
\text { Manufacturers Association } \\
\text { (NEMA) standard efficiency motor }\end{array}$ & Variable-speed/direct-drive/ECM \\
\hline Refrigeration Circuit(s) & $\begin{array}{l}\text { Two DX circuits with thermostatic } \\
\text { expansion valves/constant speed } \\
\text { scroll compressors }\end{array}$ & $\begin{array}{l}\text { Single DX circuit served by one } \\
\text { variable-speed scroll compressor } \\
\text { and one constant speed scroll } \\
\text { compressor with electronic } \\
\text { expansion valves }\end{array}$ \\
\hline Condenser Fan(s) & $\begin{array}{l}\text { Two fans at constant speed with } \\
\text { NEMA standard efficiency motors }\end{array}$ & Two fans at variable speed \\
\hline OA Damper & $\begin{array}{l}\text { Gear-driven parallel blade damper } \\
\text { with direct coupled actuator } \\
\text { No edge or jamb seals: ASHRAE } \\
\text { 90.1-2010 code-min leakage } \\
\text { Not certified to Air Movement and } \\
\text { Control Association Standard } 511\end{array}$ & $\begin{array}{l}\text { Actuator/linkage-driven opposing } \\
\text { blade damper } \\
\text { Low-leakage damper with edge and } \\
\text { jamb seals }\end{array}$ \\
\hline Humidity Control & Hot gas reheat coil & Modulating hot gas reheat coil \\
\hline Cabinet Casing & Single-wall with no insulation & Double-wall with foam insulation \\
\hline \multicolumn{3}{|c|}{$\begin{array}{l}\text { Notes: (1) Per UFGS-23 } 8100.00 \text { 20, the baseline is a code-minimum RTU meeting ASHRAE Standard 90.1-2010 } \\
\text { prescriptive performance requirements of } 11.2 \text { EER and } 11.4 \text { IEER, based on Table 6.8.1A for air conditioners } \geq \\
65,000 \text { Btuh ( } 5.4 \text { tons) and }<135,000 \text { Btuh ( } 11.3 \text { tons). RTU has a constant-speed supply fan, fixed outdoor-air } \\
\text { damper, and basic thermostatic control. (2) EER-rated conditions are at an ambient dry-bulb of } 95^{\circ} \mathrm{F} \text { and a mixed air } \\
\text { dry-bulb of } 80^{\circ} \mathrm{F} / \text { wet-bulb of } 67^{\circ} \mathrm{F} \text { per AHRI Standard 340/360-2007. (3) IEER rating represents the part-load } \\
\text { performance of an RTU per AHRI Standard 340/360-2007. }\end{array}$} \\
\hline
\end{tabular}




\subsection{Monitoring Plan}

A Web-based building management system called the eIQ ${ }^{13}$ was installed on site and enabled cellular control and monitoring of both RTUs. The baseline RTU was fitted with an advanced RTU control system called the CATALYST. ${ }^{14}$ The CATALYST changes the supply fan to variable speed, controls the OA damper, and sequences the compressors. Through the eIQ, the CATALYST system was controlled remotely based on the defined baseline operation. The CATALYST also provided RTU operation and airside and power monitoring points, which are summarized in Table F-1 in Appendix F. Through BACnet, the eIQ also controlled the Rebel and monitored its internal points, which are summarized in Table F-2 in Appendix F. Figure 7 provides the power and airside measurements for both RTUs.

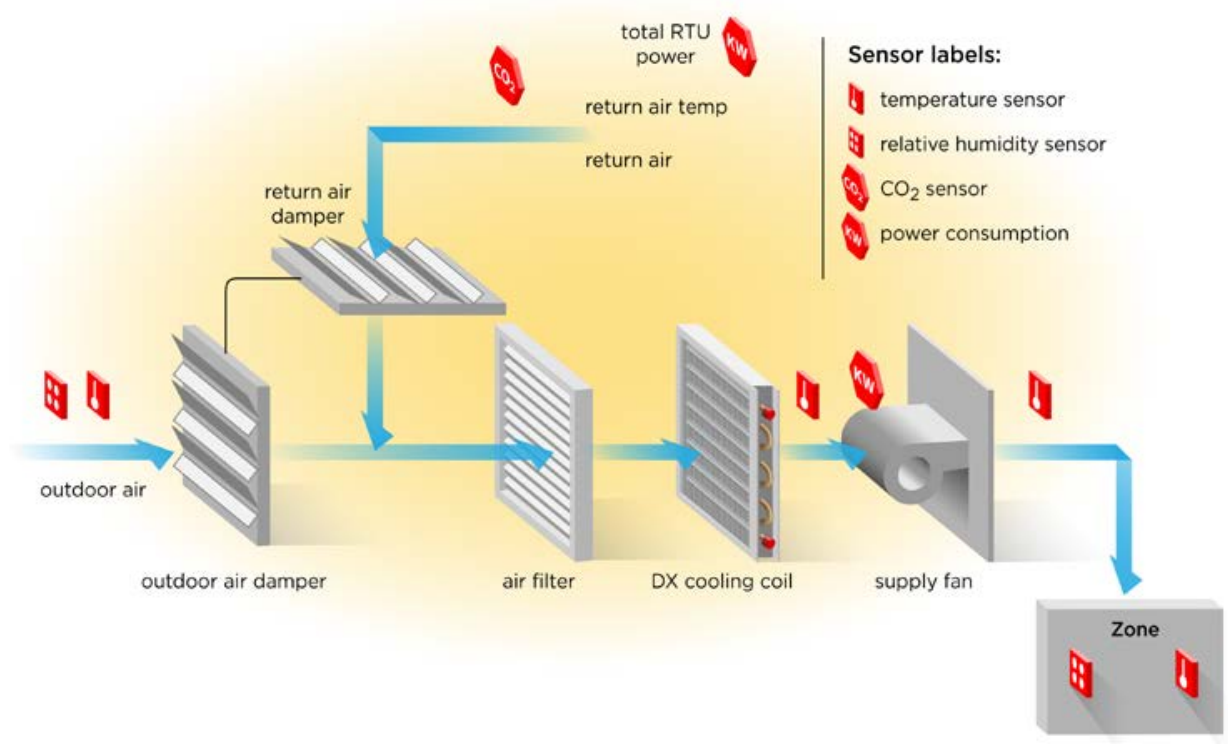

Figure 7. Airside monitoring

Credit: Al Hicks, NREL

Beyond the airside and total power monitoring, NREL monitored the refrigerant side in detail to implement a methodology that would calculate total DX cooling capacity and coefficient of performance (COP) in real time. Figure 8 and equations 1-3 provide a summary of the methodology for a simple DX circuit. By measuring the refrigerant temperature and pressure at points 1, 2, and 3 on the DX circuit and assuming the compressor jacket heat loss, the DX COP can be calculated in real time. Then, by measuring the compressor power, the real time cooling capacity can be calculated. When the DX circuit has achieved steady state, typically 2 minutes after the compressor starts, the ClimaCheck methodology provides performance accuracy to $\pm 5 \%$

\footnotetext{
13 “eIQ Platform.” Transformative Wave Technologies, undated. https://transformativewave.com/technologysolutions/eiq-platform.

14 “Catalyst.” Transformative Wave Technologies, 2013. https://transformativewave.com/technologysolutions/catalyst.
} 
and capacity accuracy to $\pm 7 \% .{ }^{15}$ Appendix A summarizes the ClimaCheck methodology in more detail.

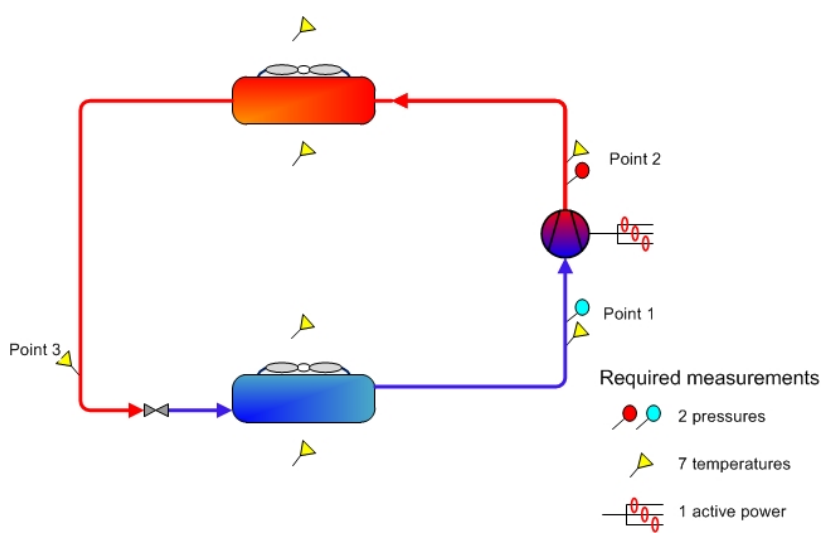

(a)

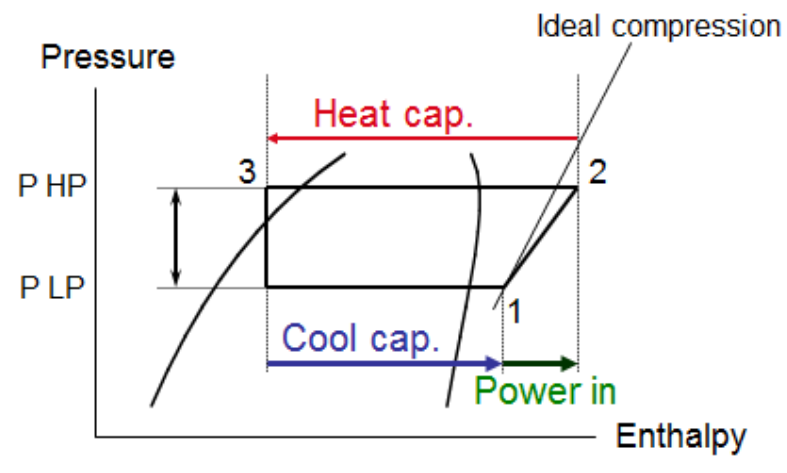

(b)

Figure 8. ClimaCheck methodology to measure temperatures, pressure, and power of the DX circuit to calculate real-time cooling capacity and COP

COPcool $=\frac{h_{1}-h_{3}}{h_{2}-h_{1}} *(1-$ comp_heat_loss $)$

Refrigerant Massflow $=\frac{\text { comp_power } *(1-\text { comp_heat_loss })}{h 1-h 2}$

Real Time Cooling Capacity = COPcool $*$ comp_power

where

$h 1$ is the superheated refrigerant enthalpy entering the compressor $h 2$ is the superheated refrigerant enthalpy leaving the compressor $h 3$ is the subcooled refrigerant enthalpy entering the thermostatic expansion valve comp_power is the power of the DX compressor comp_heat_loss is the percentage of the compressor power loss to the ambient environment (power not delivered to the refrigerant).

\footnotetext{
${ }^{15}$ Berglof, K. Performance Inspections with Innovative Analyzing Equipment Results in Significant Energy Savings in Air-Conditioning and Refrigeration Systems. Accessed January 10, 2013: www.eeswest.com/wpcontent/themes/xero/pdf/pr-berglof-performance-inspections-iir-prag-2011(v2).pdf.
} 


\subsection{Maintaining Internal Sensible and Latent Loads}

Soon after both RTUs were installed, building 550's occupants in the second-floor office space were moved to another office location. Fortunately, NREL had monitored the space temperature, space RH, and power consumption of the original Trane TCH120 RTUs from December 2012 through May 2013 prior to installing the new RTUs. Based on these monitored data and on interviews with the original occupants of the second-floor space, NREL installed heat lamps and humidifiers on timers to represent typical office space sensible and latent internal loads. NAVFAC personnel were also scheduled to turn on/off the overhead lights. Table 3 provides a summary of the artificial loads. Appendix E reviews the sensible and latent loads maintained in the space during the demonstration period in more detail.

Table 3. Artificial Internal Sensible and Latent Loads Established to Represent a Typical Office Space

\begin{tabular}{|c|c|c|}
\hline & Load and Schedule & Schedule/Notes \\
\hline Overhead Lights & $1 \mathrm{~W} / \mathrm{ft}^{2}$ & $\begin{array}{l}\text { NAVFAC personnel would turn lights } \\
\text { on at } 0700 \text { and off at } 1700\end{array}$ \\
\hline Occupancy & $\begin{array}{l}34 \text { occ }\left[146 \mathrm{ft}^{2} / \mathrm{occ}\right] \\
\text { Sensible }=8,500 \text { Btuh (250 Btuh/occ) } \\
\text { Latent }=4.2 \text { gal/day (200 Btuh/occ) }\end{array}$ & $\begin{array}{l}\text { Timers would control to } 0700-1700 \\
\text { Sensible represented by heat lamps } \\
\text { Latent represented by humidifiers }\end{array}$ \\
\hline Plug Loads & $0.4 \mathrm{~W} / \mathrm{ft}^{2}$ & $\begin{array}{l}\text { Timers would control to } 0700-1700 \\
\text { Sensible represented by heat lamps } \\
\text { Office plug loads are not a latent load }\end{array}$ \\
\hline
\end{tabular}




\section{Technical Performance Analysis and Assessment}

The demonstration was initiated as planned, with simultaneous operation of the baseline and Rebel RTUs cooling to the same $76^{\circ} \mathrm{F}$ set point. However, the monitored data clearly showed the Rebel and baseline RTUs interact with the space very differently. The Rebel's set point deadbands and control logic differ from the baseline in a way that caused the Rebel to provide more than $70 \%$ of the cooling and, consequently, use more energy.

The Rebel has a $2^{\circ} \mathrm{F}\left( \pm 1^{\circ} \mathrm{F}\right)$ control deadband about the set point. The baseline's control deadband was $+0.5^{\circ}$ to $+1^{\circ} \mathrm{F}$ above the set point for first stage and $+1^{\circ}$ to $+1.5^{\circ} \mathrm{F}$ above the set point for second stage. Therefore, given the same temperature set point of $76^{\circ} \mathrm{F}$, the Rebel would maintain a slightly cooler temperature range of $75^{\circ}-77^{\circ} \mathrm{F}$ compared to the baseline range of $76.5^{\circ}-77.5^{\circ} \mathrm{F}$.

In the hope of balancing out the loading, NREL compensated for the deadband control difference by setting the baseline RTU set point to $74.5^{\circ} \mathrm{F}$, while the Rebel continued to control to a $76^{\circ} \mathrm{F}$ set point. Figure 9(a) shows how offsetting the baseline set point resulted in both RTUs maintaining their respective sections of the office space within $\pm 1^{\circ} \mathrm{F}$. These set points are recommended for use after the demonstration period.

However, the Rebel RTU still provided most of the cooling because its control logic maintains the compressor on for almost the entire cooling period shown in Figure 9(b). Comparatively, the baseline cycles its compressors. Table 4 provides a daily summary between the RTUs. While the Rebel maintained a higher daily average EER, it provided more than twice the cooling and consumed significantly more energy than the baseline unit. This is fine for long-term conditioning of the space, but it did not meet the needs of the demonstration, as NREL needed the RTUs evenly loaded to provide a true comparison.

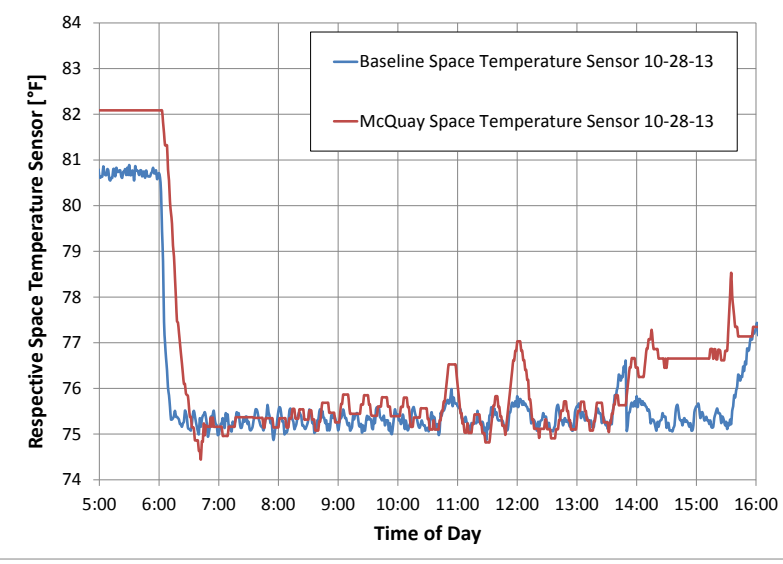

(a)

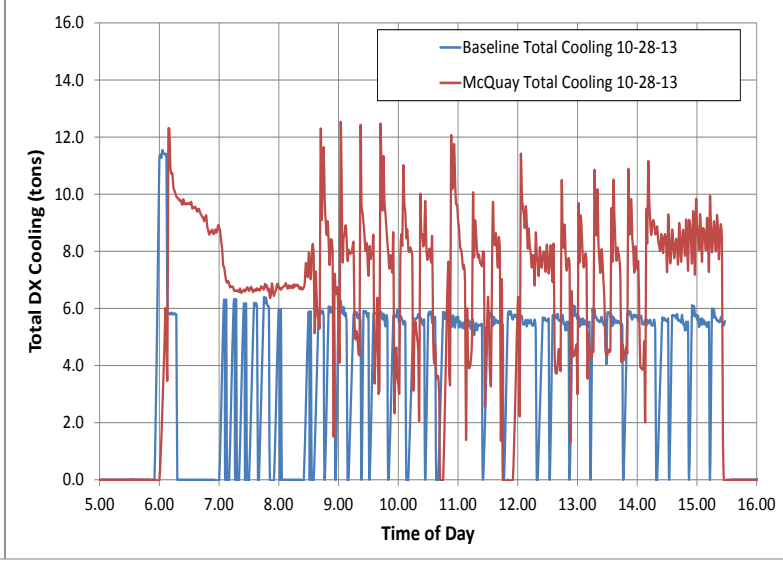

(b)

Figure 9. Rebel and baseline RTU simultaneous operation on October 28, 2013: (a) space temperature measured by each RTU's temperature sensor (b) total DX cooling by each RTU 
Table 4. Performance Comparison Between Baseline and Rebel RTUs on October 28, 2013

\begin{tabular}{|c|c|c|}
\hline & Baseline RTU & Rebel RTU \\
\hline Total Cooling Delivered ${ }^{a}$ & 34 ton-h & 69 ton-h \\
\hline DX Energy ${ }^{b}$ & $30 \mathrm{kWh}$ & $52 \mathrm{kWh}$ \\
\hline Supply Fan Energy & $18 \mathrm{kWh}$ & $6 \mathrm{kWh}$ \\
\hline Daily Average EER ${ }^{c}$ & 8.6 & $14.1^{d}$ \\
\hline
\end{tabular}

a Calculated based on the ClimaCheck methodology.

${ }^{\mathrm{b}}$ Includes compressors, condenser fans, and controller.

${ }^{\mathrm{c}}$ Includes supply fan energy.

${ }^{\mathrm{d}}$ Discharge air temperature (DAT) set point to $55^{\circ} \mathrm{F}$ (daily average EER equals

$17-19$ with a $60^{\circ} \mathrm{F}$ DAT set point).

Therefore, NREL modified its demonstration plan to run the units independently, alternating weeks between the Rebel and the baseline RTU operations, starting in November 2013. Because the space was unoccupied during the demonstration period, NREL was not concerned about leaving half the space unconditioned. The focus of the demonstration period was collecting calibration data for baseline and Rebel energy models. The performance data collected are described in Section 4.1.

Table 5 provides a summary of the demonstration data utilized for both model calibrations. The total number of days shown in Table 5 does not include the demonstration period days in October 2013 when both RTUs were being run simultaneously. Although NREL could not use days of simultaneous day operation for calibrating the models (could only use alternating operational days), the performance data were still useful in developing DX performance models of the baseline and Rebel RTUs, which are summarized in Section 4.1.

Table 5. Summary of Performance Data Used to Develop and Calibrate the Baseline and Rebel Energy Models Across Dates November 10, 2013, through January 26, 2014

\begin{tabular}{lll}
\hline & $\begin{array}{l}\text { Rebel Measured } \\
\text { Performance Data } \\
\text { Used for Calibration }\end{array}$ & $\begin{array}{l}\text { Baseline Measured } \\
\text { Performance Data } \\
\text { Used for Calibration }\end{array}$ \\
\hline Days of Operation & 35 days & 36 days \\
DX Operation Time & $262 \mathrm{~h}$ & $241 \mathrm{~h}$ \\
Supply Fan Operation Time & $332 \mathrm{~h}$ & $342 \mathrm{~h}$ \\
\hline
\end{tabular}

To achieve a true RTU comparison, NREL used the calibrated models of the baseline and Rebel RTUs to simulate each conditioning building 550. The methodology used to calibrate each model is summarized in Section 4.1, Appendix C, and Appendix D. The baseline model was simulated as if two Baseline RTUs were conditioning the entire space. Similarly, the Rebel model was simulated with the entire space being conditioned by two Rebel RTUs. Both models incorporated identical building envelope, infiltration, and internal loads (Appendix E). The internal space loads mirrored the artificial sensible and latent heat gains maintained during the actual demonstration period (Section 3.4). The results from the calibrated models addressed the demonstration objectives of energy savings and thermal comfort described in Sections 4.2 and 
4.3, respectively. The TAB results addressed the ventilation demonstration objectives in Section 4.4. Table 6 summarizes the performance objective results.

Table 6. Performance Objective Results

\begin{tabular}{|c|c|c|c|}
\hline & $\begin{array}{l}\text { Performance } \\
\text { Objective }\end{array}$ & Success Criteria & Results \\
\hline 1 & $\begin{array}{l}\text { Annual Energy } \\
\text { Savings }\end{array}$ & $\begin{array}{l}\text { The Rebel reduces } \\
\text { energy usage by at least } \\
30 \% \text { compared to the } \\
\text { baseline RTU }\end{array}$ & $\begin{array}{l}\text { The Rebel met the energy savings } \\
\text { demonstration objective. The calibrated } \\
\text { energy models showed the Rebel saving } \\
34 \%-37 \% \text { annual energy compared to a } \\
\text { baseline RTU with a typical leaky OA } \\
\text { damper fixed at a } 5 \%-20 \% \text { position. }\end{array}$ \\
\hline 2 & $\begin{array}{l}\text { Interior } \\
\text { Thermal } \\
\text { Comfort }\end{array}$ & $\begin{array}{l}\text { The Rebel maintains a } \\
\text { narrower temperature } \\
\text { band and lower annual } \\
\text { average RH by at least } \\
5 \%\end{array}$ & $\begin{array}{l}\text { The temperature band for both RTUs } \\
\text { depends on their respective deadbands. } \\
\text { Based on its default setting, the Rebel } \\
\text { maintains a } \pm 1^{\circ} \mathrm{F} \text { temperature band while } \\
\text { the baseline maintains a } \pm 0.5^{\circ} \mathrm{F} \\
\text { temperature band. Yet despite a larger } \\
\text { temperature band, the Rebel provides } \\
\text { improved thermal comfort because it } \\
\text { maintains a more stable space temperature } \\
\text { The modeling results show the Rebel } \\
\text { maintains a drier space with the annual } \\
\text { average space RH (during operational } \\
\text { hours) being } 8 \% \text { lower than that of the } \\
\text { baseline RTU model. }\end{array}$ \\
\hline 3 & $\begin{array}{l}\text { Ventilation } \\
\text { Quality }\end{array}$ & $\begin{array}{l}\text { The Rebel reduces OA } \\
\text { damper leakage by } 30 \% \\
\text { compared to the baseline } \\
\text { RTU; Rebel and baseline } \\
\text { maintain proper } \\
\text { ventilation rates during } \\
\text { occupied hours }\end{array}$ & $\begin{array}{l}\text { The Rebel and Baseline met the minimum } \\
\text { ventilation rates according to ASHRAE } \\
62.1-2010 \text {. Compared to the leaky baseline } \\
\text { OA damper, the Rebel maintained } \sim 60 \% \\
\text { reduction in ventilation flow rate while still } \\
\text { meeting ASHRAE } 62.1 \text { minimum ventilation } \\
\text { rates. }\end{array}$ \\
\hline
\end{tabular}

\subsection{Monitored Performance Data for Model Calibration}

The models were calibrated using performance data from November 10, 2013, through January 25, 2014. To achieve a larger cross section of operation, the control parameters were modified during the demonstration period (see Table 7). The Rebel RTU supply fan speed was controlled to modulate at $34 \%-100 \%$. The Rebel compressors throttled to maintain a DAT set point from $55^{\circ}-65^{\circ} \mathrm{F}$. NREL changed the DAT set point during the demonstration period to capture the impact of different suction pressures on performance. 
Table 7. Rebel and Baseline Control Parameters During Demonstration Period

\begin{tabular}{|c|c|c|}
\hline & Rebel & Baseline \\
\hline $\begin{array}{l}\text { Temperature Set Point } \\
\text { Schedule }\end{array}$ & $\begin{array}{l}\text { Ranged from } 70^{\circ}-76^{\circ} \mathrm{F} \\
0600-1530\end{array}$ & $\begin{array}{l}\text { Ranged from } 68^{\circ}-76^{\circ} \mathrm{F} \\
0600-1530\end{array}$ \\
\hline $\begin{array}{l}\text { Temperature Control } \\
\text { Deadband }\end{array}$ & $\pm 1.0^{\circ} \mathrm{F}$ & $\begin{array}{l}1^{\text {st }} \text { stage: }+0.5 \text { to }+1.0 \\
2^{\text {nd }} \text { stage: }+1.0 \text { to }+1.5\end{array}$ \\
\hline Temperature Set Back & $100^{\circ} \mathrm{F}$ & $100^{\circ} \mathrm{F}$ \\
\hline Humidity Control & None & None \\
\hline DAT Set Point & Ranged from $55^{\circ}-65 \mathrm{~F}^{\mathrm{a}}$ & N/A \\
\hline Supply Fan Control & SZVAV & Constant \\
\hline Supply Flow Rate & $\begin{array}{l}1,601-4,069 \mathrm{cfm}^{\mathrm{c}} \\
\text { (controller range } 34 \%-100 \% \text { fan speed) }\end{array}$ & $3,558 \mathrm{cfm}$ \\
\hline OA Damper & $\begin{array}{l}\text { Position Range }=5 \%-15 \%{ }^{d} \\
\text { Ventilation Range }=219-342 \mathrm{cfm}\end{array}$ & $\begin{array}{l}\text { Position Range }=0 \%-20 \% \\
\text { Ventilation }=574-1,413 \mathrm{cfm}^{\mathrm{e}}\end{array}$ \\
\hline
\end{tabular}

${ }^{a}$ For SZVAV control, the Rebel RTU controls the compressors to maintain a constant DAT regardless of the fan speed.

${ }^{\mathrm{b}}$ For SZVAV control, the Rebel RTU controls the supply fan using a PI logic based on the current and previous minute's space temperature compared to set point (see Appendix C).

${ }^{\mathrm{c}}$ The Rebel supply fan was allowed to ramp from $34 \%-100 \%$ based on the controller's settings. The TAB report provided the supply flow rates associated with these settings.

${ }^{\mathrm{d}}$ Prior to the TAB, the Rebel OA damper was fixed at $15 \%$ open; after the TAB, the Rebel OA damper was controlled to open linearly from $5 \%$ at $100 \%$ fan speed to $15 \%$ at $40 \%$ fan speed.

${ }^{\mathrm{e}}$ The baseline OA damper was measured to have significant leakage. After the TAB report, NREL and its subcontractor, Transformative Wave Technologies (TWT), separately measured the ventilation flow rate at a $0 \%$ damper position and verified the baseline RTU was still bringing in almost $600 \mathrm{cfm}$ of OA.

For both RTUs, the temperature set points were lowered below $76^{\circ} \mathrm{F}$ for some days to ensure sufficient operation in second stage. Figure 10 shows that despite these lower set points, both RTUs operated most of the time near $50 \%$ of capacity. Although the baseline does not have a variable-speed compressor, the cooling capacity at both of its stages change slightly based on the mixed-air conditions (entering the evaporator coil) and ambient dry-bulb conditions (entering the condenser coil). 


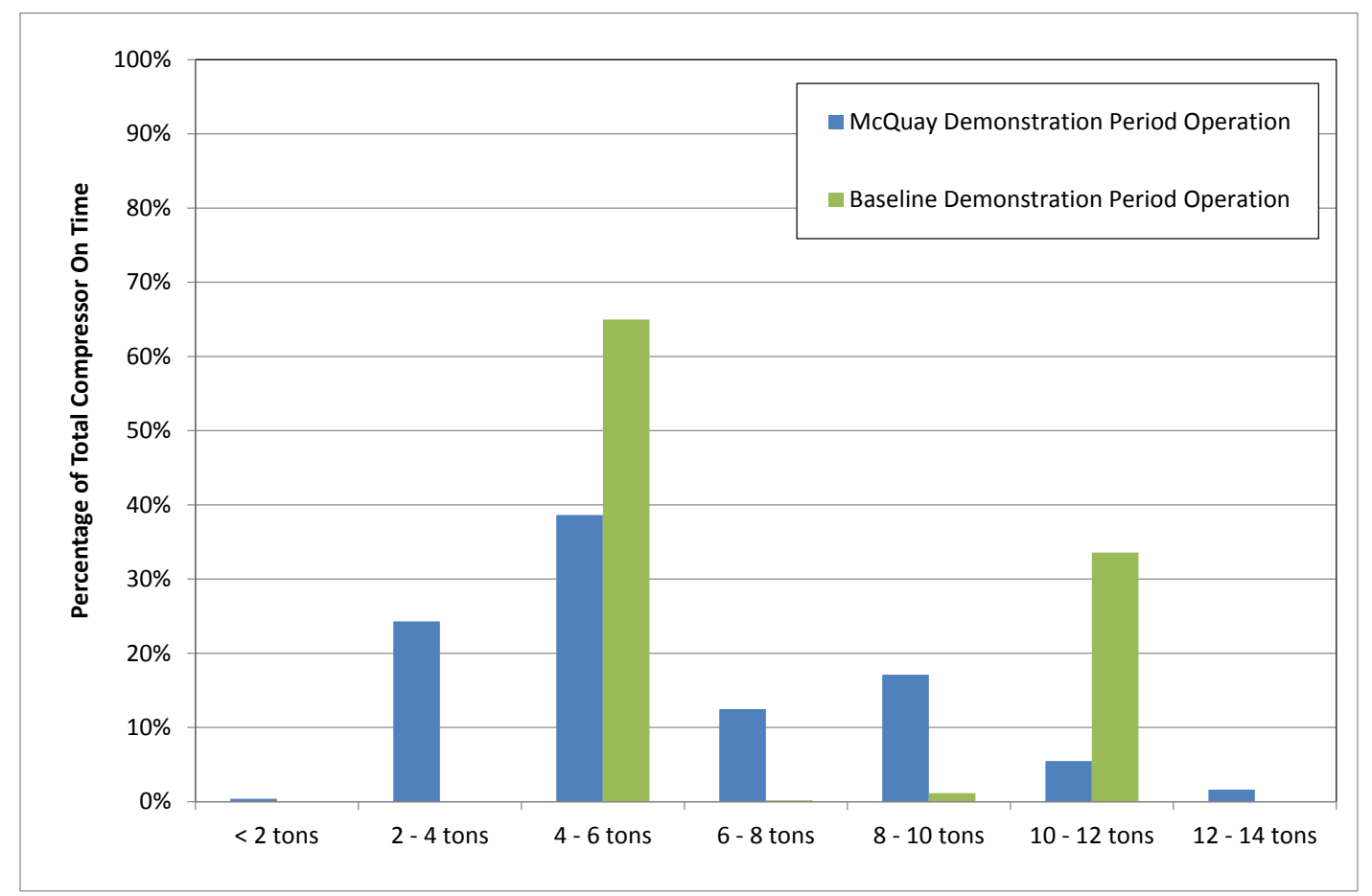

Figure 10. Histogram of monitored baseline and Rebel operational cooling capacities

After gathering a sufficient range of calibration data under various control configurations (most of November 2013), NREL configured the Rebel to achieve its maximum efficiency while meeting NAVFAC's standards of comfort and ventilation. Two Rebel control settings that had a dramatic impact on performance were DAT set point and OA damper position. These maximum efficiency control settings were maintained for the remainder of the demonstration period from November 24, 2013, through January 25, 2014.

DAT set point. The warmer the DAT set point, the more efficient the DX operation. However, the supply fan would then have to work harder (move more air) to meet the space conditioning load. At first, NREL was considering a $65^{\circ} \mathrm{F}$ DAT set point. Yet, the warmer the supply air, the higher the resulting space moisture conditions, causing discomfort and greater potential for mold growth. To balance DX efficiency with space moisture, NREL specified a constant $60^{\circ} \mathrm{F}$ DAT set point.

At a $60^{\circ} \mathrm{F}$ DAT set point, the saturated supply air would have a dew point ranging from $56^{\circ}-$ $58^{\circ} \mathrm{F}$. NREL determined this supply air dew point range was sufficient to maintain a space dew point $<63^{\circ} \mathrm{F}\left(<65 \% \mathrm{RH}\right.$ at a $76^{\circ} \mathrm{F}$ dry-bulb set point). The only moisture-based requirement in UFC or UFGS is UFC 3-410-01 Section 3-4.3.1 (dated July 1, 2013), which states “ $78^{\circ} \mathrm{F}\left(26^{\circ} \mathrm{C}\right)$ dry bulb and a maximum of $55^{\circ} \mathrm{F}\left(12.8^{\circ} \mathrm{C}\right)$ dew point." However, this is a design-based requirement, namely for sizing HVAC equipment. There are no operational moisture (RH or dew point) requirements throughout the UFC, UFGS, Commander Navy Installations Command Common Output Level Standards, or NAVFAC Hawaii energy mandates. NREL proposed-and NAVFAC agreed-to use $65 \% \mathrm{RH}$ (maximum $63^{\circ} \mathrm{F}$ dew point at a $76^{\circ} \mathrm{F}$ dry-bulb set point) as the moisture threshold during occupied hours. A maximum RH of 65\% is based on ASHRAE Standard 55-2010 for maintaining thermal comfort and mitigating mold issues. 
OA damper position. Based on the TAB report, the Rebel OA damper was configured to maintain the minimum ventilation per ASHRAE 62.1-2010 (the DCV features were not exercised in this demonstration according to UFC 3-410-01 Section 401.1 [dated July 1, 2013]; see Section 2.2). The OA damper position was controlled based on the supply fan speed; $5 \%$ open at $100 \%$ fan speed to $15 \%$ open at $40 \%$ fan speed. Section 4.4 reviews the ventilation rates maintained compared to the ASHRAE 62.1-2010 minimum requirement.

Table 8 presents representative Rebel RTU daily performance for five weekdays of the demonstration period. The "Total DX Cooling” is the daily sum of refrigeration-based cooling calculated using the ClimaCheck methodology summarized in Appendix A. Dividing this daily total DX cooling (converted to Btuh) by the daily total electric energy usage (converted to Watthour) provides a daily average EER that includes the supply fan energy. Note these daily average EERs should not to be compared against rated EER or IEER conditions because these field measurements were not at proper AHRI rating conditions.

To fully characterize performance, the baseline was operated at a $68^{\circ} \mathrm{F}$ set point for many hours of the demonstration to realize more second-stage operation. NREL found that the greater percentage of time the baseline RTU operated in first stage cooling, the lower the overall daily EER. The baseline under first-stage operation realizes a lower performance because both fixedspeed condenser fans are operating with only one compressor providing cooling. These additional parasitic power draws drive down the real-time EER. During the demonstration period days with a $76^{\circ} \mathrm{F}$ set point, the baseline RTU would operate more often under first-stage operation, which would further drive down the daily average EER. Table 9 presents the baseline RTU daily performance for five weekdays of the demonstration period when the set point was $68^{\circ} \mathrm{F}$.

The baseline RTU also experiences performance degradation caused by compressor cycling the ClimaCheck methodology does not capture. The ClimaCheck methodology is accurate only when the DX circuit has reached steady-state operation, which is typically 2 minutes after the compressors turns on. When the baseline RTU turned on a compressor, the ClimaCheck method was calculating a cooling rate well beyond the capacity of that DX circuit. For example, when the second-stage compressor turned on, the first minute of operation would report 10 tons of additional cooling, the second minute 7 tons of additional cooling, and from the third minute on, the additional cooling would settle to a realistic 5 tons. When calculating the daily total DX cooling, NREL set the first and second minute cooling rates to that measured in the third minute each time a compressor started. Yet this adjustment of the monitored data does not fully address the performance degradation caused by significant compressor cycling. Therefore, the daily average EER provided in Table 9 may overstate the baseline RTU performance. The true daily average EER may be up to $8 \%$ below that shown, based on the uncertainty in the measurement.

The daily average EERs and energy usage from Table 8 and Table 9 should not be used for the true RTU comparison, nor should they be compared to the unit's rated IEER. They are field test measurements, not lab test results at proper AHRI rating conditions. Instead, the monitored data from the demonstration period were used to calibrate a Rebel RTU model and baseline RTU model. NREL used calibrated whole-building energy models to establish a true RTU performance comparison. 
Table 8. Monitored Daily Rebel RTU Performance ${ }^{a}$

\begin{tabular}{lllllll}
\hline Date & $\begin{array}{l}\text { Avg. } \\
\text { OAT } \\
\left({ }^{\circ} \mathrm{F}\right)\end{array}$ & $\begin{array}{l}\text { Total DX } \\
\text { Cooling } \\
\text { (ton-h) }\end{array}$ & $\begin{array}{l}\text { Compressor }+ \\
\text { Cond. Fan } \\
\text { Energyc } \\
\mathbf{( k W h )}\end{array}$ & $\begin{array}{l}\text { Supply Fan } \\
\text { Energy }^{\mathbf{d}} \\
\mathbf{( k W h )}\end{array}$ & $\begin{array}{l}\text { Total } \\
\text { Energy } \\
\text { (kWh) }\end{array}$ & $\begin{array}{l}\text { Daily } \\
\text { Average }^{\text {EER }}\end{array}$ \\
\hline $12 / 9 / 13$ & 81.2 & 54 & 30.6 & 3.6 & 36.0 & 17.9 \\
\hline $12 / 10 / 13$ & 80.1 & 52 & 31.6 & 4.0 & 37.0 & 16.7 \\
\hline $12 / 11 / 13$ & 78.4 & 47 & 25.7 & 3.4 & 30.9 & 18.1 \\
\hline $12 / 12 / 13$ & 78.5 & 38 & 23.2 & 3.2 & 27.1 & 17.0 \\
\hline $12 / 13 / 13$ & 77.5 & 40 & 20.9 & 3.1 & 25.5 & 19.0 \\
\hline
\end{tabular}

${ }^{a}$ For December 2013, the Rebel RTU was controlled to a $76^{\circ} \mathrm{F}$ set point, $60^{\circ} \mathrm{F}$ DAT set point, modulating OA damper to maintain ASHRAE 62.1 minimum ventilation based on fan speed, and variable-supply flow rate of $1,601-4,069 \mathrm{cfm}$.

${ }^{\mathrm{b}}$ Daily DX cooling capacity calculated using the ClimaCheck methodology with $\pm 7 \%$ uncertainty.

${ }^{\mathrm{c}}$ Compressor and condenser fan energy measured at a $\pm 3 \%$ accuracy (separately submetered).

${ }^{d}$ Supply fan energy with uncertainty of 5\%; based on subtraction of compressor, condenser fan, and controller energy from total RTU energy (supply fan power was not separately submetered).

e Total RTU energy (including controller) with $\pm 3 \%$ uncertainty (separately submetered).

${ }^{\mathrm{f}}$ Daily averaged performance based on total daily cooling provided (ton-hours) and total RTU energy (including supply fan energy) with $\pm 5 \%$ uncertainty; not to be compared against rated EER or IEER conditions as these field measurements were not at proper AHRI rating conditions.

Table 9. Monitoring Daily Baseline RTU Performance ${ }^{a}$

\begin{tabular}{lllllll}
\hline Date & $\begin{array}{l}\text { Avg. } \\
\text { OAT } \\
\left({ }^{\circ} \mathrm{F}\right)\end{array}$ & $\begin{array}{l}\text { Total DX } \\
\text { Cooling }^{\mathbf{b}} \\
\text { (ton-h) }\end{array}$ & $\begin{array}{l}\text { Compressor + } \\
\text { Cond. Fan } \\
\text { Energyc } \\
\text { (kWh) }\end{array}$ & $\begin{array}{l}\text { Supply Fan } \\
\text { Energyd } \\
\text { (kWh) }\end{array}$ & $\begin{array}{l}\text { Total } \\
\text { Energy } \\
\text { (kWh) }\end{array}$ & $\begin{array}{l}\text { Daily Average } \\
\text { EER }^{\mathbf{f}, \mathbf{g}}\end{array}$ \\
\hline $12 / 2 / 13$ & 75.0 & 70 & 56.0 & 10.5 & 66.7 & 12.5 \\
\hline $12 / 3 / 13$ & 75.7 & 69 & 55.9 & 10.5 & 66.7 & 12.4 \\
\hline $12 / 4 / 13$ & 76.5 & 67 & 54.9 & 10.5 & 66.2 & 12.2 \\
\hline $12 / 5 / 13$ & 75.6 & 65 & 53.9 & 10.5 & 64.9 & 12.0 \\
\hline $12 / 6 / 13$ & 76.8 & 66 & 54.2 & 10.5 & 64.7 & 12.2 \\
\hline
\end{tabular}

${ }^{a}$ For December 2013, the baseline RTU was controlled to a $68^{\circ} \mathrm{F}$ set point, $20 \%$ fixed OA damper, and 3,558 cfm supply flow rate.

${ }^{\mathrm{b}}$ Daily cooling capacity calculated using the ClimaCheck method with $\pm 7 \%$ uncertainty.

${ }^{\mathrm{c}}$ Compressor and condenser fan energy measured at a $\pm 3 \%$ accuracy (separately submetered).

d Supply fan energy with uncertainty of 5\%; based on subtraction of compressor, condenser fan, and controller from total RTU energy (supply fan power was not separately submetered).

e Total RTU energy (including controller) with $\pm 3 \%$ uncertainty (separately submetered).

${ }^{\mathrm{f}}$ Daily averaged performance based on daily cooling provided (ton-hours) and total RTU energy (including supply fan energy) with $\pm 5 \%$ uncertainty; not to be compared against rated EER or IEER conditions as these field measurements were not at proper AHRI rating conditions.

${ }^{g}$ Baseline daily average EER ranged from 8.5-10.5 with more typical compressor staging where $80 \%$ of DX operation time was under first stage and $20 \%$ operation time under second stage. When the set point was reduced to $68^{\circ} \mathrm{F}$, the greater percentage of second-stage operation improved daily average EER to 10.5-12.5. 
The following two subsections describe how the RTUs were modeled using the EnergyPlus ${ }^{16}$ whole-building energy simulation program. Two models were constructed with identical building characteristics (geometry, envelope, and internal loads). These building parameters were based on measurements taken on site; structural drawings; and the artificial occupant, plug, and lighting loads (Section 3.4). Because the space was unoccupied for the demonstration period and the internal loads were artificial, the randomness induced by human behavior was nearly eliminated. The RTUs conditioning the space constituted the only difference between the two models.

\subsubsection{Rebel Rooftop Unit Modeling Process}

The Rebel RTU modeling was a three-part process:

1. The monitored demonstration data were used to develop mathematical models to characterize the Rebel supply fan and DX system.

2. The Rebel RTU model was integrated into a whole-building simulation of building 550 . Two unknown envelope parameters - infiltration rate and window properties (solar heat gain coefficient [SHGC] and U-value) - were adjusted within appropriate bounds to calibrate the whole-building simulation against the measured data. NREL conducted a rigorous uncertainty analysis comparing the measured versus modeled daily energy to quantify the 95\% confidence bounds of the model (Appendix H). There were 35 days in the Rebel calibration period. NREL also stipulated the model must maintain the occupied average space temperature to $\pm 1^{\circ} \mathrm{F}$ and dew point to $\pm 3^{\circ} \mathrm{F}$ of the measured space conditions. Based on these specifications, NREL was assured the model represented the measured Rebel RTU energy usage and resultant space conditions (sensible and latent).

3. The calibrated model was simulated for an entire year using typical meteorological year 3 (TMY3) weather data. The resultant annual energy usage was compared to the calibrated baseline model also simulated using TMY3 weather.

Steps 1 and 2 are described below. Step 3’s annual energy results are summarized in Section 4.2.

\section{Step 1. Rebel Supply Fan and DX System Models}

The Rebel RTU's PI supply fan control logic was integrated into the model. For each minute, the Rebel RTU calculates a projected error (difference between space temperature and set point) based on the current and previous minute's error. The supply fan speed changes based on the projected error and a gain term. Appendix $\mathrm{C}$ explains the supply fan control logic in detail. Appendix $\mathrm{C}$ also summarizes the relationship between fan speed, supply air flow rate, total static pressure drop, and supply fan power. The Rebel DX system was controlled to maintain a constant $60^{\circ} \mathrm{F}$ DAT.

Once the compressor and supply fan control logic was integrated into the EnergyPlus model, NREL used the monitored data to develop a regression model of DX (compressors and condenser fans) power. Equation 4 shows this regression model. At each time step (1 minute) in the EnergyPlus model, these predictors are known. The calculated DX power for each time step is then used to calculate energy usage.

${ }^{16}$ https://energyplus.net/ 


$$
\begin{aligned}
& D X_{\text {Power }}=-0.752+\left(-0.051 \cdot T_{D A}\right)+\left(0.077 \cdot T_{O A}\right)+ \\
& \left(6.067 \cdot \text { Cap }_{\text {Frac }}\right)+(-0.772 \cdot \text { Comp } 1 \text { or } 2)
\end{aligned}
$$

where

$D X_{\text {Power }}$ is the combined power draw of the compressors and condenser fan $(\mathrm{kW})$

$T_{D A}$ is the DAT $\left({ }^{\circ} \mathrm{C}\right)$

$T_{O A}$ is the ambient dry-bulb temperature $\left({ }^{\circ} \mathrm{C}\right)$

Cap_Frac is the capacity fraction based on the ClimaCheck calculated real-time cooling normalized to the RTU's AHRI nominal capacity (117,907 Btuh; 9.8 tons)

Comp1or 2 signifies whether operating in first or second stage $(+1=\operatorname{stg} 1 ;-1=\operatorname{stg} 2)$.

NREL included the predictor Comp1or2 because the monitored data showed a step-wise change in performance when the second-stage compressor initiated. For example, the ClimaCheck methodology would show the real-time DX efficiency operating around 18 EER (not including the supply fan energy) with only the first-stage compressor operating. When the second-stage compressor turned on, the real-time DX efficiency would immediately drop to around 15 EER (not including the supply fan energy). Including the Comp1or2 predictor in equation 4 captures this step-wise change.

Based on the monitored data, NREL found the second-stage compressor would initiate when the capacity fraction exceeded 0.6. Therefore, during the modeling process, only the first stage was operating until the capacity fraction exceeded 0.6. Figure 11 shows the Rebel DX power regression equation provides a $\pm 10 \%$ uncertainty at a $68 \%$ confidence based on the coefficient of variation of the root mean squared error (CVRMSE).

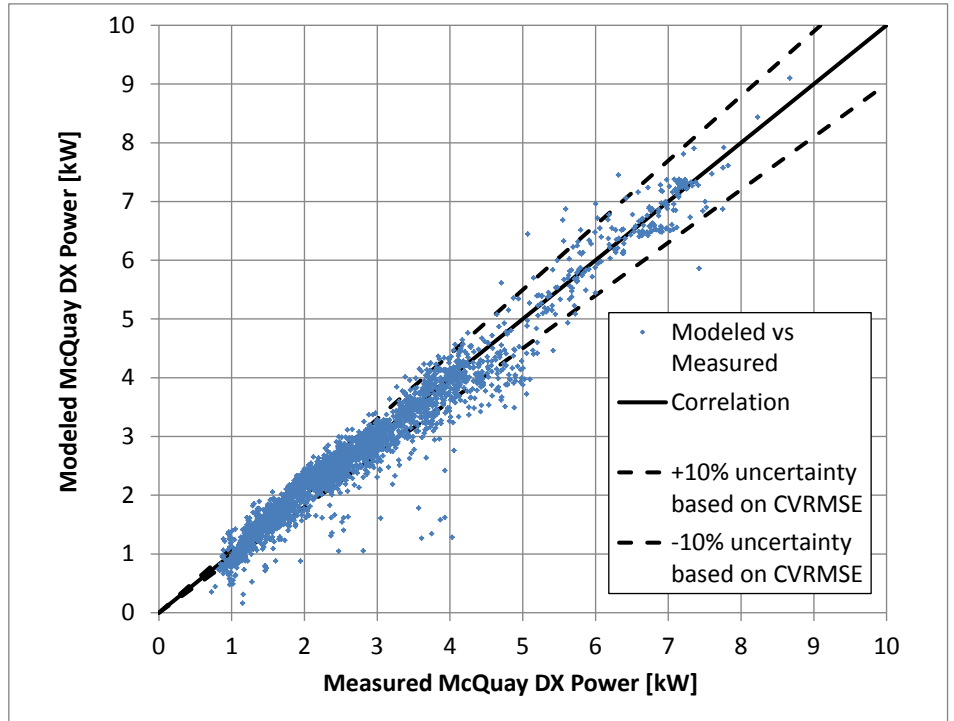

Figure 11. Rebel DX power regression modeled versus measured, including uncertainty based on CVRMSE

Table 10 summarizes the parameters of this regression model. Appendix $\mathrm{C}$ summarizes this regression model in greater detail. Figure 12 uses equation 4 to compare the Rebel's DX performance, not including the supply fan power, across a range of predictor values. The step- 
wise change in performance is apparent when the second stage compressors turn on at capacity fractions that exceed 0.6.

Table 10. Rebel RTU DX Power Regression Model Parameters

\begin{tabular}{ll}
\hline Adjusted R-squared & 0.96 \\
Standard error/CVRMSE & $0.28 \mathrm{~kW} / 10 \%$ \\
\hline Total RTU operational hours & $262 \mathrm{~h}(245 \mathrm{~h}$ first stage; $17 \mathrm{~h}$ second stage $)$ \\
\hline $\begin{array}{l}\text { Regressed DX power range } \\
\text { (includes condenser fan) }\end{array}$ & First-stage operation: $0.7-5.2 \mathrm{~kW}$ \\
Regressed $T_{D A}$ range & Second-stage operation: $3.7-8.7 \mathrm{~kW}$ \\
\hline Regressed $T_{O A C}$ & $55^{\circ}-68^{\circ} \mathrm{F}$ \\
Regressed Cap_Frac $^{\circ}$ & $61^{\circ}-87^{\circ} \mathrm{F}$ \\
\hline
\end{tabular}

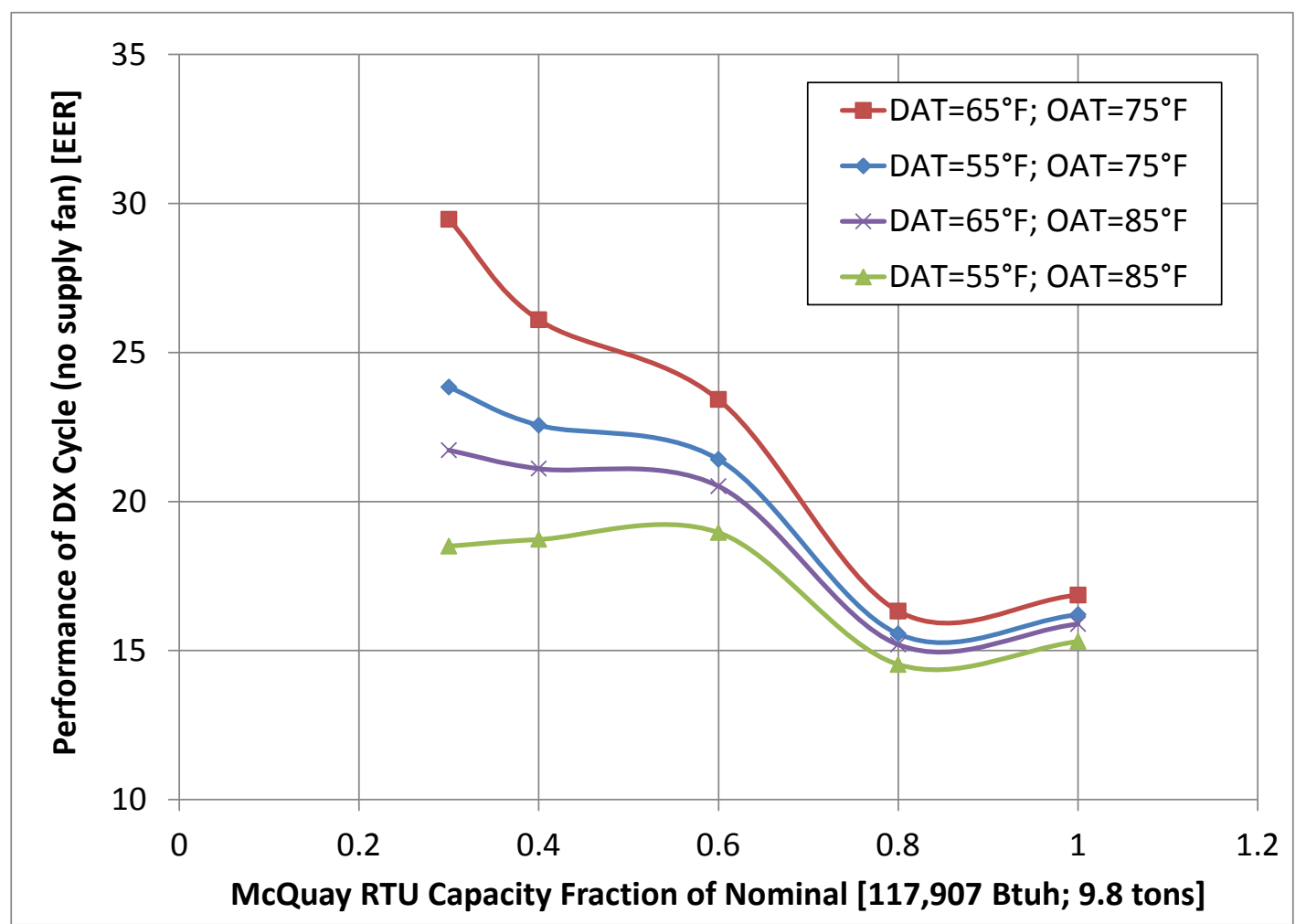

Figure 12. Using DX power regression model to calculate DX cycle performance (EER) for a range of DAT, OAT, and capacity fractions

\section{Step 2. Rebel Rooftop Unit and Building 550 Model Calibration}

With the supply fan logic, compressor logic, and DX power regression model implemented, the EnergyPlus model was calibrated against 35 days of monitored data between November 24, 2013 and January 25, 2014. These were days when only the Rebel RTU was operating, and the control parameters were adjusted to maximize efficiency while meeting thermal comfort requirements. These control parameters included a $76^{\circ} \mathrm{F}$ set point, $60^{\circ} \mathrm{F}$ DAT set point, and OA damper 
modulating from $15 \%$ open at $40 \%$ fan speed to $5 \%$ open at $100 \%$ fan speed. The ventilation flow rate at this supply fan and OA damper control met the ASHRAE 62.1 minimum ventilation requirements. The model was simulated using a 1-minute time step and the measured National Oceanic and Atmospheric Administration Honolulu International Airport weather data.

For calibration, NREL adjusted two "knobs" to ensure the model aligned with the monitored data. These were two model inputs that characterized building 550's envelope; infiltration rate and double-pane window properties (SHGC and U-value). Appropriate upper and lower bands were established for both inputs. NREL found an infiltration of $0.10 \mathrm{cfm} / \mathrm{ft}^{2}$ of wall area at 0.05 in. water column (WC) pressure (equivalent to 0.34 air changes per hour), glazing SHGC of 0.50 , and glazing $U$-value of 0.5 resulted in the best fit to the measured daily energy usage.

Figure 13b shows the comparison for the daily RTU energy calibration (including supply fan, compressors, and condenser fans). Using the uncertainty analysis in Appendix $\mathrm{H}$, the uncertainty of the Rebel EnergyPlus model was based on the CVRMSE. The CVRMSE was calculated to be $\pm 17 \%$ at a $68 \%$ confidence. These confidence bands are plotted in Figure $13 \mathrm{~b}$. Appendix H goes into further detail regarding the propagation of modeling error in the final annual energy savings prediction. Figure 13a shows the daily RTU energy usage versus the daily average ambient drybulb temperature. The plots trend well together and provide confidence that the Rebel RTU model captured the impact of weather on energy usage. Appendix C summarizes all the Rebel calibration results.

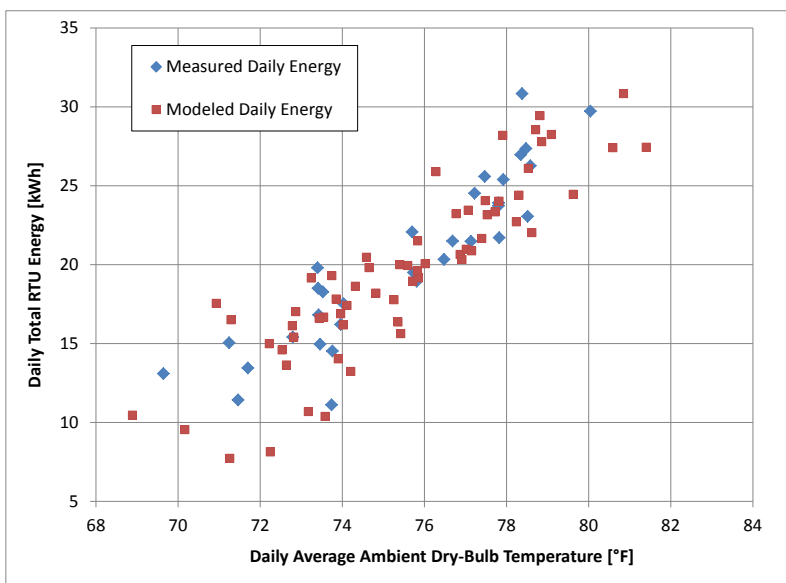

(a)

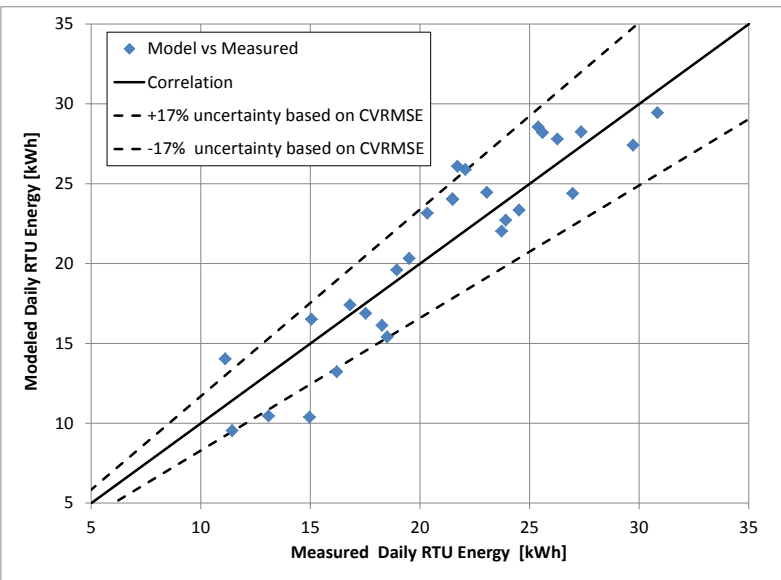

(b)

Figure 13. Rebel RTU model versus measured daily RTU energy usage 


\subsubsection{Baseline Rooftop Unit Modeling Process}

The baseline RTU modeling was a three-part process:

1. The monitored data were used to develop mathematical models characterizing the baseline's supply fan and DX system.

2. The baseline RTU model was integrated into a whole-building simulation of building 550. The infiltration and window properties established during the Rebel RTU model calibration were maintained for the baseline RTU model. The baseline RTU model was calibrated based on the same set of specifications:

a. Measured versus modeled daily energy usage

b. Model must maintain the occupied average space temperature to $\pm 1^{\circ} \mathrm{F}$ and dew point to $\pm 3^{\circ} \mathrm{F}$ of the measured space conditions.

3. The calibrated model simulated two baseline RTUs that served the entire office space in building 550 using TMY3 normalized weather data.

The following subsection summarizes step 1 and step 2 . Section 4.2 reviews the annual energy results from step 3.

The baseline RTU was modeled by determining for each time step whether first- or second-stage compressors were operating based on the space temperature versus set point error. Depending on the stage of operation, the mixed-air wet-bulb temperature, ambient dry-bulb temperature, and two sets of regression equations were used to calculate the cooling capacity and associated DX (compressor(s) and condenser fans) power. Based on the baseline RTU sequence, both condenser fans operated whether in stage 1 or 2 cooling operation. The baseline RTU OA damper was modeled at $20 \%$ open based on how it was configured during the days used in the calibration period. The supply fan was modeled with a constant 3,558 cfm based on the TAB report.

\section{Step 1. Regression Models}

The baseline RTU was characterized with two sets of regression equations. Equations 5 and 6 capture the variations in the first- and second-stage DX system power draw, respectively, based on the mixed-air wet-bulb and ambient dry-bulb temperatures. NREL found the ambient drybulb temperature had the most significant impact on compressor power because it directly impacts discharge pressure (saturated condensing temperature) and refrigerant subcooling. To a lesser extent, the mixed-air wet-bulb impacted the compressor power because it influences the suction pressure (saturated suction temperature).

$$
\begin{aligned}
& \text { Stage } 1 \text { DX Power } 15,058+\left(-919 \cdot T_{W B}\right)+\left(16 \cdot T_{W B}{ }^{2}\right)+ \\
& \left(-283 \cdot T_{O A}\right)+\left(1.4 \cdot T_{O A}{ }^{2}\right)+\left(16 \cdot T_{W B} \cdot T_{O A}\right) \\
& \text { Stage } 2 \text { DX Power } 17,559+\left(-487 \cdot T_{W B}\right)+\left(-6 \cdot T_{W B}{ }^{2}\right)+ \\
& \left(-634 \cdot T_{O A}\right)+\left(3.1 \cdot T_{O A}{ }^{2}\right)+\left(34 \cdot T_{W B} \cdot T_{O A}\right)
\end{aligned}
$$

where

$D X$ Power includes the compressors and condenser fans power (W),

$T_{W B}$ is the mixed-air wet-bulb temperature entering the evaporator coil $\left({ }^{\circ} \mathrm{C}\right)$, and

$T_{O A}$ is the ambient dry-bulb temperature $\left({ }^{\circ} \mathrm{C}\right)$. 
The DX system power includes the compressors and condenser fans power draw. Although the mixed-air wet-bulb was not measured directly during the demonstration period, NREL used the return air temperature/RH conditions, ambient temperature/RH conditions, and OA fraction based on the TAB report to calculate the mixed-air wet-bulb temperature. Figure 14 shows the regression model for both stages of cooling with both having a $2 \%$ uncertainty at a $68 \%$ confidence interval based on the models' CVRMSE.
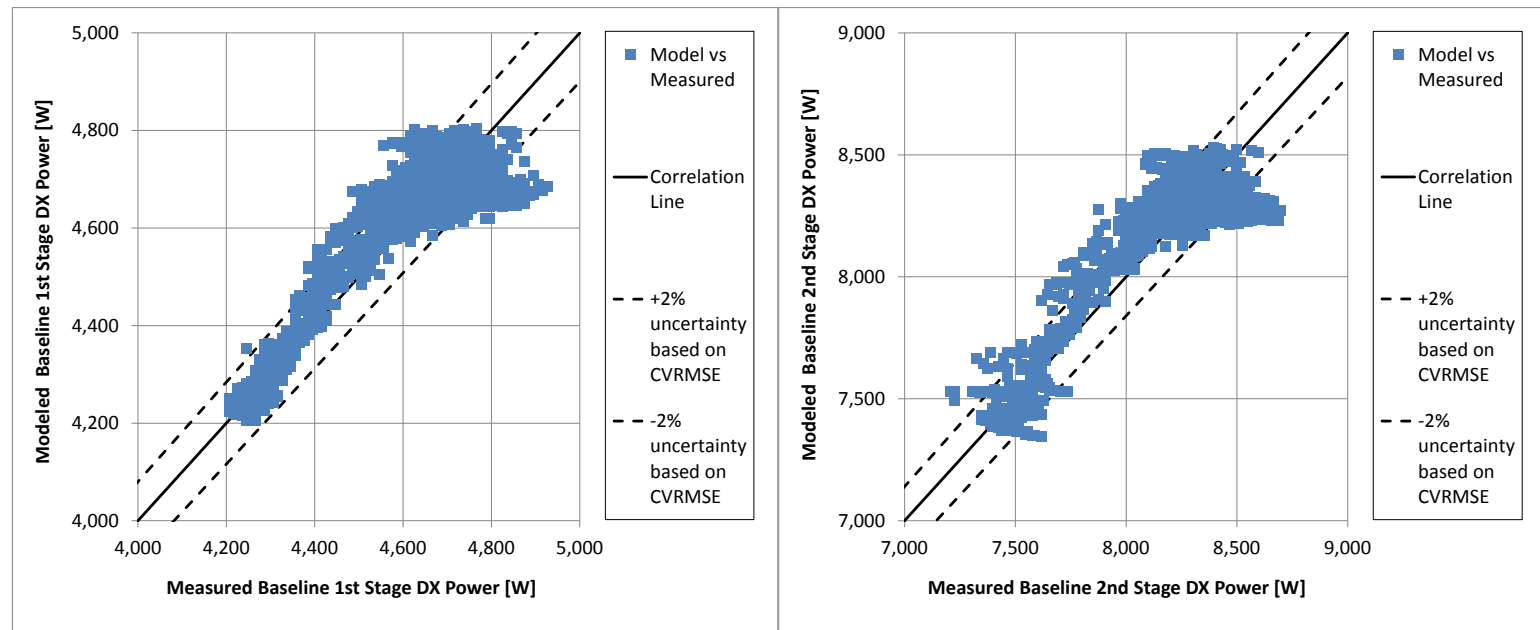

Figure 14. Baseline RTU DX power regression (including compressors and condenser fans)

Table 11 shows some additional regression parameters. A second set of regressions was conducted that related the cooling capacity under first- and second-stage operation to the mixedair wet-bulb temperature and ambient dry-bulb temperature (see Appendix D).

Table 11. Baseline RTU DX Power Regression Parameters (including Compressors and Condenser Fans)

\begin{tabular}{lll}
\hline & First-Stage DX & Second-Stage DX \\
\hline Adjusted R-squared & 0.86 & 0.83 \\
Standard error / CVRMSE & $0.08 \mathrm{~kW} / 2 \%$ & $0.16 \mathrm{~kW} / 2 \%$ \\
$\begin{array}{l}\text { Regressed DX power range } \\
\text { (includes cond. fans) }\end{array}$ & $4.2-5.0 \mathrm{~kW}$ & $7.1-8.7 \mathrm{~kW}$ \\
Regressed operational hours & $173 \mathrm{~h}$ & $68 \mathrm{~h}$ \\
Regressed $T_{W B}$ range & $62^{\circ}-68^{\circ} \mathrm{F}$ & $62^{\circ}-69^{\circ} \mathrm{F}$ \\
Regressed $T_{O A}$ range & $62^{\circ}-86^{\circ} \mathrm{F}$ & $63^{\circ}-87^{\circ} \mathrm{F}$ \\
\hline
\end{tabular}

\section{Step 2. Baseline Rooftop Unit and Building 550 Model Calibration}

Figure 15 shows the calibration of the model versus monitored daily DX energy usage. Compared to the Rebel model, the baseline model showed a better calibration with respect to the measured daily energy usage with a $\pm 7 \%$ uncertainty at a $68 \%$ confidence interval based on the CVRMSE. Additional calibration results are presented in Appendix D. 

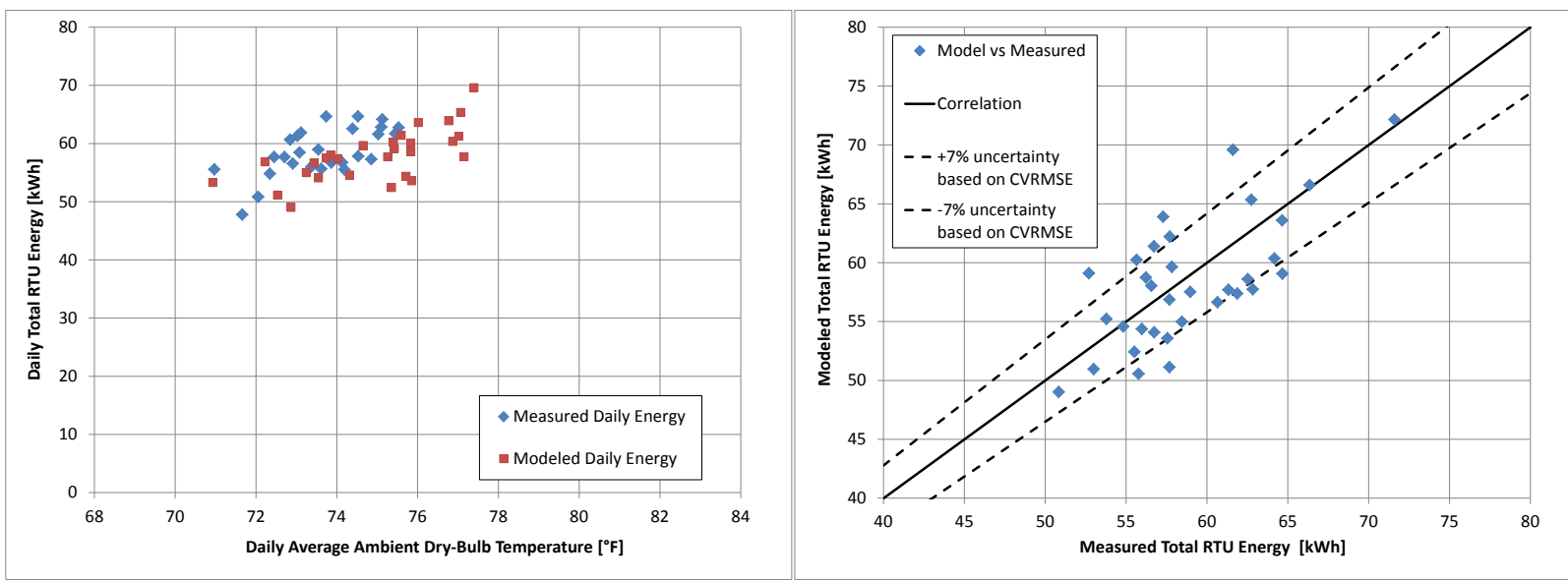

Figure 15. Baseline RTU model versus measured daily DX energy usage

\subsubsection{Supply Fan Models}

Table 12 provides a performance comparison between the Rebel and baseline RTU supply fans. The Rebel's ECM direct drive supply fan achieves a much higher static efficiency compared to the baseline. NREL found the baseline static efficiency was lower than the expected range of $40 \%-50 \%$. Regardless, the power draw was consistent with expectations and used as the baseline fan power for the model.

Table 12. Supply Fan Comparison

\begin{tabular}{lll}
\hline & Rebel & Baseline \\
\hline Fan Type & $\begin{array}{l}\text { Variable-speed } \\
\text { Direct-drive ECM }\end{array}$ & $\begin{array}{l}\text { Belt driven } \\
\text { Constant-speed } \\
\text { NEMA std eff }\end{array}$ \\
Flow Rate During Demonstration & $1,600-3,575 \mathrm{cfm}$ & $3,558 \mathrm{cfm}$ \\
Pressure Drop at Peak Flow Rate & $1.96 \mathrm{in.} \mathrm{WC}$ & $0.91 \mathrm{in.} \mathrm{WC}$ \\
Power Draw at Peak Flow Rate & $1.3 \mathrm{~kW}$ & $1.1 \mathrm{~kW}$ \\
\hline
\end{tabular}

The Rebel total static pressure drop was significant because the Rebel had to be transitioned from vertical discharge to horizontal discharge. Most standard RTUs can be provided in either configuration. The Rebel was designed for vertical discharge only, but is adaptable to horizontal discharge through a custom roof curb. The supply air duct leaving the roof curb under the Rebel was a small, cross-sectional area of $1.9 \mathrm{ft}^{2}$ compared to $4.5 \mathrm{ft}^{2}$ horizontal discharge ductwork on the baseline. The Rebel air speeds at 1,880 feet per minute (fpm), compared to $870 \mathrm{fpm}$ for the baseline, resulted in a significant supply fan static pressure drop. The 1.3-kW Rebel supply fan power was implemented in the model at the TAB measured $3,575 \mathrm{cfm}$. To capture the fan power changes at variable supply fan speeds, the fan power was correlated to variable supply air flow rates established from the TAB report. See Appendix C and Appendix D for more detailed summaries of the supply parameters for the Rebel and baseline supply fans, respectively. 


\subsection{Model Results}

The two calibrated models were then simulated for a year's operation using Honolulu TMY3 weather data. TMY3 weather data eliminate weather abnormalities and provide an annual RTU energy use that would be expected averaged over 30 years of operation. Table 13 provides the control parameters for each RTU model. For the most part, the models mirrored the controls implemented during the December 2013 through January 2014 timeframe of the demonstration period.

Table 13. Rebel and Baseline Control Parameters

\begin{tabular}{|c|c|c|}
\hline & Rebel & Baseline \\
\hline \multirow{3}{*}{$\begin{array}{l}\text { Temperature Set Point } \\
\text { Schedule }\end{array}$} & $76^{\circ} \mathrm{F}$ & $74.5^{\circ} \mathrm{F}$ \\
\hline & $\begin{array}{l}\text { 0600-1530 weekdays (Summer May 1- } \\
\text { October 31) }\end{array}$ & \multirow{2}{*}{$\begin{array}{l}\text { 0600-1530 Weekdays } \\
\text { (Summer May 1-October 31) } \\
\text { 0800-1530 Weekdays (Winte } \\
\text { November 1-April 30) }\end{array}$} \\
\hline & $\begin{array}{l}\text { 0800-1530 Weekdays (Winter November } \\
\text { 1-April 30) }\end{array}$ & \\
\hline $\begin{array}{l}\text { Temperature Control } \\
\text { Deadband }\end{array}$ & $\pm 1.0^{\circ} \mathrm{F}$ & $\begin{array}{l}\text { First stage: }+0.5 \text { to }+1 \\
\text { Second stage: }+1 \text { to }+1.5\end{array}$ \\
\hline Temperature Setback & $100^{\circ} \mathrm{F}$ & $100^{\circ} \mathrm{F}$ \\
\hline Humidity Control & None & None \\
\hline DAT Set Point & $60^{\circ} \mathrm{F}^{\mathrm{a}}$ & $\mathrm{N} / \mathrm{A}$ \\
\hline Supply Fan Control & SZVAVb & Constant speed \\
\hline Min-Max Flow Rate & $1,601-3,575 \mathrm{cfm}$ & $3,558 \mathrm{cfm}$ \\
\hline OA Damper & $\begin{array}{l}\text { Minimum position (Closed all other times) } \\
0800-1530 \text { weekdays (Summer May 1- } \\
\text { October 31) 1000-1530 weekdays (Winter } \\
\text { November 1-April 30) Ventilation range } \\
219-342 \mathrm{cfm} \text { Meets ASHRAE } 62.1^{\mathrm{c}}\end{array}$ & $\begin{array}{l}\text { Fixed } 5 \% \text { open Ventilation }{ }^{d}= \\
672 \mathrm{cfm} \text { Meets ASHRAE } 62.1\end{array}$ \\
\hline
\end{tabular}

${ }^{a}$ Rebel controls the compressors to maintain a constant DAT at any fan speed.

${ }^{\mathrm{b}}$ Rebel controls the supply fan based on its SZVAV logic, which ramps the fan using a PI control based on the current and previous minute's space temperature compared to set point (see Appendix C).

${ }^{\mathrm{c}}$ Rebel model simulated OA flow rates based on correlation between OA flow rate and supply air flow rate established using the TAB report. OA flow rates meets minimum ventilation rate according to ASHRAE Standard 62.1 non-DCV requirements.

${ }^{\mathrm{d}}$ Baseline model simulated constant OA flow rate of $672 \mathrm{cfm}$, based on the TAB report.

The major control change to the baseline RTU model was maintaining the OA damper fixed at $5 \%$ compared to the $20 \%$ position during the demonstration. As summarized in Section 4.4, the excessive leakage of the OA damper even at a 5\% damper position resulted in approximately three times the ventilation required per ASHRAE 62.1-2010. The baseline temperature set point was maintained lower than the Rebel because of their respective deadbands. This offset ensured both models maintained the average office space temperature within $\pm 1^{\circ} \mathrm{F}$ of each other; to be considered a true RTU comparison, both models needed to maintain nearly the same bulk space temperature during occupied hours.

The calculated energy consumptions of the two Rebel RTUs were averaged together. Similarly, the two baseline RTU's energy consumptions were averaged together. Table 14 then compares 
these averages to show the energy savings of one 10-ton Rebel RTU versus one 10-ton baseline RTU serving a small office space. The Rebel provides 34\% energy savings compared to the baseline RTU at a fixed 5\% OA damper position. Despite a much larger total static pressure drop, the Rebel supply fan still provided a 51\% energy savings compared to the baseline supply fan.

The annualized EER was calculated based on the annual cooling provided by each RTU (in British thermal units) divided by the annual energy usage (in Watt-hour). As mentioned previously, the EER numbers below should not be compared to the unit's rated IEER because they are modeled results averaged across a year's operation (not lab test results at proper AHRIrating conditions). The Rebel 15.6 annualized EER is slightly below the daily EER range measured during the demonstration period as shown in Table 8. The daily range shown in Table 8 represents cooler days in the winter while the slightly hotter summer months drive down the annualized EER. The baseline 10.1 annualized EER was lower than the EER range measured during the demonstration period because the annualized EER is influenced by summer operation and the fact the baseline RTU operated significantly more in first-stage operation where its realtime EER is lower because two condenser fans were operating.

Appendix $\mathrm{H}$ summarizes the uncertainty analysis of the predicted annual energy savings. Based on the measured power, sampling, and model uncertainties, NREL calculates the 3,682 kWh annual energy savings presented in Table 14 has a $\pm 27 \%$ uncertainty at a $95 \%$ confidence interval. This energy savings was then used in Section 5 to conduct the ROI analysis.

Table 14. Modeled Annual Energy Consumption and Savings Between One 10-Ton Rebel RTU Versus One 10-Ton Baseline RTU Serving the Building 550 Small Office Space

\begin{tabular}{llll}
\hline & $\begin{array}{l}\text { 1 Baseline RTU } \\
\text { 5\% OA Damper }\end{array}$ & 1 Rebel RTU & Savings \\
\hline Supply Fan & $2,607 \mathrm{kWh}$ & $1,268 \mathrm{kWh}$ & $1,339 \mathrm{kWh}(51 \%)$ \\
Compressors + Condenser Fans & $8,855 \mathrm{kWh}$ & $6,332 \mathrm{kWh}$ & $2,523 \mathrm{kWh}(28 \%)$ \\
Total RTU & $11,462 \mathrm{kWh}$ & $7,600 \mathrm{kWh}$ & $3,862 \mathrm{kWh}^{\mathrm{a}}(34 \%)$ \\
Total Cooling & $9,616 \mathrm{ton}-\mathrm{h}$ & $9,879 \mathrm{ton}-\mathrm{h}$ & \\
$\begin{array}{l}\text { Annualized EER } \\
\text { IEER) }\end{array}$ & $10.1 \mathrm{EER}$ & $15.6 \mathrm{EER}$ & \\
\hline
\end{tabular}

${ }^{a}$ Propagation of uncertainty yields $\pm 27 \%$ of the annual energy savings, based on a $95 \%$ confidence interval (see Appendix $\mathrm{H}$ )

${ }^{\mathrm{b}}$ Not to be compared against rated EER or IEER conditions as these model results are annualized and not at proper AHRI rating conditions.

Figure 16 shows a histogram of the annual capacity operation for the Rebel and baseline RTUs. The baseline RTU spent more than $90 \%$ of its DX operational hours in first stage. Because the Rebel was able to vary its capacity, it spent most of its time lower than 4 tons. The reason both the baseline and Rebel RTUs operate at a lower capacity is most likely because they are oversized. Based on site visits of different RTU installations at JBPHH, the typical range is 250$400 \mathrm{ft}^{2}$ /ton. Building 550 at 20 tons serving 5,000 ft is on the small side of $250 \mathrm{ft}^{2} /$ ton. These RTUs serving spaces in the $300-400 \mathrm{ft}^{2} /$ ton range would operate more hours at a larger capacity. 
Figure 17 compares the daily energy usage versus the daily average ambient dry-bulb for both RTUs.

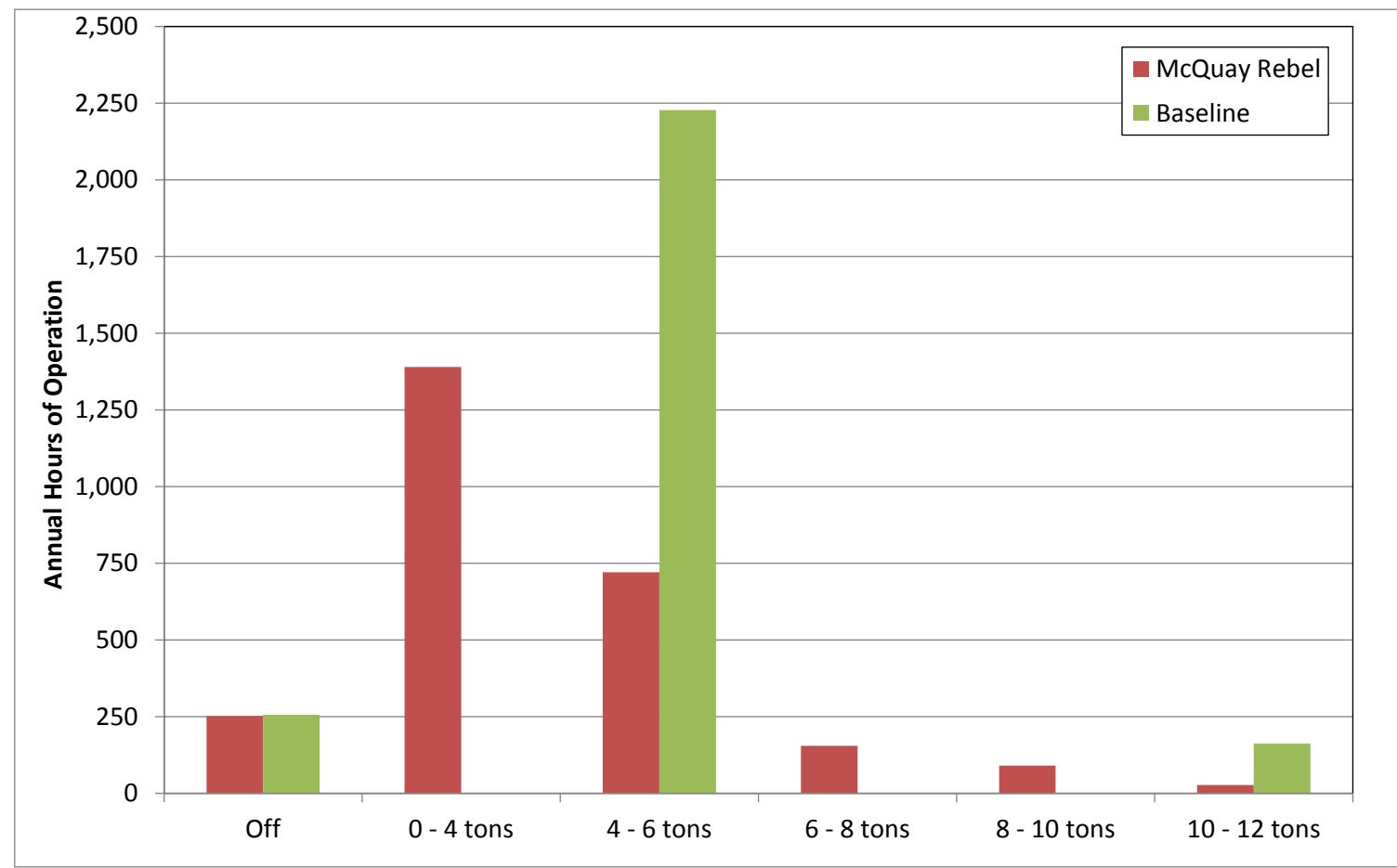

Figure 16. Baseline and Rebel annual operating hours at different capacity bins

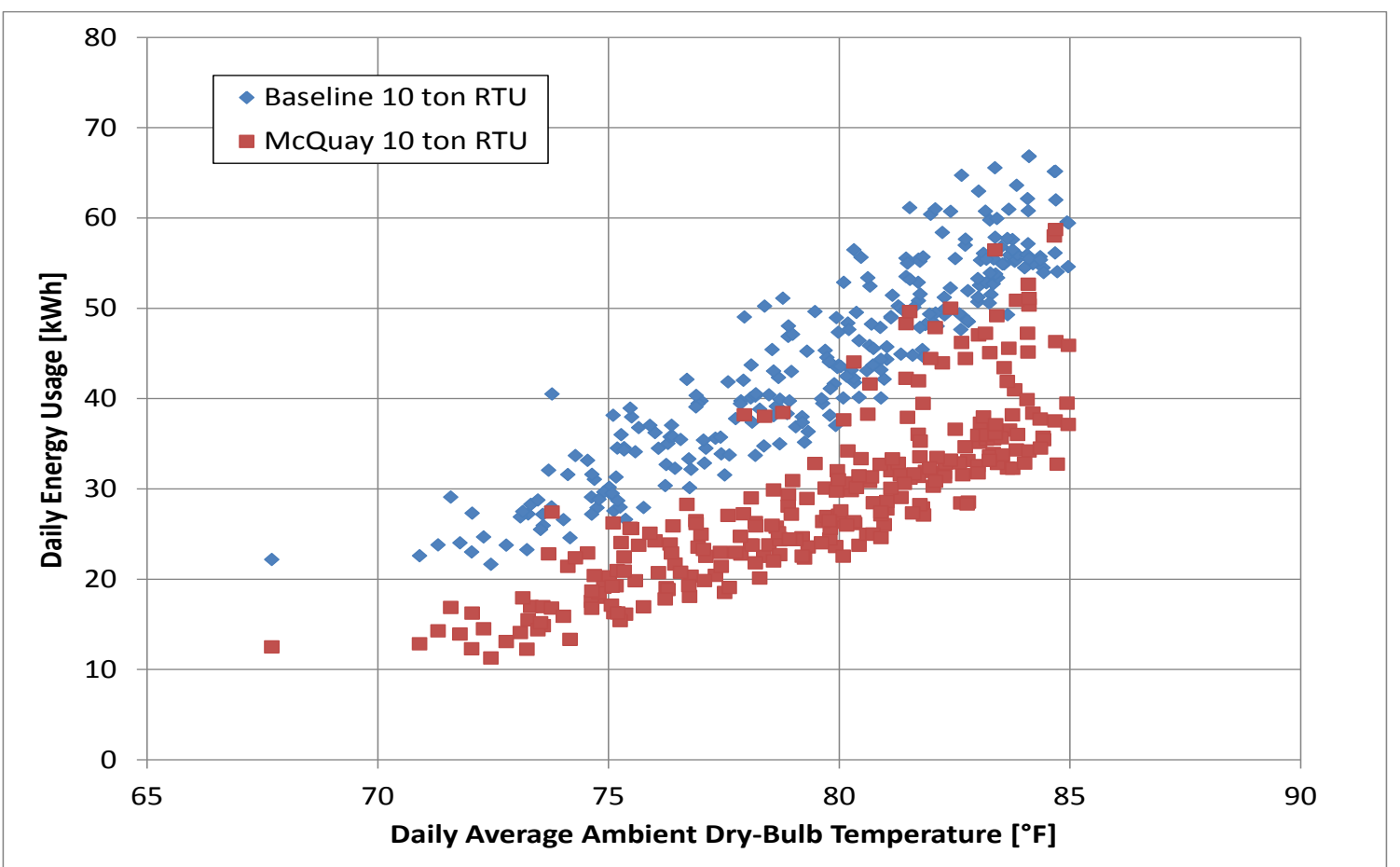

Figure 17. Baseline and Rebel daily energy usage versus daily average dry-bulb temperature 
Based on JBPHH site visits, NREL found that typical RTU OA dampers were fixed at some arbitrary 5\%-20\% opening. These OA dampers were also of typical construction-not low leakage. To provide a better cross-section of savings beyond the $5 \%$ damper position shown in Table 14, NREL compared the Rebel energy usage versus two additional OA damper configurations. One configuration represented a low leakage damper installed on a baseline unit, which provides just the correct amount of ventilation to meet ASHRAE 62.1-2010. This configuration isolates the energy savings of the Rebel from its variable-speed supply fan and variable refrigerant flow technologies - eliminating the energy savings of the Rebel's lowleakage OA damper. Based on correspondence with the local HVAC distributors on Oahu, codeminimum RTUs can be specified with low-leakage dampers. The second configuration represented OA dampers set to a larger 20\% opening. Table 15 shows the energy savings ranges from 29\%-37\%, depending on the OA damper configuration of the baseline RTU. Considering that the typical OA damper at JBPHH is not low leakage and the fixed positions fluctuate from $5 \%-20 \%$, the annual energy savings should be within the $34 \%-37 \%$ range.

In 2018, the Rebel model was rerun with a lower fan pressure drop. When the demonstration was completed in 2014, Daikin Applied only provided a downward discharge configuration. To integrate with the existing ductwork, the installation at the small office used a roof curb to transition the airflow from downward to horizontal, resulting in an additional inch of static pressure. The Rebel now has a horizontal discharge option. In Table 15 below, the number in brackets shows the Rebel energy savings with the lower fan pressure drop. Across the three baseline damper configurations, the energy savings ranged from 33-42\%.

Table 15. Modeled Rebel Savings Over the Baseline RTU Maintaining Different Ventilation Flow Rates

\begin{tabular}{|c|c|c|c|c|}
\hline & 1 Baseline RTU & 1 Rebel RTU & Savings & \\
\hline $\begin{array}{l}\text { Baseline with low-leakage OA } \\
\text { damper meeting ASHRAE } 62.1 \\
\text { minimum ventilation rate }\end{array}$ & $10,634 \mathrm{kWh}$ & $\begin{array}{l}7,600 \mathrm{kWh} \\
{\left[7,099 \mathrm{kWh}^{\mathrm{b}}\right]}\end{array}$ & $\begin{array}{l}3,034 \mathrm{kWh}^{\mathrm{a}} \\
{\left[3,535 \mathrm{kWh}^{\mathrm{b}}\right]}\end{array}$ & $\begin{array}{l}(29 \%) \\
(33 \%)\end{array}$ \\
\hline $\begin{array}{l}\text { Baseline with standard OA damper } \\
\text { fixed at } 5 \% \text { open }\end{array}$ & $11,462 \mathrm{kWh}$ & $\begin{array}{l}7,600 \mathrm{kWh} \\
{[7,099 \mathrm{kWh}]}\end{array}$ & $\begin{array}{l}3,862 \mathrm{kWh}^{\mathrm{a}} \\
{\left[4,363 \mathrm{kWh}^{\mathrm{b}}\right]}\end{array}$ & $\begin{array}{l}(34 \%) \\
(38 \%)\end{array}$ \\
\hline $\begin{array}{l}\text { Baseline with standard OA damper } \\
\text { fixed at } 20 \% \text { open }\end{array}$ & $12,151 \mathrm{kWh}$ & $\begin{array}{l}7,600 \mathrm{kWh} \\
{[7,099 \mathrm{kWh}]}\end{array}$ & $\begin{array}{l}4,552 \mathrm{kWh}^{\mathrm{a}} \\
{\left[5,052 \mathrm{kWh}^{\mathrm{b}}\right]}\end{array}$ & $\begin{array}{l}(37 \%) \\
(42 \%)\end{array}$ \\
\hline
\end{tabular}

${ }^{a}$ Propagation of uncertainty yields $\pm 27 \%$ of the annual energy savings based on a $95 \%$ confidence interval (see Appendix H).

During the site inspections of 30 RTUs throughout JBPHH, NREL found that most office buildings were not abiding by the NAVFAC Pacific operating hours limits for HVAC equipment. Table 13 above shows these allowed hours. Outside these hours, the RTUs were supposed to be completely off, not even maintaining a set-back temperature set point. While NREL found a large range in the times the thermostats were set to enable cooling, the general trend was from 0600 to 1800 , or 12 hours a day. Since most of these thermostats had 7-day programmable capability, these operating hours were just during the weekdays - the thermostats were correctly set to prevent weekend operation. 
To account for the longer hours of operation, NREL ran the Rebel and baseline energy models from 0600 to 1800 on weekdays. NREL chose the baseline with a standard OA damper fixed at $5 \%$ open. The annual energy savings was 7,426 kWh, nearly double that shown in Table 15. NREL found that the percentage energy savings increased to $48 \%$ because of the larger number of hours in the early morning and late afternoon that the Rebel was able to operate in its improved part load operation of the supply fan and DX circuit. Essentially, the longer the operating hours of the facility, the larger the percentage energy savings for high-efficiency RTUs that enable improved part-load performance.

\subsection{Interior Thermal Comfort}

The modeling results also show the Rebel will provide slightly more cooling over a year compared to a baseline RTU because it will provide more latent cooling. The Rebel maintains a lower space dew point because it can maintain a constant DAT. At a $60^{\circ} \mathrm{F}$ DAT set point, the Rebel is providing supply air at a $57^{\circ} \mathrm{F}$ dew point or lower. The baseline RTU supply air dew point changes based on the cooling stage and the cycle rate. Under consistent first-stage cooling (over 10 consecutive minutes), the baseline RTU is typically maintaining a $65^{\circ}-68^{\circ} \mathrm{F}$ supply air temperature, which results in a supply dew point of $60^{\circ}-63^{\circ} \mathrm{F}$. Only under consistent secondstage cooling can the baseline supply air at $55^{\circ}-60^{\circ} \mathrm{F}$ yielding a supply dew point of $53^{\circ}-58^{\circ} \mathrm{F}$.

Yet, when the second stage frequently cycles, as was seen during the demonstration period and in the model, the second stage provides negligible latent cooling. While the second-stage compressor is on for 5 minutes, moisture is condensing on the coil and fin surfaces. When the compressor turns off, that moisture re-evaporates into the supply air. Because the baseline RTU typically operates in first-stage cooling and cycles the second stage on for brief periods only, the supply air dew point will be consistently $60^{\circ}-63^{\circ} \mathrm{F}$. As a result, the Rebel's supply of lower dew point air will maintain a drier space, but the additional latent cooling will require more work from the DX system. Therefore, the Rebel provides both energy savings and improved thermal comfort by maintaining a drier space. Section 4.3 further summarizes the difference in thermal comfort between the Rebel and the baseline RTUs.

For the same reasons energy modeling was used to predict annual energy savings, the models were also used to predict interior space conditions throughout the year. The Rebel and baseline RTUs were modeled according to what NREL defined as the typical JBPHH interpretation of the NAVFAC Hawaii Region Energy Instruction. This mandate states that thermostats should not be set lower than $78^{\circ} \mathrm{F}$. Based on discussions with NAVFAC building energy managers, most JBPHH small office buildings were being set to a $76^{\circ} \mathrm{F}$ set point. The NAVFAC building energy managers justified this lower set point by stating a thermostat set point at $76^{\circ} \mathrm{F}$ would ensure the hottest location within the conditioned space would not exceed $78^{\circ} \mathrm{F}$. NREL also took into consideration the Common Output Level Standards established by the Commander Navy Installations Command. Although Common Output Level Standards 3 and 4 push the minimum thermostat requirement warmer than $78^{\circ} \mathrm{F}$, these levels are not typical. Therefore, NREL established $76^{\circ} \mathrm{F}$ as the average space temperature to maintain for both RTU models (Table 13).

Regarding set point schedules, NAVFAC Hawaii Region Energy Instruction stipulates air conditioning is allowed only from 1000-1500 for winter hours (November 1-April 30) and 0800-1600 for summer hours (May 1-October 31). During the demonstration period, NREL defined a thermostat schedule based on what was determined to be typical from discussions with 
NAVFAC building energy managers. This schedule was 1000-1530 for winter hours and 08001530 for summer hours. NREL was concerned about the RH within the space when these schedules were implemented while the office space was still occupied by NAVFAC personnel (June to July 2013). The RH was exceeding 65\%, which NREL established with NAVFAC as the maximum allowable. NREL found that by starting the RTUs 2 hours prior to the NAVFAC Hawaii Region Energy Instruction schedule, the space was sufficiently dehumidified and maintained space RH lower than 65\% for the remainder of the day. Therefore, the RTU operation was modeled to occur from 0800-1530 for winter hours (November 1-April 30) and 0600-1530 for summer hours (May 1-October 31), as shown in Table 13Table 13.

Figure 18 plots a histogram of the hourly average space temperature maintained during occupied hours for both models. Despite a few fringe hours during the morning cooldown (temperature bins higher than $77^{\circ} \mathrm{F}$ ), the temperature bins emphasize each respective RTU's deadband control. The baseline RTU shows a tighter temperature range of $75^{\circ}-76 \mathrm{~F}$ as the two DX stages are cycled to maintain the space at $0.5^{\circ}-1.5^{\circ} \mathrm{F}$ higher than the $74.5^{\circ} \mathrm{F}$ set point. The Rebel $2^{\circ} \mathrm{F}$ deadband is shown with most of the hourly averages at $75^{\circ}-77^{\circ} \mathrm{F}$. This histogram of binned hourly averages appears to show that the baseline RTU maintains improved thermal comfort. However, dialing down to 1-minute monitored, not model, data show the Rebel maintaining a more stable space temperature.

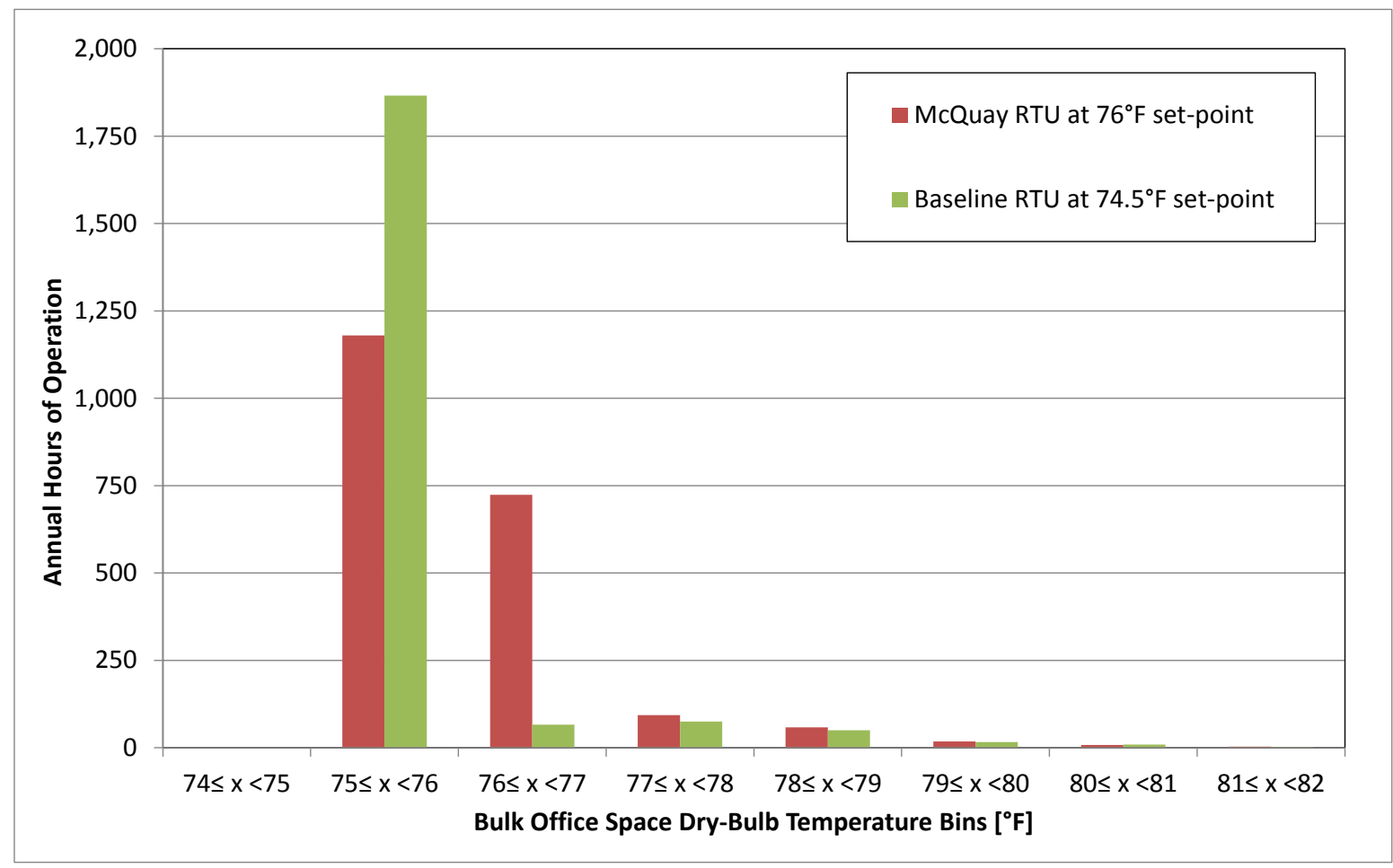

Figure 18. Office space dry-bulb temperature histogram comparing the Rebel model versus the baseline model with a fixed $5 \%$ OA damper position

Figure 19 plots the measured space temperature under Rebel-only operation on December 10, $2013\left(76^{\circ} \mathrm{F}\right.$ set point), compared to baseline-only operation on December 4, $2013\left(68^{\circ} \mathrm{F}\right.$ set point). Just focusing on the shape of the temperature profiles (ignoring the set point differences), the Rebel leverages its variable capacity to maintain a smooth temperature profile compared to 
the baseline, which experiences more dramatic temperature swings because the compressor cycles - at a warmer set point of $74.5^{\circ} \mathrm{F}$, the baseline unit experienced a lower cycling frequency but the general trend was the same. Consequently, the smoother temperature control of the Rebel enables it to provide improved thermal comfort despite a larger deadband of $2^{\circ} \mathrm{F}$ (compared to $1^{\circ} \mathrm{F}$ deadband for the baseline). Note the Rebel enables users to reduce the deadband control from $2^{\circ} \mathrm{F}$ to $1^{\circ} \mathrm{F}$. NREL recommends the control is kept to a $2^{\circ} \mathrm{F}$ deadband because it achieves greater energy savings while still providing improved comfort compared to a baseline RTU.

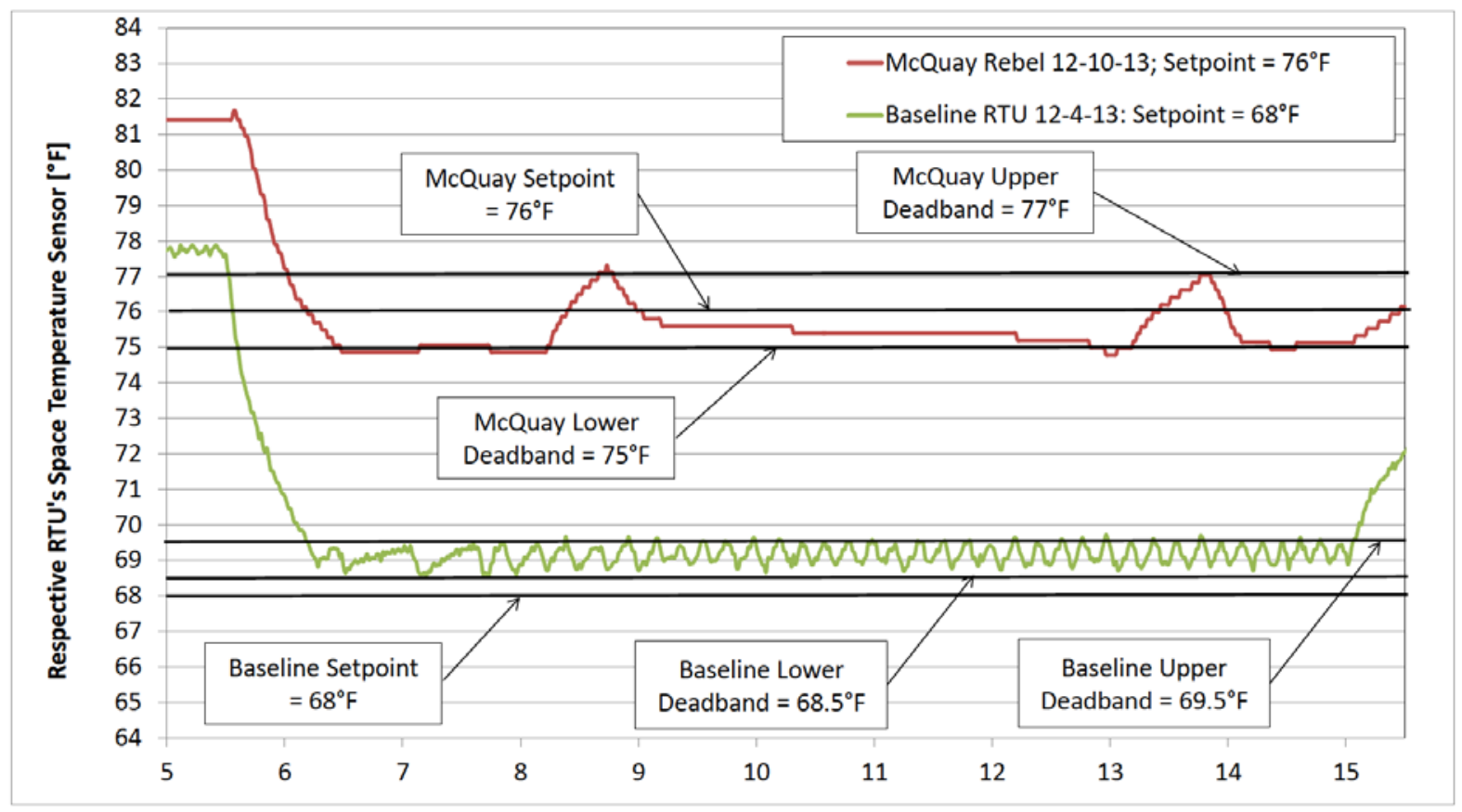

Figure 19. Measured (not modeled) space temperature fluctuation across the day between the Rebel RTU at a $76^{\circ} \mathrm{F}$ set point and baseline RTU at a $68^{\circ} \mathrm{F}$ set point

Figure 20 plots the modeling results of the Rebel versus baseline hourly average space $\mathrm{RH}$ (operational hours only). This histogram clearly shows the Rebel maintaining a drier space. The annual average space RH during occupied hours was $53 \%$ for the Rebel compared to $61 \%$ for the baseline. Therefore, the models indicate that by maintaining a constant $60^{\circ} \mathrm{F} \mathrm{DAT}$, the Rebel was able to maintain a more comfortable space with a lower annual average $\mathrm{RH}$ of at least $5 \%$ compared to a baseline RTU (see Figure 20). 


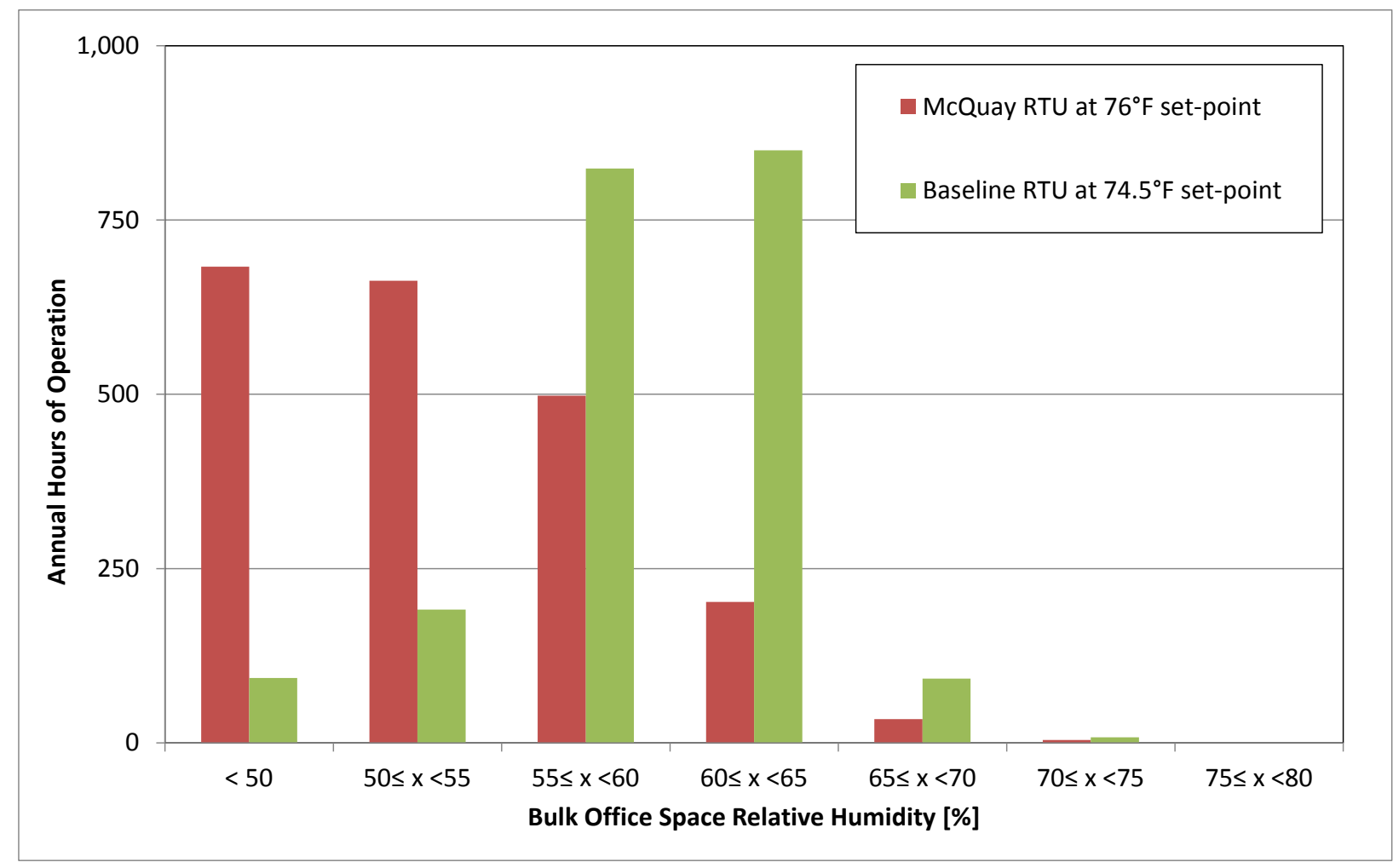

Figure 20. Office space RH histogram comparing the Rebel model versus the baseline model with a $5 \%$ OA damper position

For future applications of the Rebel, if a lower moisture condition is desired, the control can be changed to maintain a lower DAT and maintain the same space temperature set point. For example, setting the DAT to $55^{\circ} \mathrm{F}$ will maintain the supply air dew point lower than $53^{\circ} \mathrm{F}$, and the space set point can be left at $76^{\circ} \mathrm{F}$. This flexibility enables users to control the Rebel to provide more latent cooling and maintain a drier space-lower $\mathrm{RH}$ - if so desired. Note the lower the DAT set point, the lower the overall efficiency of the Rebel, resulting in increased energy usage. To balance space moisture conditions with energy usage, users want to determine the maximum DAT set point that maintains the space under some specified moisture threshold which was $65 \% \mathrm{RH}$ for this demonstration.

\subsection{Ventilation Rates}

UFGS 230593 “Testing, Adjusting, and Balancing for HVAC” mandates that ventilation rates must meet ASHRAE standard 62.1-2010 requirements. According to UFC 3-410-01 Section 401.1 (dated July 1, 2013), "Use of CO2 sensors for ventilation control is prohibited unless approved by AHJ.” To provide the most flexibility for applying these demonstration results for future installations (where the AHJ may not grant approval for DCV), NREL operated the Rebel model without DCV capability. Therefore, the annual energy savings provided in Section 4.2 is based on the Rebel meeting ASRHAE 62.1-2010 minimum ventilation requirements.

The building 550 minimum ventilation rates are presented in Table 16. The DCV-based minimum ventilation is provided for reference only, as the Rebel was evaluated without DCV enabled. Compared to other building types, the ASHRAE 62.1 Ventilation Rate Procedure has 
lower requirements for offices. Table 16 shows the difference between the non-DCV and DCV requirements is approximately $30 \%$.

Table 16. Office Minimum Ventilation Rates per ASHRAE Standard 62.1-2010

\begin{tabular}{|c|c|c|c|c|c|c|c|c|}
\hline Building & $\begin{array}{l}\text { Area } \\
\text { Served }\end{array}$ & $\begin{array}{l}\text { Occupancy } \\
\text { Ventilation } \\
\text { Rate }\end{array}$ & $\begin{array}{l}\text { Default } \\
\text { Occupant } \\
\text { Density }\end{array}$ & $\begin{array}{l}\text { Area } \\
\text { Ventilation } \\
\text { Rate }\end{array}$ & $\begin{array}{l}\text { Combined } \\
\text { Ventilation } \\
\text { Rate Inc. } \\
\text { Occ. and } \\
\text { Area }\end{array}$ & $\begin{array}{l}\text { Min. } \\
\text { Required } \\
\text { (no DCV) }\end{array}$ & $\begin{array}{l}\text { Min. } \\
\text { Required } \\
\text { (with DCV) }\end{array}$ & $\begin{array}{l}\text { Delta } \\
\text { Between } \\
\text { Min. } \\
\text { Required }\end{array}$ \\
\hline Baseline & $2,400 \mathrm{ft}^{2}$ & $5.0 \mathrm{cfm} / \mathrm{occ}$ & $\begin{array}{l}5 \mathrm{occl} \\
1,000 \mathrm{ft}^{2}\end{array}$ & $0.06 \mathrm{cfm} / \mathrm{ft}^{2}$ & $0.09 \mathrm{cfm} / \mathrm{ft}^{2}$ & 204 cfm & $144 \mathrm{cfm}$ & $\begin{array}{l}60 \mathrm{cfm} \\
(29 \%)\end{array}$ \\
\hline Rebel & $2,576 \mathrm{ft}^{2}$ & $5.0 \mathrm{cfm} / \mathrm{occ}$ & $\begin{array}{l}5 \mathrm{occl} \\
1,000 \mathrm{ft}^{2}\end{array}$ & $0.06 \mathrm{cfm} / \mathrm{ft}^{2}$ & $0.09 \mathrm{cfm} / \mathrm{ft}^{2}$ & $219 \mathrm{cfm}$ & $155 \mathrm{cfm}$ & $\begin{array}{l}64 \mathrm{cfm} \\
(29 \%)\end{array}$ \\
\hline
\end{tabular}

The ventilation rates of both RTUs were measured during the TAB, and these measurements were input into the energy models. Table 17 shows the baseline RTU far exceeded the ASHRAE 62.1 minimum ventilation rates. NREL was surprised by the significant leakage through the OA damper, even at $0 \%$ and $5 \%$ positions. To validate these measurements, NREL then directly measured the ventilation flow rate into the damper using a pitot tube grid. At a 5\% damper position, NREL measured $487 \mathrm{cfm}$. At a $0 \%$ damper position, NREL again measured $487 \mathrm{cfm}$. Repeatability in the measurements leads NREL to believe the baseline OA damper was leaking around $500 \mathrm{cfm}$, even at a 0\% OA damper position (approximately $185 \mathrm{fpm}$ face velocity across the OA damper). Consequently, NREL was confident in the TAB results, and therefore, used the Table 17 OA flow rates in baseline models.

Table 17. Baseline RTU Ventilation Flow Rates

\begin{tabular}{lll}
\hline $\begin{array}{l}\text { OA Damper } \\
\text { Position }\end{array}$ & $\begin{array}{l}\text { Ventilation } \\
\text { Flow Rate }^{\mathrm{a}}\end{array}$ & $\begin{array}{l}\text { Meets } \\
\text { ASHRAE 62.1 }\end{array}$ \\
\hline $0 \%$ & $574 \mathrm{cfm}$ & Yes \\
$5 \%$ & $672 \mathrm{cfm}$ & Yes \\
$20 \%$ & $1,413 \mathrm{cfm}$ & Yes \\
\hline \multicolumn{2}{c}{${ }^{\text {a Based on TAB measurements. }}$}
\end{tabular}

Table 18 shows the ventilation flow rates calculated at different OA damper and supply fan speed configurations. For the demonstration period and the model, the Rebel was operated from $5 \%$ position at $100 \%$ fan speed to $15 \%$ position at $40 \%$ fan speed. 
Table 18. Rebel Ventilation Flow Rates

\begin{tabular}{llll}
\hline $\begin{array}{l}\text { OA Damper } \\
\text { Position }\end{array}$ & $\begin{array}{l}\text { Fan } \\
\text { Speed }\end{array}$ & $\begin{array}{l}\text { Ventilation } \\
\text { Flow Rate }^{\mathrm{a}}\end{array}$ & $\begin{array}{l}\text { Meets ASHRAE } \\
\mathbf{6 2 . 1} \text { Minimum }\end{array}$ \\
\hline $0 \%$ & $88 \%$ & $3 \mathrm{cfm}$ & No \\
$5 \%$ & $100 \%$ & $318 \mathrm{cfm}$ & Yes \\
$7 \%$ & $88 \%$ & $350 \mathrm{cfm}$ & Yes \\
$11 \%$ & $63 \%$ & $288 \mathrm{cfm}$ & Yes \\
$15 \%$ & $40 \%$ & $233 \mathrm{cfm}$ & Yes \\
\hline \multicolumn{2}{r}{ a Based on TAB measurements }
\end{tabular}

The Rebel met the ventilation-based demonstration objectives. At all OA damper and supply fan speed configurations (except for the $0 \%$ damper position), the Rebel provided ventilation that exceeded the ASHRAE 62.1 minimum requirement. Additionally, the Rebel maintained an OA flow rate range of $233-318 \mathrm{cfm}$, which is an approximately $60 \%$ reduction from the OA flow rate for the baseline RTU, even at a 0\% damper position. Section 4.2 summarizes the annual energy savings impacts of the Rebel maintaining a lower ventilation flow rate while still maintaining the minimum ASHRAE 62.1 requirements (Table 15). 


\section{Economic Performance Analysis and Assessment}

Economic results of the demonstration indicate application of high-efficiency RTUs can yield a positive economic return in Hawaii. In demonstration of the Rebel, the aggregate annual energy savings is estimated at 3.8 MWh/yr for a 10-ton RTU serving a small office building. In comparison to a baseline RTU, minimally compliant with ASHRAE Standard 90.1-2010, NREL estimates a total discounted operational savings of $\$ 18,000$ over a 15 -year operational life, with a simple payback occurring within the ninth year of operation. The economic analysis conducted (results shown in Table 19) was based on a cost different between the Rebel versus the baseline which included the Rebel's larger incremental costs for the cabinet coating, condenser coil coating, extended 5 year parts and compressor warranties, and roof curb. NREL thought it important to add that just comparing the RTUs themselves, excluding these incremental costs, the same energy savings yields a simple payback in the fifth year of operation.

Regional factors, including Hawaii's relatively high electricity pricing and year-round demand for cooling, were key contributors to the cited economic return. Results indicate the Navy would achieve a positive ROI in deployment of this technology in Hawaii assuming a minimum of 15 year economic life. These energy savings and ROI are not directly transferable to other geographic regions (see note b for Table 19). Section 8 states that additional field demonstrations are recommended to quantify savings in other climates that most likely have much lower utility rates.

Table 19 provides a full summary of economic results, in addition to key analysis inputs. Estimates for total discounted operational savings, savings to investment ratio, and simple payback were calculated using the latest version of the National Institute of Standards and Technology-developed Building Life-Cycle Cost (BLCC) Program. eROI values were provided using the latest available version of the Neptune eROI calculator, as provided by NAVFAC. ${ }^{17}$

\footnotetext{
${ }^{17}$ eROI is a Navy-specific metric for evaluating benefits of investment in energy technologies. The benefit figure reflects the present value of the project's anticipated contributions to energy, as well as its contribution, in dollarequivalent terms, to other Navy objectives, such as improving energy reliability for critical infrastructure, reducing greenhouse gas emissions, meeting regulatory mandates, and so on. An eROI greater than 1 indicates the project's benefits are anticipated to exceed its costs. The higher the eROI value, the more attractive the project.
} 
Table 19. Overall Economic Analysis of Rebel RTU Demonstration

\begin{tabular}{llll}
\hline Economic Analysis Results & \multicolumn{3}{c}{ Key Analysis Inputs } \\
\hline eROI Value & 12.4 & Annual energy savings & $3.8 \mathrm{MWh} / \mathrm{yr}$ \\
$\begin{array}{l}\text { Total Discounted } \\
\text { Operational Savings }\end{array}$ & $\$ 18,000$ & Electricity price $^{\mathrm{a}}$ & $\$ 0.425 / \mathrm{kWh}$ \\
$\begin{array}{l}\text { Savings to Investment Ratio } \\
\text { Simple Payback }\end{array}$ & 1.4 & Investment cost delta $^{\mathrm{b}}$ & $\$ 14,519$ \\
$\begin{array}{l}\text { Adjusted Internal Rate of } \\
\text { Return }\end{array}$ & $5 \%$ & Units installed & 1 \\
\hline
\end{tabular}

${ }^{a}$ Electricity pricing reflects the average price of FY 2013 and FY 2014 rates at JBPHH.

${ }^{\mathrm{b}}$ Investment delta reflects the calculated difference in the purchase price between a code-minimum, baseline RTU versus the high-efficiency RTU including the Rebel's larger incremental cost adds for the cabinet coating, condenser coil coating, extended 5 year parts and compressor warranties, and roof curb. Excluding these incremental costs, the investment cost delta is $\$ 9,679$.

Based on the uncertainty analysis (Appendix $\mathrm{H}$ ), the annual energy savings of $3.8 \mathrm{MWh} / \mathrm{yr}$ is $\pm 27 \%$ based on a $95 \%$ confidence interval. Consequently, the economic analysis metrics provided in Table 19 also realize the same uncertainty band.

Beyond the uncertainty bands in the predicted annual energy savings, economic results were reviewed to evaluate performance sensitivities and potential sources of error in the estimates provided. Three key factors are identified and described below:

- Utility electricity rate volatility. Significant volatility in JBPHH utility rates from FY 2013 to FY 2014 indicate analysis results may be susceptible to uncertainty in projecting future year utility rate pricing. More specifically, electricity rates jumped from $\$ 0.24 / \mathrm{kWh}$ in FY 2013 to \$0.58/kWh in FY 2014. The expectation, based on discussion with NAVFAC Hawaii personnel, is for utility rates to decline in FY 2015, but an exact value remains uncertain. This volatility in pricing must be considered in evaluating economic results of this demonstration, as applied to JBPHH.

A preliminary sensitivity analysis was performed to evaluate the effect of electricity pricing uncertainty on economic yield. Figure 21 shows savings to investment ratio estimates for a 15-year economic life across an electricity pricing range of \$0.325$\$ 0.525 / \mathrm{kWh}$. This range encompasses a $\pm \$ 0.10 / \mathrm{kWh}$ sensitivity band around the nominal rate applied to the economic analysis. As indicated by the figure, electricity pricing has a significant impact on estimated economic return. 


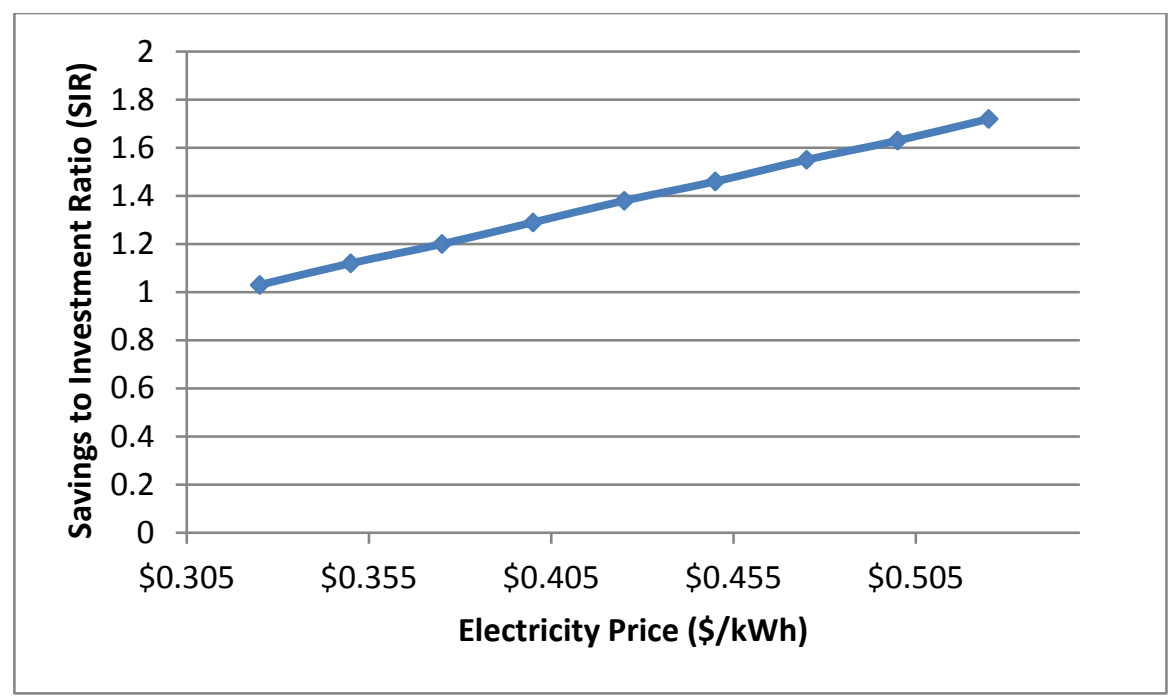

Figure 21. Sensitivity analysis on electricity pricing

- Results are region-specific. Electricity pricing, weather patterns, and climate are key input parameters in estimating energy and cost savings. Hawaiian values for these parameters, although reasonably attributable to other areas of the Pacific, deviate considerably relative to other applicable regions, such as the continental United States. Energy and cost saving estimates as presented, although promising, are not directly translatable to other geographic regions.

- Results based on a single sample. The annual energy savings was calculated by comparing a single high-efficiency RTU to a single, code-minimum, baseline RTU serving one type of building, a small office. Applying the annual energy savings from this field demonstration to a larger population for potential future high-efficiency RTU installations is susceptible to significant sampling uncertainty. In Section 8, NREL recommends additional monitoring of other high-efficiency RTU installations to achieve a larger sample size with which to provide greater confidence in the annual energy saving expectations. 


\section{Project Management Considerations}

Execution of this technology demonstration was programmatically straightforward. Challenges experienced were unique to the constraints of the demonstration. Section 6.2 summarizes how the acquisition using a minor construction contract mechanism resulted in lack of response from several design-build firms b burdensome administrative requirements associated with the demonstration. Further deployment of this technology should not present significant challenges beyond those typical to the installation of RTUs. There are negligible cost differences in the design (Section 6.3) and installation (Section 6.4) activities between high-efficiency and baseline RTUs. Table 20 provides a summary of programmatic elements of this project and a high-level timeline of events.

Table 20. Summary of Programmatic Elements

\begin{tabular}{lll}
\hline Programmatic Summary & & \\
\hline Implementation Method & Design-build contractor, minor construction \\
Key Contractors & TWT & \\
& Critchfield Pacific Inc. & \\
\hline Period of Performance & 20 months & \\
& March 2012-September 2012 & Site selection and approval \\
\hline \multirow{3}{*}{ Project Timeline } & October 2012-February 2013 & Design build solicitation and award \\
& March 2013-June 2013 & Design \\
& June 2013-July 2013 & Site construction \\
\hline & August 2013-October 2013 & Commissioning and TAB \\
\hline
\end{tabular}

\subsection{Site Approval, National Environmental Policy Act, and DD1391}

Site selection was based on identification of facilities needing RTU replacement and evaluation of these facilities in providing an effective environment for comparison of the high-efficiency RTU to a baseline RTU. Site approval, the National Environmental Policy Act, and DD1391 activities were required for this demonstration. All of these activities presented minimal administrative burden and were performed over a period of a few months. For the National Environmental Policy Act evaluation, a categorical exclusion was determined.

\subsection{Contracts and Procurement}

The implementation strategy for this project used a competitively selected design-build contract. As a technology demonstration of a set of two RTUs, acquisition using a minor construction, the design-build contract presented a solicitation challenge. Applicable Division 01, General Requirements, utilized by this project are presented in Table 21. 
Table 21. Applicable Division 01, General Requirements

\begin{tabular}{ll}
\hline \multicolumn{2}{l}{ Unified Facilities Guide Specifications } \\
\hline \multicolumn{1}{l}{ Division 01-General Requirements } \\
\hline 011100 & Summary of Work \\
011400 & Work Restrictions \\
013000 & Administrative Requirements \\
013300 & Submittal Procedures \\
013526 & Governmental Safety Requirements \\
014500.1020 & Quality Control for Minor Construction \\
015719.0020 & Temporary Environmental Controls \\
017419 & Construction and Demolition Waste Management \\
017800 & Closeout Submittals \\
\hline
\end{tabular}

For future acquisitions, we recommend the following:

1. Facility owners should consider defining equipment conditions that determine an RTU's useful lifetime, accounting for economic considerations and applicable climate zones.

2. Facility owners should perform an evaluation of their RTUs, using defined conditions of a useful lifetime, which will enable them to determine whether a funded action constitutes an activity of "repair" or "construction." This is especially important for government agencies to ensure the correct funding mechanism is applied.

3. Projects should be considered for individual facilities (that result in a complete and usable facility) within funding source restrictions. Economy-of-scale benefits are, however, realizable in a large number of multifacility deployments of this technology.

4. Extended warranties should be considered, but economic payback should be considered in evaluation of the net benefits.

\subsection{Design}

Design requirements of the Rebel RTU were limited and consistent with installations of commercially available RTUs. A roof curb was required for transitioning the Rebel RTU from a vertical discharge to a horizontal discharge unit. This is not a typical requirement in RTU installations. UFGS facility construction and technical design specifications were developed, and are presented in Table 22. 
Table 22. UFGS Facility Construction/Technical Design Specifications Used in the Construction Activity

\begin{tabular}{ll}
\hline \multicolumn{2}{l}{ Unified Facilities Guide Specifications } \\
\hline \multicolumn{2}{l}{ Division 23-Heating, Ventilating, and Air Conditioning } \\
\hline 230000 & Air Supply, Distribution, Ventilation, and Exhaust Systems \\
230593 & Testing, Adjusting, and Balancing for HVAC \\
230800.0010 & Commissioning of HVAC Systems \\
230953.0020 & Space Temperature Control Systems \\
238202.0010 & Unitary Heating and Cooling Equipment \\
\hline Division 26-Electrical & \\
\hline 260000.0020 & Basic Electrical Materials and Methods \\
\hline 262000 & Interior Distribution System \\
\hline
\end{tabular}

\subsection{Installation and Construction (includes permitting, interconnect agreements, factory acceptance testing, commissioning)}

RTU installation was straightforward and easily executed for the baseline and Rebel RTUs. Except for some additional commissioning work to set up the Rebel's more advanced controller, there was no difference in the construction activity or construction cost between the baseline and Rebel. The additional Rebel controls configuration is no more than 2 hours during the commissioning activity. The additional 2 hours of a commissioning agent were not factored into the economic analysis in Section 5, as this additional cost was minimal relative to the cost of the entire installation; an additional 2 hours of commissioning costs approximately \$300, based on \$150 per hour.

Both RTUs were installed over the course of a few weeks. Utilization of a crane for removing existing RTUs and installing the new RTUs presented the greatest degree of permitting and site coordination but remained consistent with this type of construction activity.

TAB of the RTUs did present some scheduling challenges. Initial TAB report results were not consistent with ASHRAE 62.1, and a second TAB activity was required. Unfortunately, coordination with the independent TAB provider to execute the second TAB activity took significantly longer than expected; commissioning activities were not completed until October 2013 (3 months postcompletion of RTU installation). These delays, although unfortunate, were related to facility conditions and contractual issues, and were not caused by the technical performance of the installed RTUs.

\subsection{Operation and Maintenance}

The maintenance activities for the Rebel RTU will be similar to those for a baseline RTU, such as filter changes and blowing drains. Yet, some of the routine maintenance inspections will require interfacing with the advanced controller on the Rebel. The controller settings are numerous and can be overwhelming to an untrained technician. Although Rebel provides significant control, installation, and O\&M literature on its website (www.go.Rebel.com/rebel), if NAVFAC begins to adopt high-efficiency RTUs, NREL recommends the NAVFAC HVAC 
technicians receive formal training to work on them. As a part of the DOE challenge specification, these high-efficiency RTUs incorporate more sophisticated AFDD. The advanced controller on the Rebel can be leveraged for enhanced troubleshooting and deep dive assessment of system components.

\subsection{Training}

At the completion of the construction activity, NREL, subcontractor TWT, and the local Rebel distributor, Norman S. Wright, held a 3-hour training for NAVFAC HVAC technicians. One hour was spent in the classroom reviewing the capabilities of the Rebel and reviewing the control and O\&M literature for the unit. Two hours were spent at the Rebel RTU, reviewing the system layout and interfacing with the controller. In Section 8, NREL recommends NAVFAC HVAC technicians receive formal Rebel training to enable them to provide the same level of maintenance they currently provide on baseline RTUs. NAVFAC HVAC shop’s standard routine maintenance procedure is summarized in Appendix I. 


\section{Commercial Readiness Qualitative Assessment}

High-efficiency RTUs that meet the DOE Challenge specification are at technology readiness level 9. In addition to the Rebel, Carrier has a high-efficiency RTU called the WeatherExpert. Table 23 provides a summary. Both Rebel and Carrier distributors in Hawaii have been trained on these two new units. These high-efficiency RTUs currently are higher priced and have a 6week longer lead time than their standard RTU equivalents.

Table 23. Commercially Available DOE RTU Challenge RTUs

\begin{tabular}{ll}
\hline $\begin{array}{l}\text { Daikin Applied Rebel (DPS) } \\
\text { (www.go.rebel.com/rebel) }\end{array}$ & $\begin{array}{l}\text { Carrier WeatherExpert (48LC I 50LC) } \\
\text { (www.carrierweatherexpert.com) }\end{array}$ \\
\hline 3-15 ton capacity & $3-23$ ton capacity \\
$\begin{array}{l}\text { 18.5-20.6 IEER range ( }>5 \text { ton) } \\
\text { 16.9-17.0 SEER range ( } \leq 5 \text { ton) }\end{array}$ & $\begin{array}{l}17.8-20.8 \text { IEER range ( }>5 \text { ton) } \\
17.1-17.5 \text { SEER range ( } \leq 5 \text { ton) }\end{array}$ \\
$\begin{array}{l}\text { Variable-speed lead compressor } \\
\text { Fixed-compressor added above } 5 \text { tons }\end{array}$ & $\begin{array}{l}\text { Fixed-speed compressors } \\
\text { 2 stages } \leq 5 \text { ton; } 3 \text { stages }>5 \text { ton }\end{array}$ \\
Variable ECM direct-drive supply fan & $\begin{array}{l}\text { Variable-speed belt-driven supply fan } \\
\text { ECM direct-drive option for } \leq 5 \text { ton }\end{array}$ \\
\hline Variable-speed direct-drive condenser fans & Direct-drive ECM condenser fans \\
\hline $\begin{array}{l}\text { Low-leakage OA damper with dry-bulb or } \\
\text { enthalpy economizing and DCV capability }\end{array}$ & $\begin{array}{l}\text { Low-leakage OA damper with dry-bulb or } \\
\text { enthalpy economizing and DCV capability }\end{array}$ \\
\hline Heat pump, electric heat, gas heating & Electric heat, gas heat \\
\hline $\begin{array}{l}\text { Heat pump COP @ } 47^{\circ} \mathrm{F} 3.33-9.2 \\
\text { Heat pump COP @ } 17^{\circ} \mathrm{F} 2.5-2.75\end{array}$ & N/A \\
\hline
\end{tabular}

HVAC technicians will require additional training to maintain, repair, and fully benefit from the more sophisticated controls and advanced technology features. The Rebel is a much more sophisticated RTU, particularly with its variable refrigerant flow system. Compared to standard one or two stage thermostatic control, the Rebel controller has many more configuration options. NAVFAC HVAC technicians will need to have training specific on the Rebel, particularly on interfacing with the controller to change control and troubleshoot by leveraging the Rebel's extensive AFDD capabilities. The Rebel supplier in Hawaii, Norman S. Wright, has a field technician who has received the advanced training on the Rebel. At first, NAVFAC will need to rely heavily on external HVAC technicians, who have been specifically trained on these highefficiency RTUs to resolve advanced maintenance issues. Eventually, NAVFAC HVAC technicians will achieve the skills and confidence necessary to perform the same level of maintenance they currently perform on code minimum RTUs.

To leverage the full performance of the WeatherExpert, the unit should be controlled using Carrier's ComfortLink interface or by a building management system to enable the supply fan's variable speed capability and separately control each cooling stage. The WeatherExpert's incorporation of belt-driven supply fans and standard fixed-speed compressors may be less of a technology jump for NAVFAC HVAC technicians compared to the Rebel. As the Navy continues to demonstrate these types of high-efficiency RTUs, the performance impacts should be analyzed and captured for incorporation into revisions of the UFGSs and UFCs. 


\section{Recommended Next Steps}

The Rebel RTU showed significant (34\%-37\%) energy savings compared to the code-minimum, baseline RTU meeting UFGS 23810000 20. For the Hawaii climate, the year-round demand for cooling and dehumidification translates these large percentage savings into larger kilowatt-hour savings compared to RTUs in less cooling dominated climates. Because high-efficiency RTUs are new to the industry ( 2 years for the Rebel and 1 year for the WeatherExpert), they have a significant cost premium, which reduces their cost effectiveness.

Yet, NAVFAC new construction or retrofit projects should find that high-efficiency RTUs meeting the DOE RTU challenge specification will meet the DOD's ROI criteria based on life cycle cost analysis, not just using the simple payback metric. Life cycle cost analysis is required according to UFC 1-200-02 for either new construction or replacement activities.

Based on NAVFAC's adoption of high-efficiency RTUs, NREL has three recommendations:

1. Conduct field demonstrations of other high-efficiency RTUs that meet the DOE RTU Challenge (such as the Carrier WeatherExpert) in Hawaii and leverage the results of other ongoing demonstrations. More specifically, DOD is partnering with the DOE on additional field demonstrations of DOE Challenge RTUs. These demonstrations should be completed by spring 2015. NAVFAC is participating in three of these demonstrations within the continental United States. NREL recommends comparing the energy savings discussed in this report with these other demonstrations in different climates.

2. In a coordinated manner, train NAVFAC HVAC technicians on these high-efficiency RTUs. To be successful over the long term, the NAVFAC HVAC technicians will need specific training to provide the same level of maintenance they provide on code-minimum RTUs. Appendix I provides a summary of typical maintenance procedures NAVFAC technicians provide quarterly on RTUs. The nature of HVAC, particularly in Hawaii and Guam where cooling is continuous, is that maintenance issues will always arise. Daikin Applied offers 2.5day training classes on the Rebel at its facility in Plymouth, Minnesota. ${ }^{18}$ At the time of writing this report, NREL was not aware of specific WeatherExpert training by Carrier. NREL recommends NAVFAC contact its local HVAC distributors to learn about local, onsite training. NREL contacted Rebel and Carrier distributors for Hawaii and was told that custom training can be provided to NAVFAC HVAC technicians.

3. Incorporate 2 to 4 hours of additional commissioning time for each high-efficiency RTU installation. The greater control complexity of these RTUs needs additional attention from a commissioning agent to maximize comfort and energy savings. In addition, Carrier and Daikin Applied stated that they can pre-program their controllers in the factory based on NAVFAC's specific control requirements, thereby reducing installation time and maintaining consistent high performance in the field. Moreover, Daikin Applied has started to offer remote on-going commissioning by connecting to their controller over a cellular modem. NAVFAC should investigate these on-going services from manufacturers or third parties, incorporating the potential deferred O\&M costs and improved energy savings within their life cycle cost analysis.

18 “Rebel Rooftop Training Course.” Daikin Applied, 2014. http://www.daikinapplied.com/training.php. 


\section{Bibliography}

ASHRAE. (2002). ASHRAE Guideline 14-2002. Measurement of Energy and Demand Savings. American Society of Heating, Refrigerating and Air-Conditioning Engineers, Atlanta, GA.

Berglof, K. (2011). Performance Inspections with Innovative Analyzing Equipment Results in Significant Energy Savings in Air-Conditioning and Refrigeration Systems, Accessed Jan. 10, 2013: www.eeswest.com/wp-content/themes/xero/pdf/pr-berglof-performance-inspections-iirprag-2011(v2).pdf.

Wang, W.; Katipamula, S. (September 2013). Part-Load Performance Characterization and Energy Savings Potential of the RTU Challenge Unit: Daikin Rebel, PNNL-22720. Accessed Oct. 5, 2013: www.pnl.gov/main/publications/external/technical_reports/PNNL-22720.pdf.

Daikin. (March 2013). MicroTech III Unit Controller for Rebel Commercial Package Rooftop Systems. Accessed April 3, 2013:

http:/lit.daikinapplied.com/bizlit/DocumentStorage/RooftopSystems/InstallationandOperationM anuals/OM_1141-2_Rebel_DPS-MT3_Controller.pdf.

Unified Facilities Criteria UFC-1-200-02. (March 2013). High Performance and Sustainable Building Requirements. Accessed June 6, 2013: www.wbdg.org/ccb/browse_cat.php?c=4.

Unified Facilities Criteria UFC-3-410-01. (July 2013). Heating, Ventilating, and Air Conditioning Systems. Accessed July 15, 2013: www.wbdg.org/ccb/browse_cat.php?c=4.

Unified Facilities Guide Specifications UFGS-23 8100.00 20. (November 2009). Division 23 Heating, Ventilating, and Air Conditioning. Accessed Nov. 10, 2012:

www.wbdg.org/ccb/browse_cat.php?c=3. 


\section{Appendix A: ClimaCheck Methodology}

Figure A-1 and Figure A-2 show the schematics of the Rebel and baseline RTUs through the ClimaCheck website. For each minute of DX operation, the ClimaCheck methodology utilizes refrigerant pressure, refrigerant temperature, and compressor power measurements to calculate real-time EER and cooling capacity. ${ }^{19}$

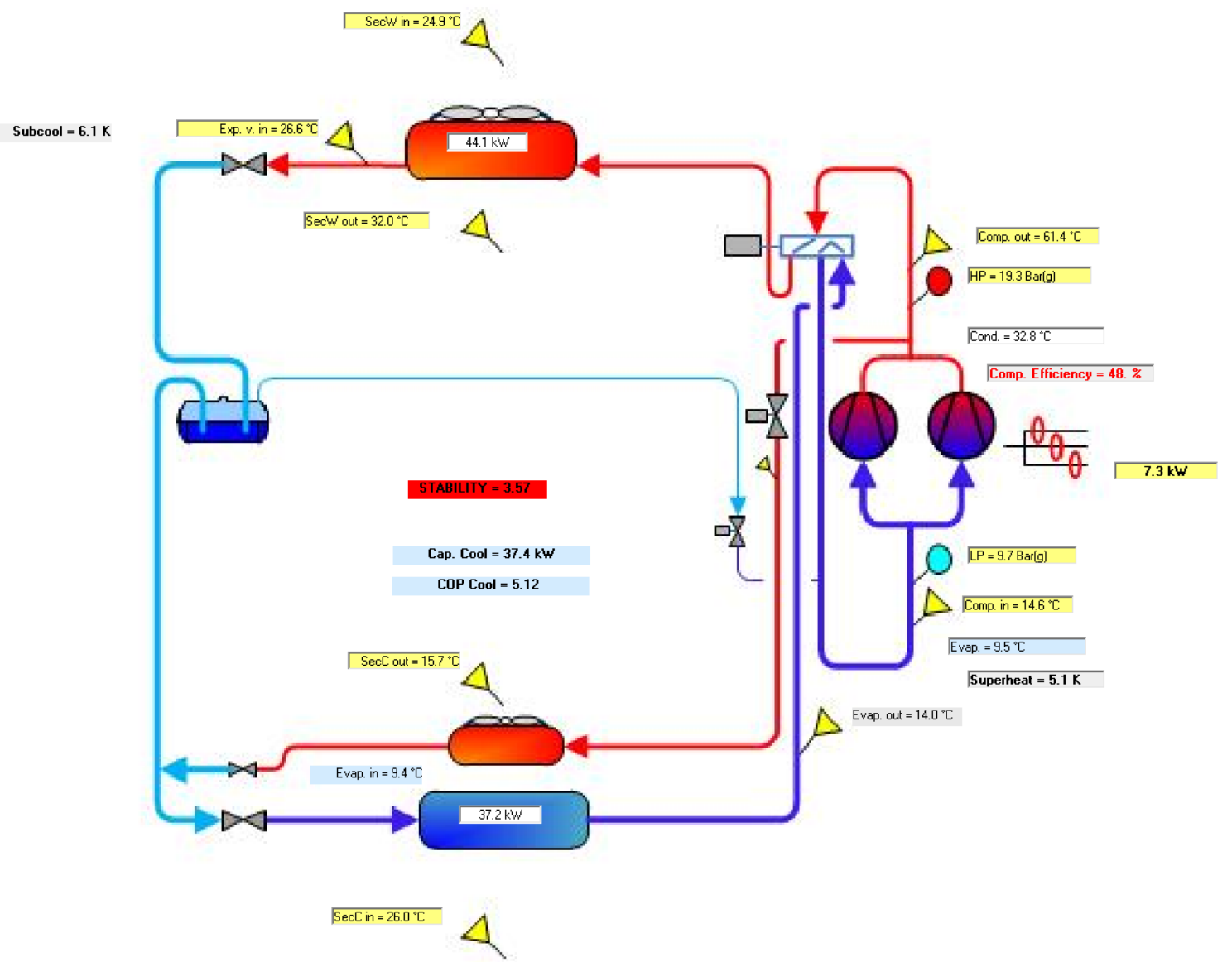

Figure A-1. Rebel refrigerant-side monitoring (instance December 10, 2013 6:40)

Source: ClimaCheck

\footnotetext{
${ }^{19}$ Berglof, K. Performance Inspections with Innovative Analyzing Equipment Results in Significant Energy Savings in Air-Conditioning and Refrigeration Systems. Accessed January 10, 2013: www.eeswest.com/wpcontent/themes/xero/pdf/pr-berglof-performance-inspections-iir-prag-2011(v2).pdf.
} 


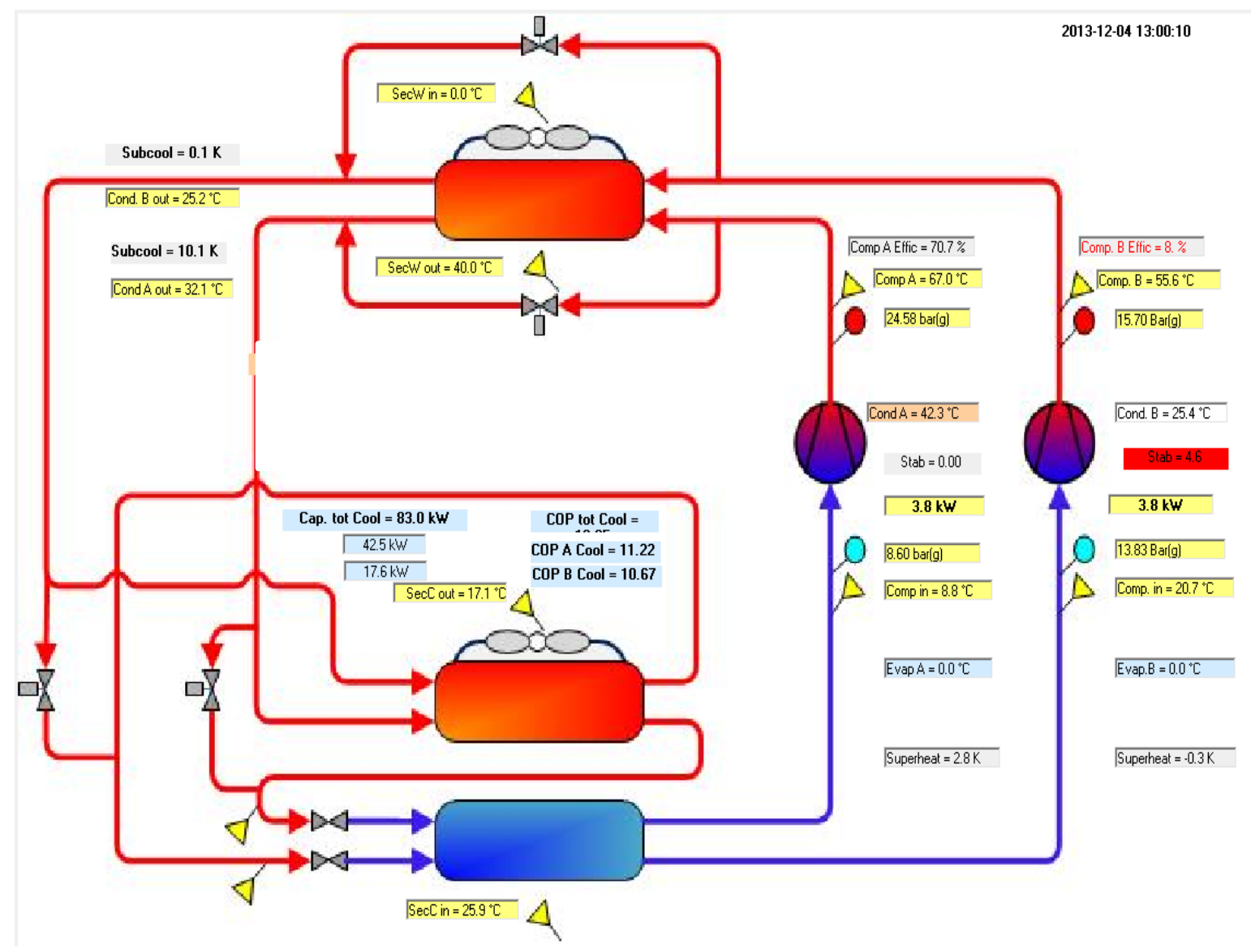

Figure A-2. Baseline refrigerant-side monitoring (instance December 4, 2013 13:00)

Source: ClimaCheck 


\section{Appendix B: Model Geometry, Envelope, and Internal Loads}

NREL dimensioned the entire space and developed a three-dimensional model of building 550, as shown in Figure B-1. Based on the actual air distribution layout, the space was split into two separate thermal zones. The southern zone (dimensioned 60 feet $\times 43$ feet) was served by the Rebel. The northern zone (dimensioned 60 feet $\times 40$ feet) was served by the baseline RTU. The two zones were simulated to exchange air based on a 1 flow per minute air cross-flow through the imaginary wall that split the space. The southernmost wall was simulated as adiabatic (no heat transfer) as the actual wall abutted a separately conditioned space on the other side of the building.

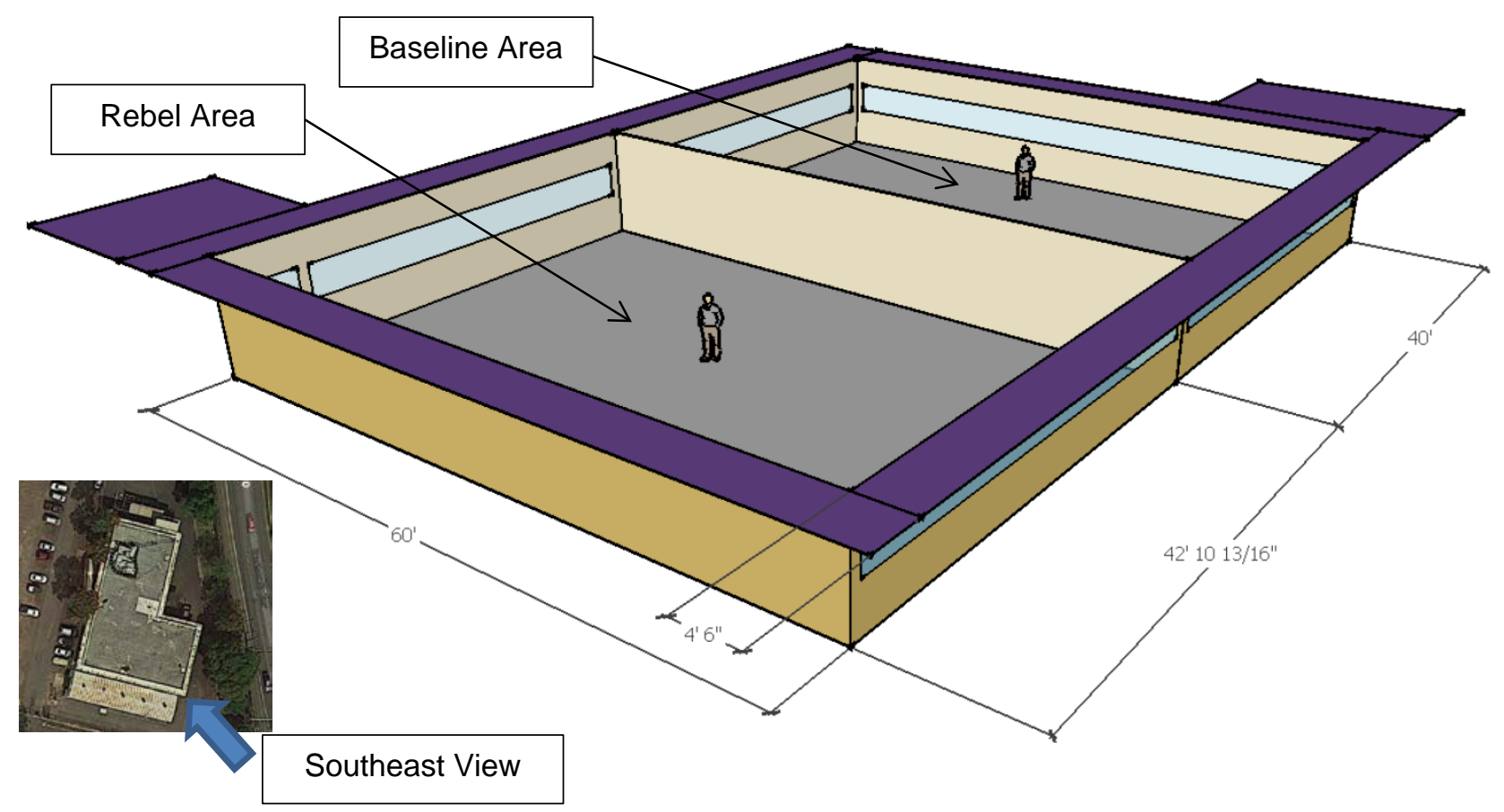

Figure B-1. Southeast view of building 550 model

Source: Google Maps and NREL SketchUp Model

Table B-1 summarizes the model parameters that significantly influence building sensible and latent heat loads. The model included the 4.5-foot overhang around the entire building's perimeter to capture the shading impacts (purple in Figure B-1). The internal sensible and latent loads were based on the artificial loads actually set up in the space during the demonstration period using heat lamps and humidifiers on timers (see Section 3.4). Two of the model inputs, infiltration rate, and window properties (SHGC and U-value), were not known or measured. Therefore, NREL adjusted these parameters within appropriate bounds for calibrating the models. All the assumptions are specified in Table B-1. 
Table B-1. Summary of Building Envelope and Internal Load Parameters

\begin{tabular}{|c|c|}
\hline Parameter & Comments \\
\hline Total Area $=4,976 \mathrm{ft}^{2}$ & $\begin{array}{l}\text { Total model dimensions } 60 \mathrm{ft} \times 83 \mathrm{ft} \text {; Rebel side } 2,576 \mathrm{ft}^{2} \text {; Baseline side } \\
2,400 \mathrm{ft}^{2}\end{array}$ \\
\hline $\begin{array}{l}\text { Floor = Carpeting over } \\
\text { 8-in. Concrete } \text { Slab }^{\text {Sin }}\end{array}$ & $\begin{array}{l}\text { Based on structural drawings; underside of slab set to adiabatic (no heat } \\
\text { transfer) as first-floor space was separately conditioned to } 76^{\circ} \mathrm{F}\end{array}$ \\
\hline Wall $=10$-in. Concrete ${ }^{a}$ & Based on structural drawings; no wall insulation \\
\hline $\begin{array}{l}\text { Roof = Black Asphalt } \\
\text { over 8-in. Polystyrene } \\
\text { above 6-in. Concrete } \\
\text { Slab }\end{array}$ & $\begin{array}{l}\text { Based on structural drawings and measured roof insulation during RTU } \\
\text { installation; total construction R-value }=42 \mathrm{~h}-\mathrm{ft}^{2}-\mathrm{F} / \mathrm{Btu}\end{array}$ \\
\hline Window Area $=668 \mathrm{ft}^{2}$ & $\begin{array}{l}\text { Window wall ratio }=0.23 ; \text { SHGC }=0.5 \text { (double pane with some low-e } \\
\text { coating); U-value }=0.50 ; \text { SHGC and } U \text {-value assumed, no data available } \\
\text { regarding window construction type other than being double paned }\end{array}$ \\
\hline $\begin{array}{l}\text { Nominal Infiltration Set } \\
\text { to } 0.10 \mathrm{cfm} / \mathrm{ft}^{2} \text { of } \\
\text { Exterior Wall Area; } \\
\text { Equates to } 0.34 \text { Air } \\
\text { Changes per Hour for } \\
\text { Building } 550\end{array}$ & $\begin{array}{l}\text { Based on typical building envelope pressure of } 0.02 \mathrm{in} \text {. WC with typical } \\
\text { leakage values }{ }^{\mathrm{b}} \text { for commercial buildings equal to } 0.10 \mathrm{cfm} / \mathrm{ft}^{2} \text { of exterior } \\
\text { wall area; nominal infiltration rate is modified; each model time step based } \\
\text { on the DOD BLAST program's (predecessor to EnergyPlus) } \\
\text { recommended equation: } 0.606+0.03636 \text { (Tzone-TOAT) }+0.1177 \\
\text { (WindSpeed) }\end{array}$ \\
\hline $\begin{array}{l}\text { Overhead Lighting = } \\
1 \mathrm{~W} / \mathrm{ft}^{2}\end{array}$ & $\begin{array}{l}\text { Based on count of } 151 \text { T-8 fluorescent lights throughout the office space; } \\
\text { manually operated by NAVFAC personnel during business weekdays from } \\
0700 \text { to } 1500\end{array}$ \\
\hline $\begin{array}{l}\text { Occupancy Sensible }+ \\
\text { Plug Loads }=0.9 \mathrm{~W} / \mathrm{ft}^{2}\end{array}$ & $\begin{array}{l}\text { Occupancy sensible and plug loads were based on } 4,625 \mathrm{~W} \text { of heat lamps } \\
\text { distributed throughout the space }(32 \times 125 \mathrm{~W} \text { and } 5 \times 75 \mathrm{~W}) \text {; all lights on } \\
\text { timers from } 0700 \text { to } 1700 \text { daily }\end{array}$ \\
\hline Occupancy Latent & $\begin{array}{l}\text { Installed six humidifiers throughout the space that deliver } 1.5 \text { gallons of } \\
\text { moisture each per day-therefore, total latent load of } 9 \text { gallons delivered } \\
\left.\text { each day; total moisture load based on } 34 \text { occupants ( } 146 \mathrm{ft}^{2} / \mathrm{occ}\right) \text { at } 200 \\
\text { Btuh latent load per occupant; humidifiers are started at } 0700 \text { by NAVFAC } \\
\text { personnel when the overhead lights are turned on; moisture load in the } \\
\text { model is spread across } 24 \text { hours as NAVFAC personnel notified NREL } \\
\text { that humidifiers were not empty by } 1500 \text { when they came to turn the lights } \\
\text { off but were empty the following morning }\end{array}$ \\
\hline
\end{tabular}




\section{Appendix C: Rebel Model Summary}

Based on the monitored data, NREL leveraged the Rebel's capability to maintain a constant DAT set point to develop a simple modeling procedure. By always knowing the leaving air drybulb temperature, the Rebel RTU model would calculate the total cooling based on the mixed-air conditions (entering the evaporator), ambient dry-bulb (entering the condenser), and supply air flow rate. The Rebel RTU model's supply air moisture content was maintained at 85\%-95\% RH based on DOE's lab test results of a 10-ton Rebel (Wang et al 2013). The supply air humidity was not monitored in this demonstration because of the significant uncertainty caused by the insufficient accuracy of field RH sensors and difficulty of ensuring the supply air was sufficiently mixed at a single RH sensor location.

The Rebel was modeled exactly as it was controlled during the demonstration period. The supply fan modulated between minimum and maximum flow rates according to a PI control that is summarized below. The Rebel ventilation rate was modeled as if the OA damper opened from $5 \%-15 \%$ as the supply air flow changed from $100 \%$ to $40 \%$, respectively. The ventilation rate maintained at all supply fan and OA damper configurations met the minimum ventilation requirements per ASHRAE Standard 62.1 without DCV operation. The Rebel was not modeled with DCV operation per UFC 3-410-01 (dated July 1, 2013). The compressors were controlled to maintain the constant DAT at $60^{\circ} \mathrm{F}$ (post-supply fan), regardless of the supply air flow rate. If the Rebel compressors at $100 \%$ capacity could not achieve a $60^{\circ} \mathrm{F}$ DAT at a given set of mixed-air conditions and supply air flow rate, the discharge air condition was calculated based on the maximum cooling rate the Rebel could provide.

The Rebel cooling capacity was limited in the model based on the maximum cooling capacity measured during the demonstration period. NREL found the Rebel would peak at 13 tons when the variable-speed compressor was at $100 \%$ capacity and the second-stage compressor was operating. These measured maximum cooling capacities occurred for the first 5-10 minutes of the initial morning cooldown period and the first 1-3 minutes that both compressors would turn on after both were off. Therefore, the Rebel's model was limited to 13 tons. Although the Rebel RTU installed had a nominal 10-ton capacity, it could overdrive the variable-speed compressor to achieve 12 tons capacity under nominal conditions. Then, based on the mixed-air conditions (entering the evaporator coil) and ambient dry-bulb (entering the condenser coil), the Rebel RTU can achieve an additional 10\% capacity above 12 tons.

The following subsections summarize the Rebel RTU modeling and then summarize the calibration procedure and results. The DX model summary is provided in Section 4.1. 


\section{Supply Fan Model}

NREL used the TAB report to correlate the fan speed setting at the MicroTech controller to the supply flow rate. Table C-1 summarizes the Rebel model's supply fan performance at different controller fan speed settings. NREL developed a correlation between the controller fan speed setting and supply air flow rate (equation C-1 and Figure C-1).

Table C-1. Rebel RTU Supply Fan Performance Based on TAB Report

\begin{tabular}{lllll}
\hline $\begin{array}{l}\text { Fan Speed Setting } \\
\text { on MicroTech } \\
\text { Controller }\end{array}$ & $\begin{array}{l}\text { Total Static } \\
\text { Pressure }\end{array}$ & $\begin{array}{l}\text { Supply } \\
\text { Air Flow }^{\mathrm{a}}\end{array}$ & $\begin{array}{l}\text { Fan } \\
\text { Power }^{\mathrm{b}}\end{array}$ & $\begin{array}{l}\text { Total Fan+ } \\
\text { Motor Static } \\
\text { Efficiency }\end{array}$ \\
\hline $100 \%$ & $2.54 \mathrm{in.} \mathrm{WC}$ & $4,069 \mathrm{cfm}$ & $2,144 \mathrm{~W}$ & $63 \%$ \\
\hline $88 \%$ & $1.96 \mathrm{in.} \mathrm{WC}$ & $3,575 \mathrm{cfm}$ & $1,578 \mathrm{~W}$ & $59 \%$ \\
\hline $63 \%$ & $1.24 \mathrm{in.} \mathrm{WC}$ & $2,547 \mathrm{cfm}$ & $693 \mathrm{~W}$ & $50 \%$ \\
\hline $34 \%$ & $0.37 \mathrm{in.} \mathrm{WC}$ & $1,601 \mathrm{cfm}$ & $214 \mathrm{~W}$ & $42 \%$ \\
\hline
\end{tabular}

$\dot{V}_{S A}=\left(4,114 \cdot\right.$ fan $\left._{\text {setting }}\right)-45$

where

$\dot{V}_{S A}$ is the supply air flow rate $(\mathrm{cfm})$

fan $_{\text {setting }}$ is the control fan speed setting.

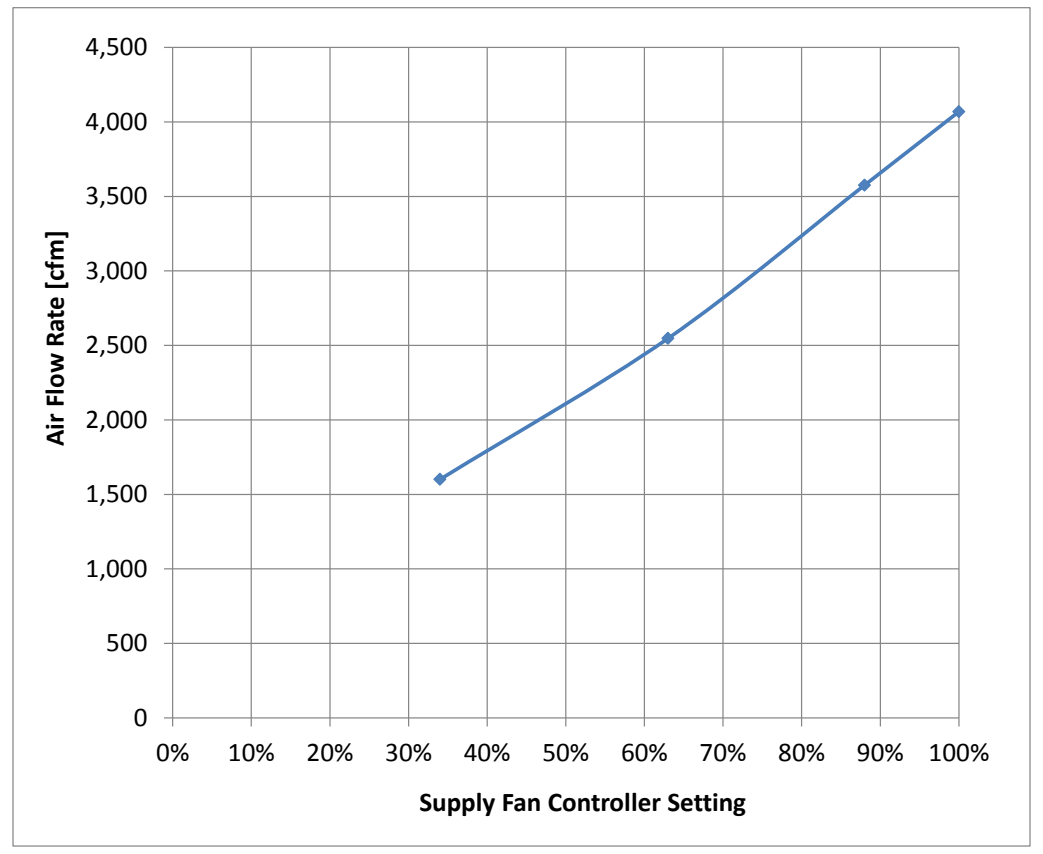

Figure C-1. Correlation between supply fan controller speed setting and supply air flow rate based on TAB 
At each fan speed, the model needs the associated total static pressure and total static efficiency to calculate fan power. Equation C-2 and Equation C-3 provide regression models of total static pressure and fan efficiency versus flow fraction, respectively (Figure C-2a). At each time step, the EnergyPlus Rebel RTU model will calculate the supply fan power based on the supply air flow fraction, static pressure, and fan efficiency (Figure C-2b).

Pressure Fraction $=1.0518 \cdot f f^{2.0269}$

where

Pressure Fraction is the fraction of the peak 2.57 in. WC (639 Pa) pressure at $100 \%$ fan speed

$\mathrm{ff}$ is the flow fraction of the $4,069 \mathrm{cfm}\left(1.92 \mathrm{~m}^{3} / \mathrm{s}\right)$ supply air flow at $100 \%$ fan speed.

Fan Efficiency Fraction $=(0.5076 \cdot f f)+0.5081$

where

Fan Efficiency Fraction is the fraction of the peak 63\% efficiency at $100 \%$ fan speed $\mathrm{ff}$ is the flow fraction of the $4,069 \mathrm{cfm}\left(1.92 \mathrm{~m}^{3} / \mathrm{s}\right)$ supply air flow at $100 \%$ fan speed.
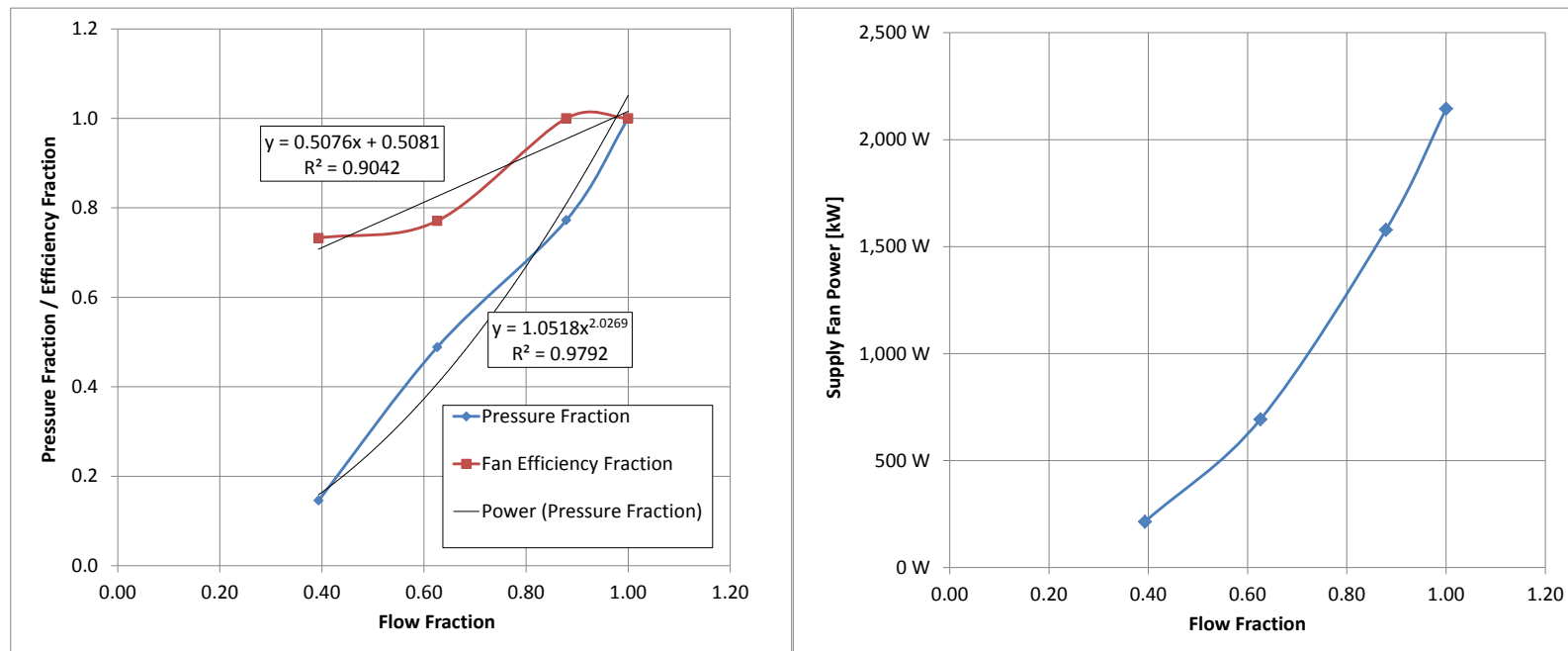

Figure C-2. (a) Regression model of supply fan pressure and efficiency as a function of flow fraction (b) EnergyPlus model of supply fan power based on flow fraction

The Rebel supply fan was controlled based on the single-zone variable-air zone control logic built into the MicroTech III controller. The supply fan modulates its speed between a specified minimum and maximum using a PI control based on space temperatures relative to set point. Rebel defines three PI control parameters including gain, sample time period, and projected ahead time. Due to unstable operation of the supply fan speed identified from the monitored data, on November 1, 2013, these control parameters were changed to the following:

- Gain $=0.8$ (originally set to 1.5$)$

- $\quad$ Sample time $=60$ seconds (originally set to 30 seconds)

- $\quad$ Projected ahead time $=400$ seconds (originally set to 100 seconds). 
Upon startup, the supply fan sequence follows that shown in Table C-2. For the first few minutes, the supply fan goes from off (0), start (1), recirculation (2) to fan only (3). During off and start, the supply fan speed remains at $0 \%$. During recirculation, the supply air flow speed is controlled to the keypad adjustable maximum heating speed (default 100\%). When in cooling, the supply fan varies between minimum cooling speed (default 40\%) and maximum cooling speed (default 100\%) as space temperature changes. During heating, the supply fan speed varies between minimum heating speed (default 40\%) and maximum heating speed (default 100\%) as space temperature changes. During fan only and minimum DAT, the supply fan is controlled to the minimum cooling speed (default $40 \%$ ) or minimum heating speed (default $40 \%$ ), depending on which operation (cooling or heating) the RTU is moving toward.

Table C-2. Fan Operational Sequence Based on Startup

\begin{tabular}{ll}
\hline Unit State (BACnet enumeration) & Supply Fan Operation \\
\hline Off (1) & Set to $0 \%$ \\
Start (2) & Set to $0 \%$ \\
Recirculation (3) & $\begin{array}{l}\text { Controlled to keypad-adjusted maximum heating speed } \\
\text { defaulted to } 100 \%\end{array}$ \\
Fan Only (4) & \\
\hline
\end{tabular}

The Rebel implements the PI loop as follows:

- The current space temperature is set at T1. The current error is calculated using equation C-4:

$$
\text { error }_{\text {current }}=T_{1}-\text { Set Point }
$$

- The previous space temperature, sample time minutes prior, is set at T2. The previous error is calculated using equation C-5:

$$
\text { error }_{\text {previous }}=T_{2}-\text { Set Point }
$$

- Rebel then calculates the projected error based on the rate the error is changing a function of the previous error and current error shown in equation C-6. Projected error equals:

$$
\text { Projected_Error }=\text { Current_Error }+\left(\frac{\text { error }_{\text {current }}-\text { error }_{\text {previous }}}{S T} * P A T\right)
$$

- The change in fan speed (Do) after each sample time period is calculated using equation C-7:

$$
\Delta \text { Speed }=\text { Gain } \cdot(\text { Projected_Error })
$$

Figure C-3 shows a schematic of the PI logic from the Rebel operations manual. 


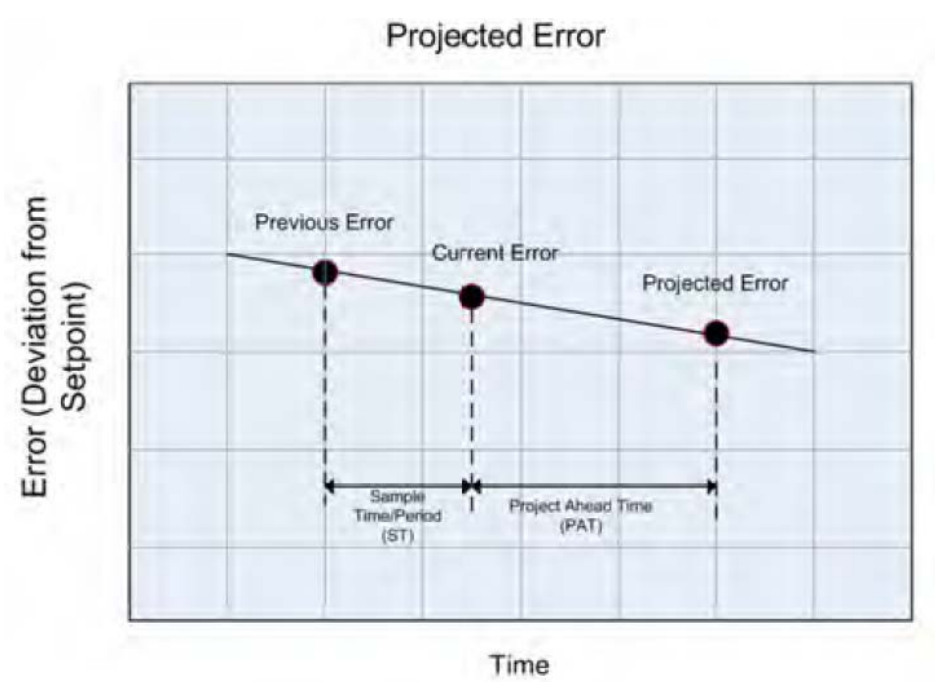

Figure C-3. Projected error timeline from MicroTech III unit controller operation manual

\section{Outdoor Air Flow Rates}

During the demonstration period, the OA damper position varied linearly from 5\% open at $100 \%$ fan speed to $15 \%$ open at $40 \%$ fan speed. The $40 \%-100 \%$ fan speeds were based on settings on the MicroTech controller. Based on the TAB report, NREL developed a correlation between OA flow rate and supply air flow rate based on this OA damper control (equation C-8 and Figure C4). The OA flow rates at all fan speeds meet the $219 \mathrm{cfm}$ minimum ventilation requirement (nonDCV) per ASHRAE 62.1. For each time step in the Rebel RTU EnergyPlus model, the OA mass flow rate was calculated based on the supply air mass flow rate.

$$
\dot{m}_{O A}=\left(-0.0502 \cdot \dot{m}_{\text {supply }}{ }^{2}\right)+\left(0.2069 \cdot \dot{m}_{\text {supply }}\right)-0.0243
$$

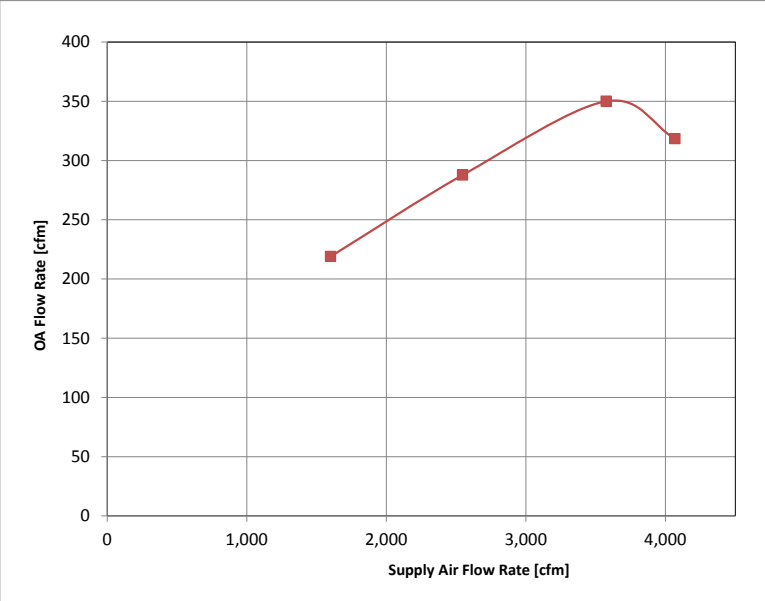

(a)

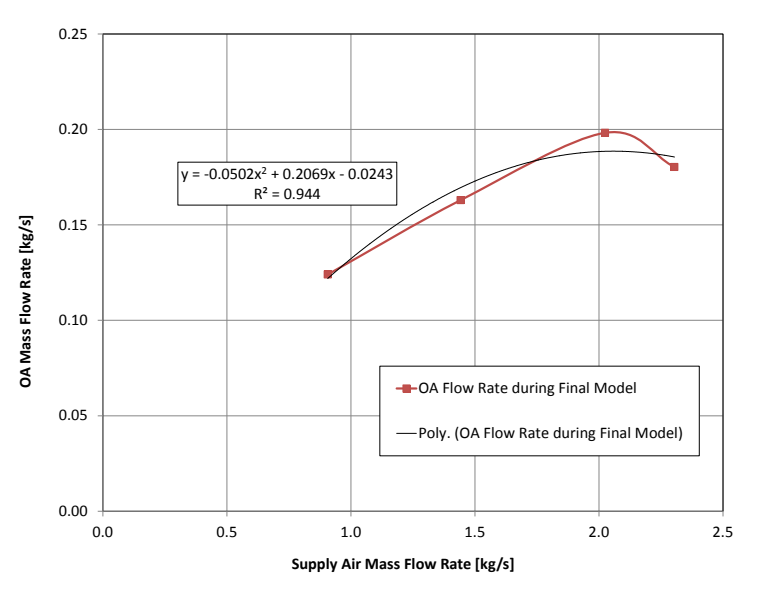

(b)

Figure C-4. OA flow rates based on the supply air flow rate (a) shows flow rates in cfm and (b) shows regression equations relating OA mass flow rates to supply air mass flow rates used in the EnergyPlus model of the Rebel RTU 


\section{Calibration Results}

Figure C-5b shows the whole-building energy model of the Rebel RTU calibrated against the 35 days of the calibration period. The modeled data compare well against the measured daily total energy versus daily average ambient dry-bulb (Figure C-5a). The 17\% CVRMSE is the uncertainty of the model. This overlap reinforces the model is properly accounting for the impact of ambient conditions on RTU behavior. Finally, Figure C-6a and C-6b show the model meets the calibration specification of average space conditions within $\pm 1^{\circ} \mathrm{F}$ dry-bulb and $\pm 3^{\circ} \mathrm{F}$ dew point, respectively.

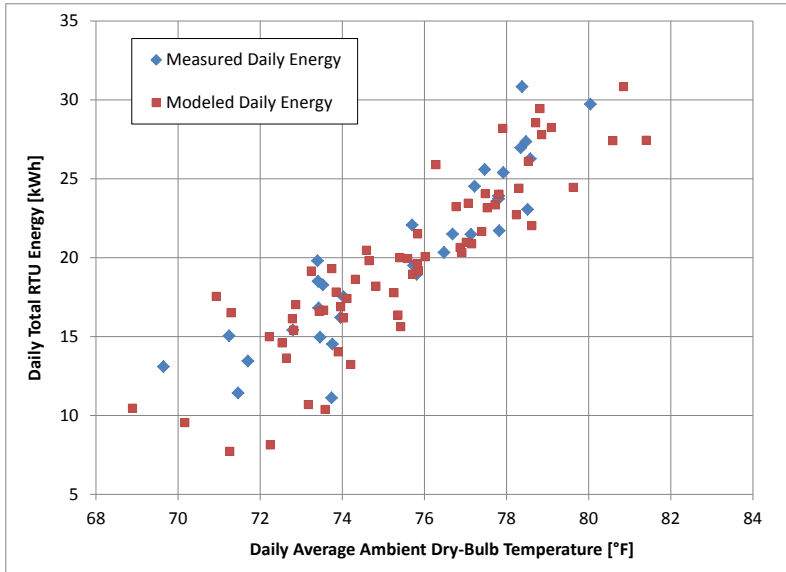

(a)

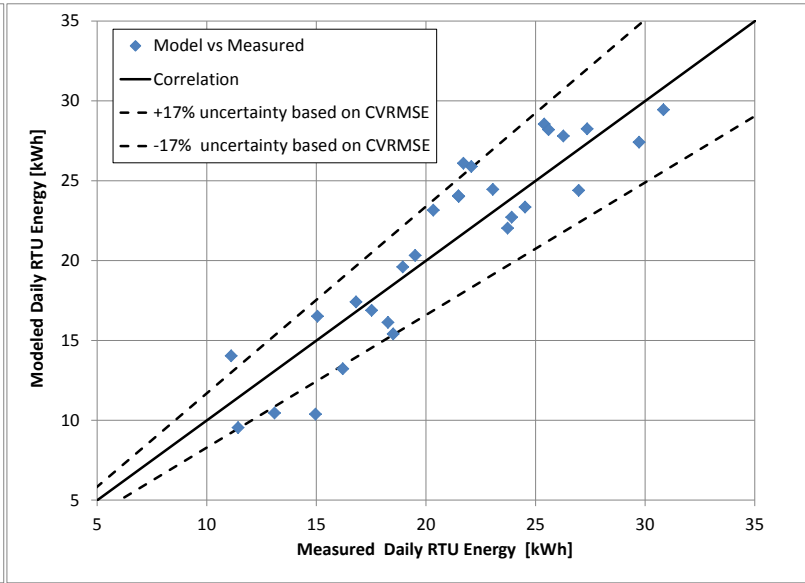

(b)

Figure C-5. Rebel RTU model versus measured daily RTU energy usage

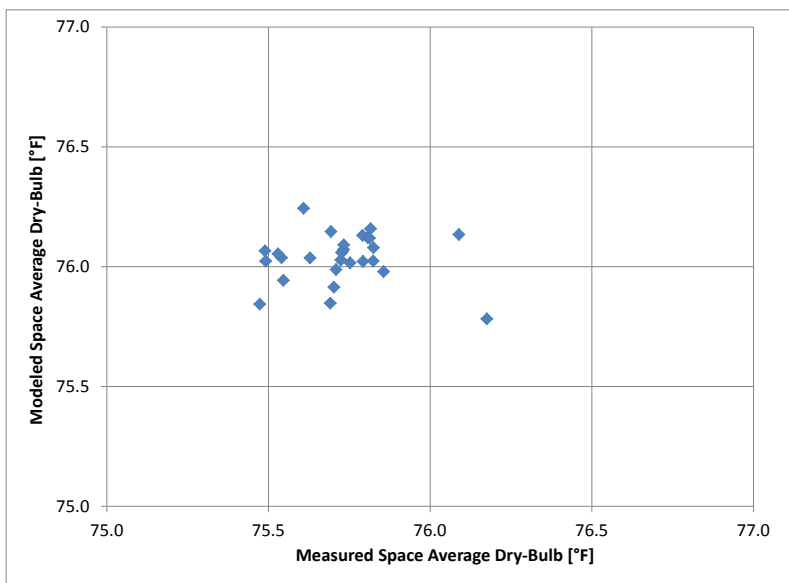

(a)

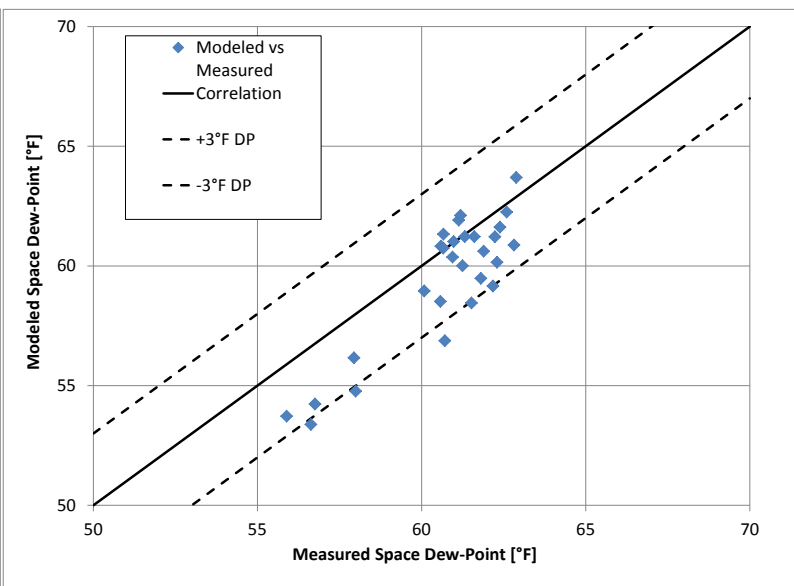

(b)

Figure C-6. Rebel RTU model versus measured space dry-bulb and dew point 


\section{Appendix D: Baseline Model Summary}

The baseline RTU was modeled conservatively without penalizing the cooling capability of the DX circuit for significant compressor cycling. Therefore, the first and second minute after a compressor would turn on, the cooling delivered to the air was modeled as if the compressor had already been operating for at least 3 minutes and had achieved steady state operation. NREL was not able to quantify the compressor cycling degradation, and therefore, did not want to incorporate any degradation in the model that was not supported by monitored performance data. Thus, the baseline RTU model annualized energy usage and performance may be slightly overstated in the final model.

The following subsection reviews the DX regression models that capture power and capacity. The calibrated results are presented next.

\section{Direct Expansion System}

The first set of regression equations that correlate DX cooling power were summarized in Section 4.1. The second set of regression equations correlate DX cooling capacity fraction to mixed-air wet-bulb and ambient dry-bulb temperatures (equations D-1 and D-2). Table D-1 summarizes these regression models’ parameters. Although the R-squared for these two regressions are low for both stages, the absolute change in capacity is not significant; under first stage the range is $0.4-0.6$ and under second stage the range is 0.9-1.2. Compared to compressor power, which was measured using a power transducer with a 3\% accuracy specification, the cooling capacity was calculated using the ClimaCheck methodology which has a $\pm 7 \%$ uncertainty. The low R-squared was due to a combination of the small variation in capacity at each stage and larger uncertainty of a calculated parameter rather than a measured one.

$$
\begin{aligned}
& \text { Stage } 1 \text { Capacity Fraction } 0.0077+\left(0.0096 \cdot T_{W B}\right)+ \\
& \left(0.0334 \cdot T_{O A}\right)+\left(-0.0008 \cdot T_{O A}{ }^{2}\right) \\
& \text { Stage } 2 \text { Capacity Fraction }-2.269+\left(0.313 \cdot T_{W B}\right)+ \\
& \left(-0.008 \cdot T_{W B}{ }^{2}\right)+\left(0.022 \cdot T_{O A}\right)+\left(-0.001 \cdot T_{O A}{ }^{2}\right)
\end{aligned}
$$

where

Capacity Fraction is the fraction of the nominal cooling capacity,

$T_{W B}$ is the mixed-air wet-bulb temperature entering the evaporator coil $\left({ }^{\circ} \mathrm{C}\right)$, and

$T_{O A}$ is the ambient dry-bulb temperature $\left({ }^{\circ} \mathrm{C}\right)$.

Table D-1. Baseline RTU Cooling Capacity Regression Parameters

\begin{tabular}{lll}
\hline & First-Stage DX & Second-Stage DX \\
\hline Adjusted R-Squared & 0.56 & 0.11 \\
Capacity Fraction Range & $0.4-0.6$ & $0.9-1.2$ \\
\hline Total RTU Operational Hours for Regressions & $173 \mathrm{~h}$ & $68 \mathrm{~h}$ \\
$T_{W B}$ & $62^{\circ}-68^{\circ} \mathrm{F}$ & $62^{\circ}-69^{\circ} \mathrm{F}$ \\
$T_{O A}$ & $62^{\circ}-86^{\circ} \mathrm{F}$ & $63^{\circ}-87^{\circ} \mathrm{F}$ \\
\hline
\end{tabular}




\section{Calibration Results}

Figure D-1b shows the baseline RTU model compares well against the measured data with respect to total energy usage per day. Based on the CVRSME, the baseline RTU daily energy usage realized a 75 uncertainty based on a $68 \%$ confidence interval. Figure D-1a shows the model captured the impact of dry-bulb temperature on daily energy usage. Figure D-2a and Figure D-2b show the baseline model met the space temperature and dew point specifications for calibration.

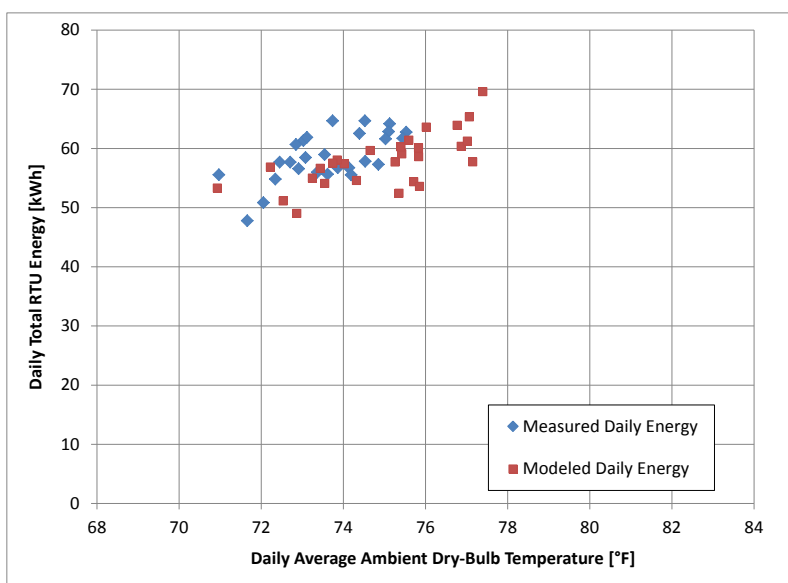

(a)

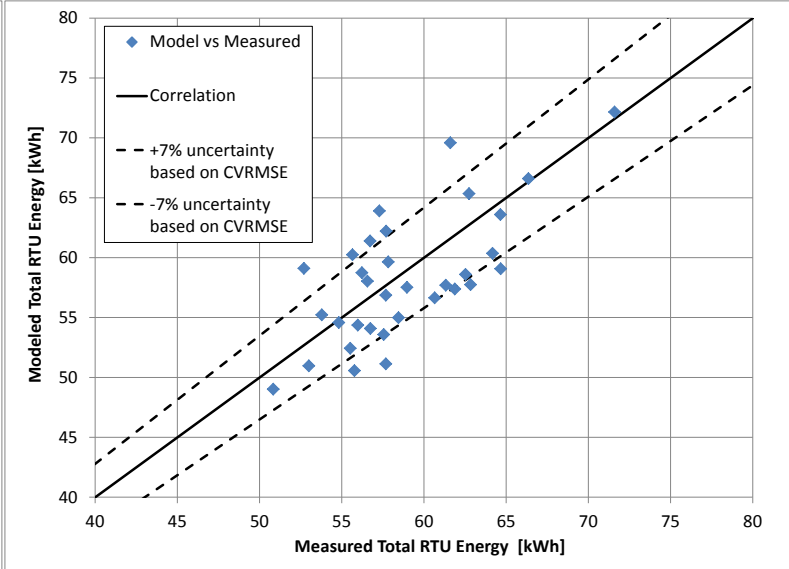

(b)

Figure D-1. Baseline RTU model versus measured daily DX energy usage

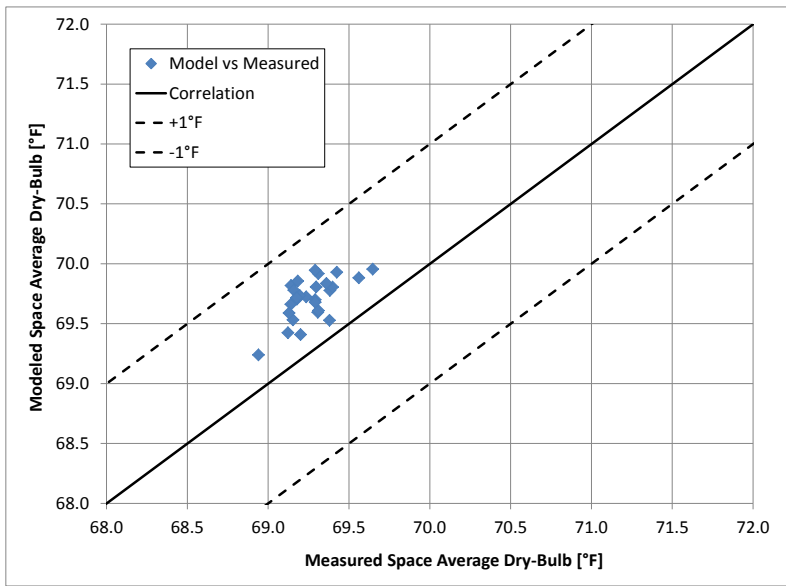

(a)

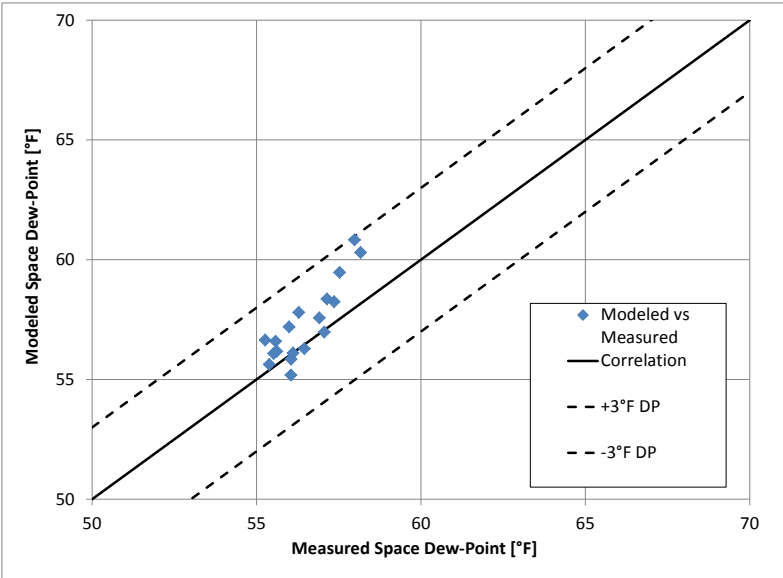

(b)

Figure D-2. Baseline RTU model versus measured space dry-bulb and dew point 


\section{Appendix E: Artificial Internal Sensible and Latent Loads}

The heat lamps and humidifiers were configured to maintain a uniform distribution across the second-floor office space such that both RTUs would be exposed to nearly the same internal loads. Although the space is somewhat divided in two because of two separate air distribution systems, there is significant air mixing because there is no wall separating these spaces. As the Rebel conditions $176 \mathrm{ft}^{2}$ more than the baseline, the additional internal sensible gain was considered negligible. Table E-1 summarizes the number of air diffusers and the internal sensible load due to overhead lights, which NREL coordinated with NAVFAC to turn on and off during the demonstration period. Table E-2 summarizes how heat lamps were installed throughout the space to represent occupant and plug load heat gains. Table E-3 summarizes the combined overhead lights, occupant, and plug load sensible internal gains.

Table E-1. Overhead Lighting Power and Schedule Maintained During the Demonstration Period

\begin{tabular}{lllllll}
\hline & Area & 4-Way Air Diffusers & \multicolumn{2}{c}{ Overhead Lights $^{\mathrm{a}}$} \\
\hline $\begin{array}{l}\text { Baseline RTU's Side of the } \\
\begin{array}{l}\text { Office Space } \\
\text { Daikin Applied Rebel's }\end{array}\end{array}$ & $2,400 \mathrm{ft}^{2}$ & 12 & $200 \mathrm{ft}^{2} / \mathrm{diff}$ & $73 \mathrm{~T}-8 \mathrm{~s}$ & $2,336 \mathrm{~W}$ & $1 \mathrm{~W} / \mathrm{ft}^{2}$ \\
$\begin{array}{l}\text { Side of the Office Space } \\
\begin{array}{l}\text { Combined Second-Floor } \\
\text { Office Space }\end{array}\end{array}$ & $2,576 \mathrm{ft}^{2}$ & 9 & $286 \mathrm{ft}^{2} / \mathrm{diff}$ & $78 \mathrm{~T}-8 \mathrm{~s}$ & $2,496 \mathrm{~W}$ & $1 \mathrm{~W} / \mathrm{ft}^{2}$ \\
\hline
\end{tabular}

${ }^{a}$ NREL coordinated with NAVFAC to have the overhead lights turned on throughout the second-floor office space in the morning between 0630-0730 until the end of the day between 1600-1700. Each T-8 bulb consumes $32 \mathrm{~W}$. 
Table E-2. NREL Installed Heat Lamps to Represent the Sensible Loads from Occupants and Plug Loads

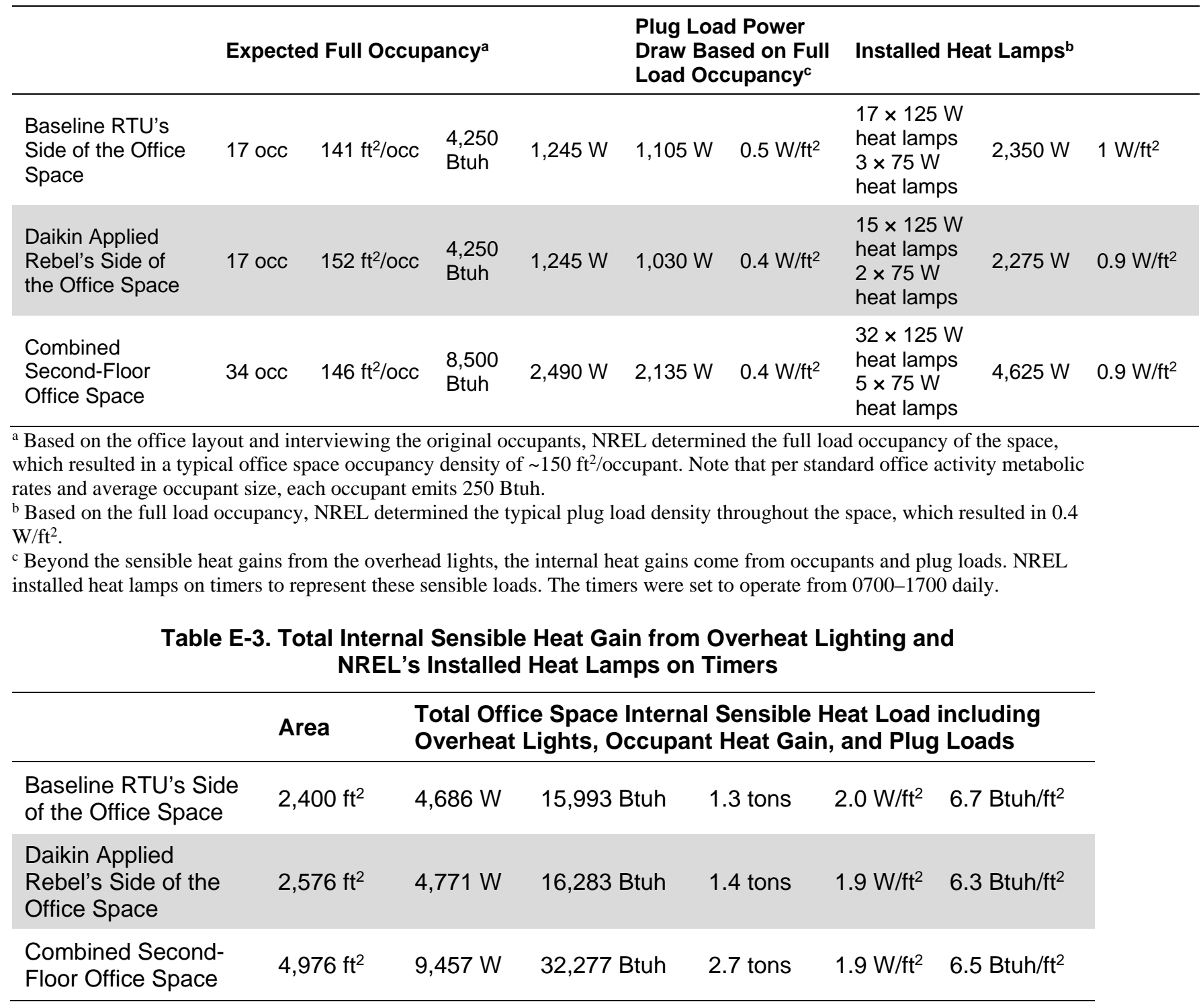

Similar to the sensible internal loads, NREL calculated the latent load based on a fully occupied office space. Table E-4 shows how six 1.5-gal humidifiers were distributed throughout the space to represent the moisture load of 34 occupants. After the NAVFAC representative turned on all the overhead lights each morning between 0630-0730 they filled each humidifier and ensure they were plugged in. Each humidifier was on a timer and staggered across the day to ensure a consistent vaporization, rather than having all the humidifiers on at once in the morning. 
Table E-4. NREL Set Up Humidifiers on Timers to Represent the Total Internal Latent Heat Gain from Occupants ${ }^{\mathrm{e}}$

\begin{tabular}{|c|c|c|c|c|c|c|c|}
\hline \multirow{2}{*}{$\begin{array}{l} \\
\text { Baseline RTU's } \\
\text { Side of the Office } \\
\text { Space }\end{array}$} & \multicolumn{2}{|c|}{ Full Occupancy } & \multicolumn{2}{|c|}{ Latent Load ${ }^{b, d}$} & \multirow{2}{*}{$\begin{array}{l}\begin{array}{l}\text { Daily } \\
\text { Moisture } \\
\text { Volume }^{c}\end{array} \\
\begin{array}{l}4.2 \\
\text { gal/day }\end{array}\end{array}$} & \multicolumn{2}{|c|}{ Installed Humidifiers } \\
\hline & 17 occ & $141 \mathrm{ft}^{2} / \mathrm{occ}$ & $\begin{array}{l}3,400 \\
\text { Btuh }\end{array}$ & $996 \mathrm{~W}$ & & $\begin{array}{l}3 \times \\
1.5-\text { gal } \\
\text { humidifier }\end{array}$ & $\begin{array}{l}\sim 4.5 \\
\text { gal/day }\end{array}$ \\
\hline $\begin{array}{l}\text { Daikin Applied } \\
\text { Rebel's Side of } \\
\text { the Office Space }\end{array}$ & 17 occ & $152 \mathrm{ft}^{2} / \mathrm{occ}$ & $\begin{array}{l}3,400 \\
\text { Btuh }\end{array}$ & $996 \mathrm{~W}$ & $\begin{array}{l}4.2 \\
\text { gal/day }\end{array}$ & $\begin{array}{l}3 \times \\
1.5-\text { gal } \\
\text { humidifier }\end{array}$ & $\begin{array}{l}\sim 4.5 \\
\text { gal/day }\end{array}$ \\
\hline $\begin{array}{l}\text { Combined } \\
\text { Second-Floor } \\
\text { Office Space }\end{array}$ & 34 occ & $146 \mathrm{ft}^{2} / \mathrm{occ}$ & $\begin{array}{l}6,800 \\
\text { Btuh }\end{array}$ & $1,992 \mathrm{~W}$ & $\begin{array}{l}8.4 \\
\text { gal/day }\end{array}$ & $\begin{array}{l}6 \times \\
1.5-\text { gal } \\
\text { humidifier }\end{array}$ & $\begin{array}{l}\sim 9.0 \\
\text { gal/day }\end{array}$ \\
\hline $\begin{array}{l}\text { a Based on the office } \\
\text { the space, which resu } \\
{ }^{\mathrm{b}} \text { Latent load based o } \\
{ }^{\mathrm{c}} \text { Based on the numbe } \\
\text { water that should be } \\
{ }^{\mathrm{d}} \text { To represent the int } \\
\text { sufficient gallons acr } \\
\text { diffusion of moisture } \\
{ }^{\mathrm{e}} \text { Regarding infiltratic } \\
\text { building } 550 \text { in the } \mathrm{m} \\
\text { windows was left pro } \\
\text { during the workday. }\end{array}$ & $\begin{array}{l}\text { out and } \\
\text { d in a ty } \\
00 \text { Btuh } \\
\text { f occup } \\
\text { orized } \\
\text { al occu } \\
\text { the day } \\
\text { roughou } \\
\text { NREL } \\
\text { nings an }\end{array}$ & $\begin{array}{l}\text { erviewing th } \\
\text { al office spac } \\
\text { cupant. } \\
\text { s and } 200 \mathrm{Bt} \\
\text { epresent occu } \\
\text { t latent load, } \\
\text { arting at } 0700 \\
\text { le office spac } \\
\text { rdinated with } \\
\text { fternoons to }\end{array}$ & $\begin{array}{l}\text { h latent } \\
\text { pant late } \\
\text { NREL st } \\
\text { Note th } \\
\text { NAVF } \\
\text { urn on/o }\end{array}$ & $\begin{array}{l}\text { Dants, NR } \\
\text { ensity of } 1 \\
\text { er occupa } \\
\text { ds for the } \\
\text { umidifiers } \\
\text { of fans we } \\
\text { eave the } € \\
\text { overhead } \\
\text { ltration fr }\end{array}$ & $\begin{array}{l}\text { L determine } \\
0 \mathrm{ft}^{2} / \text { occup } \\
\text { t, calculated } \\
\text { ffice space. } \\
\text { staggered or } \\
\text { trained on } \\
\text { trance door } \\
\text { ghts and the }\end{array}$ & $\begin{array}{l}\text { e daily tot } \\
\text { imers that } \\
\text { e humidifie } \\
\text { upen while }\end{array}$ & $\begin{array}{l}\text { ccupancy of } \\
\text { ullons of } \\
\text { to speed the } \\
\text { y were at } \\
\text { he of the } \\
\text { g the building }\end{array}$ \\
\hline
\end{tabular}




\section{Appendix F: Baseline and Rebel Monitoring Points}

Table F-1 summarizes all the monitoring points maintained on the baseline RTU other than the baseline ClimaCheck monitoring points. Similarly, Table F-2 summarizes the Rebel RTU monitoring points in addition to the ClimaCheck monitoring points.

Table F-1. Baseline RTU Monitoring Points

\begin{tabular}{|c|c|c|c|c|c|}
\hline $\begin{array}{l}\text { Digital or } \\
\text { Analog } \\
\text { Signal }\end{array}$ & $\begin{array}{l}\text { Monitoring } \\
\text { Point }\end{array}$ & $\begin{array}{l}\text { Catalyst Standard } \\
\text { Sensor or } \\
\text { Demonstration Add }\end{array}$ & $\begin{array}{l}\text { Sensor } \\
\text { Manufactu } \\
\text { rer/Model }\end{array}$ & $\begin{array}{l}\text { Sensor } \\
\text { Accuracy }\end{array}$ & Sensor Notes \\
\hline Digital-1 & $\begin{array}{l}\text { Occupied } \\
\text { Status }\end{array}$ & Standard & N/A & N/A & $\begin{array}{l}\text { Controller-calculated, } \\
\text { based on programmed } \\
\text { schedule }\end{array}$ \\
\hline Digital-2 & $\begin{array}{l}\text { First-Stage } \\
\text { Cooling }\end{array}$ & Standard & $\mathrm{N} / \mathrm{A}$ & $\mathrm{N} / \mathrm{A}$ & Signal from controller \\
\hline Digital-3 & $\begin{array}{l}\text { Second- } \\
\text { Stage } \\
\text { Cooling }\end{array}$ & Standard & N/A & N/A & Signal from controller \\
\hline Digital-4 & $\begin{array}{l}\text { Supply Fan } \\
\text { Power }\end{array}$ & Standard & $\begin{array}{l}\text { Yaskawa } \\
\text { variable } \\
\text { frequency } \\
\text { drive Output }\end{array}$ & unknown & $\begin{array}{l}\text { Value is monitored via a } \\
\text { communication output } \\
\text { on the drive; power is } \\
\text { measured internally on } \\
\text { the drive }\end{array}$ \\
\hline Digital-5 & $\begin{array}{l}\text { Total RTU } \\
\text { Power }\end{array}$ & Add & $\begin{array}{l}\text { Continental } \\
\text { watt-node } \\
\text { WNC-3D } \\
\text { with ACT } \\
\text { current } \\
\text { transducers }\end{array}$ & $\begin{array}{l} \pm 3 \% \\
\text { at leading } \\
\text { power } \\
\text { factor of } \\
0.866\end{array}$ & $\begin{array}{l}100 \mathrm{~Hz} \text { resolution Watt- } \\
\text { Node; accuracy } \\
\text { combines Watt-Node } \\
\text { and current transducers } \\
\text { (www.ccontrolsys.com/ } \\
\text { w/Metering_System_Ac } \\
\text { curacy) }\end{array}$ \\
\hline Analog-1 & $\begin{array}{l}\text { OA Temp } \\
\text { Sensor }\end{array}$ & Standard & $\begin{array}{l}\text { Senva HD- } \\
3 B\end{array}$ & $\begin{array}{l} \pm 2^{\circ} \mathrm{C} \\
\left(3.6^{\circ} \mathrm{F}\right) \text { full } \\
\text { range; } \\
0.5^{\circ} \mathrm{C} \\
\left(0.9^{\circ} \mathrm{F}\right) \text { typ } \\
@ 25^{\circ} \mathrm{C} \\
\left(77.0^{\circ} \mathrm{F}\right)\end{array}$ & $\begin{array}{l}\text { RTD; positioned inside } \\
\text { the OA hood, always in } \\
\text { the shade }\end{array}$ \\
\hline Analog-2 & $\begin{array}{l}\text { RA Temp } \\
\text { Sensor }\end{array}$ & Standard & $\begin{array}{l}\text { Senva HD- } \\
\text { 3B }\end{array}$ & $\begin{array}{l} \pm 2^{\circ} \mathrm{C} \\
\left(3.6^{\circ} \mathrm{F}\right) \text { full } \\
\text { range; } \\
0.5^{\circ} \mathrm{C} \\
\left(0.9^{\circ} \mathrm{F}\right) \text { typ } \\
@ 25^{\circ} \mathrm{C} \\
\left(77.0^{\circ} \mathrm{F}\right)\end{array}$ & $\begin{array}{l}\text { RTD; positioned at the } \\
\text { RA inlet into the RTU }\end{array}$ \\
\hline Analog-3 & $\begin{array}{l}\text { SA Temp } \\
\text { Sensor }\end{array}$ & Standard & $\begin{array}{l}\text { ACI-AN } \\
\text { Series }\end{array}$ & $\pm 0.36^{\circ} \mathrm{F}$ & $\begin{array}{l}\text { RTD in supply air } \\
\text { ductwork }\end{array}$ \\
\hline Analog-4 & $\begin{array}{l}\text { MA Temp } \\
\text { Sensor }\end{array}$ & Add & $\begin{array}{l}\text { ACI-AN } \\
\text { Series }\end{array}$ & $\pm 0.36^{\circ} \mathrm{F}$ & $\begin{array}{l}\text { Single RTD } \\
\text { measurement located at } \\
\text { the filter inlet }\end{array}$ \\
\hline Analog-5 & $\begin{array}{l}\text { OA RH } \\
\text { Sensor }\end{array}$ & Standard & $\begin{array}{l}\text { Senva HD- } \\
3 B\end{array}$ & $\begin{array}{l} \pm 3 \%, 20 \%- \\
80 \% \text { Range }\end{array}$ & $\begin{array}{l}\text { Capacitance sensor; } \\
\text { positioned inside the } \\
\text { OA hood, always in the } \\
\text { shade }\end{array}$ \\
\hline
\end{tabular}




\begin{tabular}{|c|c|c|c|c|c|}
\hline $\begin{array}{l}\text { Digital or } \\
\text { Analog } \\
\text { Signal }\end{array}$ & $\begin{array}{l}\text { Monitoring } \\
\text { Point }\end{array}$ & $\begin{array}{l}\text { Catalyst Standard } \\
\text { Sensor or } \\
\text { Demonstration Add }\end{array}$ & $\begin{array}{l}\text { Sensor } \\
\text { Manufactu } \\
\text { rer/Model }\end{array}$ & $\begin{array}{l}\text { Sensor } \\
\text { Accuracy }\end{array}$ & Sensor Notes \\
\hline Analog-6 & $\begin{array}{l}\text { RA RH } \\
\text { Sensor }\end{array}$ & Standard & $\begin{array}{l}\text { Senva HD- } \\
3 B\end{array}$ & $\begin{array}{l} \pm 3 \%, 20 \%- \\
80 \% \text { Range }\end{array}$ & $\begin{array}{l}\text { Capacitance sensor; } \\
\text { positioned at the RA } \\
\text { inlet into the RTU }\end{array}$ \\
\hline Analog-7 & $\begin{array}{l}\mathrm{RACO}_{2} \\
\text { Sensor }\end{array}$ & Standard & $\begin{array}{l}\text { AirTest TR- } \\
9291\end{array}$ & $\begin{array}{l} \pm 30 \text { PPM; } \\
\pm 3 \% \\
\text { reading }\end{array}$ & $\begin{array}{l}\mathrm{CO}_{2} \text { sensor positioned } \\
\text { in return air ductwork }\end{array}$ \\
\hline Analog-8 & $\begin{array}{l}\text { Space } \\
\text { Temperature }\end{array}$ & Add & $\begin{array}{l}\mathrm{ACl} \mathrm{A} / 1 \mathrm{~K}- \\
2 \mathrm{~W}\end{array}$ & $\begin{array}{l} \pm 1.1^{\circ} \mathrm{C} \\
\left(1.9^{\circ} \mathrm{F}\right)\end{array}$ & $\begin{array}{l}\text { Wall-mount temperature } \\
\text { sensor located at the } \\
\text { existing thermostat } \\
\text { location }\end{array}$ \\
\hline Analog-9 & $\begin{array}{l}\text { OA Damper } \\
\text { Controller }\end{array}$ & Standard & CAT-371 & $\begin{array}{l}0-10 \text { VDC } \\
\text { signal at 8- } \\
\text { bit } \\
\text { resolution }\end{array}$ & $\begin{array}{l}\text { Control signal } \\
\text { generated by controller } \\
\text { CAT-371 }\end{array}$ \\
\hline Analog-10 & Fan Speed & Standard & $\begin{array}{l}\text { Communicat } \\
\text { ing Modbus } \\
\text { signal }\end{array}$ & $N / A$ & $\begin{array}{l}\text { Control signal } \\
\text { generated by controller } \\
\text { CAT-371 }\end{array}$ \\
\hline
\end{tabular}

Table F-2. Rebel Monitoring Points ${ }^{20}$

BACnet Variable Description
Name

Eq_ID

Timestamp

Remapped from "Supply Fan Capacity (SupFanCap)." This read-only
attribute indicates the current supply fan capacity. The BACnet property reads
only the subject attribute; however, the LONWORKS variable is only a part of
the LONWORKS Unit Status network variable. See Unit State for details. This
variable will read 0\% whenever the fan is off. If the unit is configured as
constant volume, this variable reads $100 \%$ when the fan is on. Otherwise, it
will read the feedback from the variable-frequency drive.
Remapped from "Outdoor Air Temperature (OutdoorTemp)." This read-only
attribute indicates the current value of a unit-mounted outdoor air temperature
Sensor. This variable only applies if the unit is configured for an outdoor air
temperature sensor.

\footnotetext{
${ }^{20}$ Daikin. March 2013. “MicroTech III Unit Controller for Rebel Commercial Package Rooftop Systems.” Accessed April 3, 2013:

http://lit.daikinapplied.com/bizlit/DocumentStorage/RooftopSystems/InstallationandOperationManuals/OM_11412_Rebel_DPS-MT3_Controller.pdf.
} 


\begin{tabular}{ll}
\hline $\begin{array}{l}\text { BACnet Variable } \\
\text { Name }\end{array}$ & Description \\
\hline RATempRebel & $\begin{array}{l}\text { Remapped from "Return Air Temperature (RATemp)." This read-only attribute } \\
\text { that indicates the current reading from the unit return air temperature sensor. } \\
\text { This variable only applies if the unit is configured for a return air sensor. }\end{array}$ \\
DATempRebel & $\begin{array}{l}\text { Remapped from "Discharge Air Temperature (DischAirTemp)." This read-only } \\
\text { property indicates the current reading of the unit discharge air temperature } \\
\text { sensor. }\end{array}$ \\
& $\begin{array}{l}\text { Remapped from "Space Temperature Input (SpaceTemplnput)." This } \\
\text { read/write attribute indicates the current space or zone temperature that is } \\
\text { written from the network. If this network value becomes unreliable, the } \\
\text { temperature reverts to the value provided by the attached space temperature } \\
\text { sensor. This variable only applies if the unit is configured for a space } \\
\text { temperature sensor. }\end{array}$ \\
SpaceTempRebel & $\begin{array}{l}\text { This is not a BACnet point. This is monitored power from a separate meter. } \\
\text { UnitPower }\end{array}$ \\
AlarmValue & $\begin{array}{l}\text { This object allows individual notification of the highest priority active alarm. } \\
\text { The value in the table below is the largest number in its enumeration that } \\
\text { corresponds to an active alarm. This object is set to zero if no alarms are } \\
\text { active. }\end{array}$ \\
ActiveFault &
\end{tabular}

ActiveProblem

ActiveWarning

This read-only property indicates the current percentage of unit maximum cooling capacity. The BACnet property reads only the subject attribute; however, the LONWORKS variable is only a part of the LONWORKS Unit ClgCapacity Status network variable. See Page 90 for details of LONWORKS network variable. The BACnet property only applies to the subject data point. The LONWORKS variable covers six other data points: Unit State, Heating Capacity, Reheat Capacity, Supply Fan Capacity, Economizer Capacity, and In Alarm. This variable only applies if the unit is configured for cooling.

This read-only attribute indicates whether or not cooling is currently enabled. ClgStatus If cooling is disabled, the reason is indicated. $1=$ Enabled; $2=$ None; $3=\mathrm{Off}$ Amb; 4=Off Alarm; 5=Off Net; 6=Off Man.

\section{CmpClgHrs}




\section{BACnet Variable Name \\ Description}

Comp2Hrs

ControlTemp This read-only property indicates the current control temperature. As shown in the graph to the right, this parameter is set to "SpaceTempNet."

\section{CurrentState}

DewpointSp

DischLn1Temp

DischLn3Temp

EconCapacity $\quad$ Stapp

EconoHrs

EconoStatus

Eft_Lct

EffectOccup

EmergOverride
This read/write property sets the dew point set point via the network.

This read-only property indicates the current reading of the unit inverter compressor (Comp. 1) discharge line refrigerant temperature sensor.
This read-only attribute indicates the current economizer capacity or outdoor air damper position. The BACnet property reads only the subject attribute; however, the LONWORKS variable is only a part of the LONWORKS Unit Status network variable. See Unit State for details. The BACnet property only applies to the subject data point. The LONWORKS variable covers six other data points: Unit State, Cooling Capacity, Heating Capacity, Reheat Capacity, Supply Fan Capacity, and In Alarm.

This read/write property indicates the economizer accumulated run hours. It can be reset via the network.

This read-only attribute indicates whether or not the economizer is currently enabled. If the economizer is disabled, the reason is indicated. $1=$ Enabled; 2=None; 3=Off Amb; 4=Off Alarm (Not Used); 5=Off Net; 6=Off Man; 7=Off Dehum.

This read-only attribute indicates the current value of the unit entering fan/leaving coil air temperature sensor. This variable only applies to units configured for an entering fan temperature sensor.

This read-only property indicates if the unit is currently in an occupied, unoccupied, or tenant override mode of operation. $1=$ Occ; $2=$ Unocc; $3=$ TntOvrd.

This read/write property shuts off the unit controller. If this property is set to Off, the unit controller cannot start based on a time clock or any other means. The only way to start the unit controller is to change the value to Normal. If a value other than Off or EMERG_SHUTDOWN, is written, this variable reverts back to Normal. $1=$ Normal; $2=$ Off. 


\section{BACnet Variable Name}

HumiditySp

INVCMPHRS

INVCOMPPRB

RebelStatus

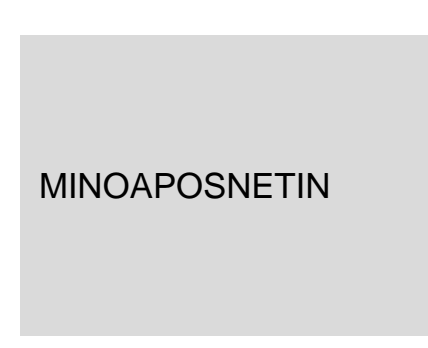

OccManCmd

Remapped from "Occupied Cooling Set Point (OccCoolSP)." This read/write
configuration property sets the Occupied Cooling Set Point is set to this value
when it is not being set by another function. This attribute uses maximum and
minimum limits. If the present value is set beyond these limits from the
network, the value is ignored and the controller continues to control to the last
valid value. The BACnet property only applies to the subject data point, but
the LONWORKS variable is a structure that covers three other data points:
Unoccupied Cooling Set Point, Occupied Heating Set Point, and Unoccupied
Heating Set Point.

\section{Description}

This is a read/write property that the network can use to set the relative humidity set point from the network.
This read/write property indicates the inverter compressor accumulated run hours. It can be reset via the network.

This read-only BACnet object indicates whether the Inverter Compressor Problem alarm is active (1) or not active (0).

This output network variable indicates the operating status of the unit controller. 1 = Enabled; 2 = Off Man; 3 = Off ManCtrl; $4=$ Off Net; $5=$ Off Alarm; 6 = Off Fan Retry.

This read/write configuration property sets the Outdoor Air Damper Minimum Position set point for MicroTech III Unit Controller. The Minimum Outdoor Air Damper Position Input set point uses this value when it is not being set by any other function and when Min OA Type is set to Network. The controller internally limits the present value that is written between the DCV Limit and the Vent Limit (see the Min OA Damper menu on the keypad/display). This variable only applies to units configured with an airside economizer.

This read/write property sets the unit into a different occupancy mode. The request is typically sent by a wall-mounted occupant-interface module or a supervisory node, typically used to manually control occupancy modes or to override the scheduled occupancy. This input is used with nviOccSchedule to determine the effective occupancy mode. Refer to Occupancy (nvoEffectOccup) section for more information. 1 = Occ; 2 = Unocc; $3=$ TntOvrd; 4 = Standby (Same as Occ); 5 = Auto.

Remapped from "Occupied Cooling Set Point (OccCoolSP)." This read/write configuration property sets the Occupied Cooling Set Point is set to this value when it is not being set by another function. This attribute uses maximum and minimum limits. If the present value is set beyond these limits from the network, the value is ignored and the controller continues to control to the last valid value. The BACnet property only applies to the subject data point, but the LONWORKS variable is a structure that covers three other data points: Heating Set Point.

RefDischP

This read-only property indicates the current reading of the unit discharge line refrigerant pressure sensor.

RefSuctionP

This read-only property indicates the current reading of the unit suction line refrigerant temperature sensor.

This read-only attribute indicates the current percentage of unit reheat capacity. The BACnet property reads only the subject attribute and only applies to the subject data point. The LONWORKS variable is only a part of the LONWORKS Unit Status network variable. See Unit State for details. The LONWORKS variable covers six other data points: Unit State, Supply Fan 


\section{BACnet Variable Name} Capacity, Cooling Capacity, Heating Capacity, Economizer Capacity, and In
Alarm.

\section{Description}

This is a read/write property the network can use to set the relative humidity from the network. If the network value becomes unreliable, the humidity reverts to the value provided by the attached relative humidity sensor.
SucnRefTemp

TenantOrHrs

UnitState

UnoccupiedCool

This read-only property indicates the current reading of the unit suction line refrigerant temperature sensor.

This read/write property indicates the tenant override operation accumulated run hours. It can be reset via the network.

This read-only property indicates the current unit operating state. This is a LONWORKS only variable that covers six other data points: Supply Fan Capacity, Cooling Capacity, Heating Capacity, Reheat Capacity, Economizer, and In Alarm. 1 = Off; 2 = Start; 3 = Recirc; 4 = FanOnly; 5 = MinDAT; 6 = Htg; 7 = Econo; 8 = Clg.

This read/write configuration property sets the temperature above which the unit starts and provides cooling (night setup) during unoccupied periods. An optional space temperature sensor is required for unoccupied cooling operation. This attribute uses maximum and minimum limits. If the present value is set beyond these limits from the network, the value is ignored and the controller continues to control to the last valid value. The BACnet property only applies to the subject data point, but the LONWORKS variable is a structure that covers three other data points: Occupied Cooling Set Point, Occupied Heating Set Point, and Unoccupied Heating Set Point.

ChargeLossPrb

This read-only BACnet object indicates whether the refrigerant system charge has been completely lost (1) or not (0).

DirtyFilterSw

DuctHiLmtSw

EmergencyOffSw

ExpValveProb
This read-only BACnet object indicates whether the Dirty Filter Warning alarm is active (1) or not active (0).

This read-only BACnet object indicates whether the Duct High Limit Fault alarm is active (1) or not active (0). This variable only applies to units configured for supply fan VFDs. 0 - Normal; 1 - Alarm.

This read-only BACnet object indicates whether the Emergency Off Fault alarm is active (1) or not active (0).

This read-only BACnet object indicates whether the Expansion Valve Problem alarm is active (1) or not active (0). 


\begin{tabular}{ll}
\hline $\begin{array}{l}\text { BACnet Variable } \\
\text { Name }\end{array}$ & Description \\
\hline HiDITempPrb & $\begin{array}{l}\text { This read-only BACnet object indicates whether the High Discharge } \\
\text { Temperature Problem alarm is active (1) or not active (0). }\end{array}$ \\
HiPress1Prb & $\begin{array}{l}\text { This read-only BACnet object indicates whether the High Pressure Circuit } 1 \\
\text { Problem alarm is active (1) or not active (0). This variable applies only to units } \\
\text { configured for two or more mechanical cooling circuits. }\end{array}$ \\
HiPress1Sw & $\begin{array}{l}\text { This read-only BACnet object indicates the condition of the High Pressure } \\
\text { Circuit 1 Switch (Closed (1) or Open (0)). The 'OffNormal' state of this object } \\
\text { indicates a High Pressure Circuit } 1 \text { Problem. }\end{array}$
\end{tabular}

IFBCommPrb This read-only BACnet object indicates whether the Interface Board Communication Problem alarm is active (1) or not active (0).

LoChargePrb This read-only BACnet object indicates whether the Low Refrigerant Charge Problem alarm is active (1) or not active (0).

LoPress1Prb

This read-only BACnet object indicates whether the Low Pressure Problem alarm is active (1) or not active (0).

LoPressDiffPrb

This read-only BACnet object indicates whether the Low Pressure Differential Problem alarm is active (1) or not active (0).

OaFanPrb

SupFanCtrl

SpaceDewPt
This read-only BACnet object indicates whether the Outdoor Fan Problem alarm is active (1) or not active (0).

This read/write property selects the supply fan airflow control used on a variable air volume unit. If this parameter is set to Duct Static Pressure (DSP), the supply fan airflow maintains the duct static pressure at the duct static pressure set point. If this parameter is set to Speed, the supply fan airflow is controlled to a variable frequency drive speed set via the Supply Fan Capacity Input. If this is set to $1 Z n V A V$, the supply fan airflow is controlled to maintain the Control Temperature at the Occupied Cooling Set Point or the Occupied Heating Set Point depending on the Unit State.

This read-only attribute indicates the current dew point calculated from the current reading of the optional relative humidity sensor. 


\section{Appendix G: Economic Analysis Details}

Economic Analysis Information

eROI Analyses

Table G-1. Summary of Key Information Regarding the eROI Analyses Developed for This Project

\begin{tabular}{ll}
\hline Input Type & Demo Actuals \\
\hline Date of Analysis & Feb. 11, 2014 \\
\hline eROI Version & V2.9.16B \\
\hline Project Overview Tab & Fac. Energy \\
\hline \multicolumn{2}{|l}{ Improv. }
\end{tabular}




\section{BLCC Analysis}

Table G-2. Summary of Key Information Regarding the Building Life-Cycle Cost Analyses Developed for This Project

\begin{tabular}{|c|c|}
\hline BLCC Analyses: Key Informatior & \\
\hline Input Type & Value \\
\hline Report Type & MILCON/ECIP \\
\hline BLCC Version & BLC 5.3-12 \\
\hline Location & Hawaii \\
\hline Discounting Convention & Mid-Year Discounting \\
\hline Analysis Type & Constant Dollar Analysis \\
\hline Base Date & October 2013 \\
\hline Beneficial Occupancy & October 2013 \\
\hline Length of Study & 15 Years \\
\hline Energy Usage Indice & $100 \%$ through Economic Life \\
\hline Initial Investment Cost ${ }^{\mathrm{a}}$ & $\$ 13,419$ \\
\hline Non-Annual Recurring Cost ${ }^{\mathrm{b}}$ & $\$ 1,100$ \\
\hline User Rates Electricity Escalation ${ }^{c}$ & $0 \%$ \\
\hline Real Discount Rate & $3.0 \%$ \\
\hline
\end{tabular}

a Initial investment cost equal to the difference between the HE RTU and ASHRAE 90.1 code compliant RTU

${ }^{\mathrm{b}}$ Additional training expense, occurring at time of beneficial occupancy.

${ }^{\mathrm{c}} \mathrm{DOE}$, State specific escalation rates were not used due to recent, high variability in pricing 


\section{Appendix H: Uncertainty Analysis}

All RTU field demonstration measurements and models based thereupon have inherent uncertainties that should be accounted for when discussing the predicted annual energy usage. The uncertainties in the measurements and models in this paper are discussed in this Appendix. All of these uncertainties contribute to the variations in the model predictions, expressed in confidence intervals.

The final uncertainty in the respective Rebel and baseline EnergyPlus models' annual energy prediction (annual kilowatt-hours) is shown in equation H-1. This uncertainty equation accounts for the power meter uncertainty, sample uncertainty (extrapolating several months of measured data to a yearly savings prediction) and modeling uncertainty. The following subsections discuss the calculation of each uncertainty term. The t-statistic was set to 2.04 based on an n-p of 70 and 95\% confidence interval (2 standard deviations). NREL calculated the total uncertainty to be $\pm 27 \%$ of the annual energy savings based on a $95 \%$ confidence interval.

$$
U_{T}=t \sqrt{R E_{\text {instrument }}^{2}+U_{S}^{2}+U_{m}^{2}}
$$

where

$U_{T}$ is the total uncertainty of the EnergyPlus model's annual energy prediction, $R E_{\text {instrument }}$ is the total uncertainty of the RTU power measurement based on the power meter manufacturer's stated accuracy, $U_{s}$ is the sampling uncertainty, $U_{m}$ is the uncertainty in the EnergyPlus model, and $t$ is the t-statistic.

\section{Rooftop Unit Power Measurement Uncertainty}

The baseline and Rebel RTUs total power were monitored using 100 hertz resolution WNC-3D watt-nodes with ACT current transducers on each phase. The manufacturer, Continental Controls, provides the calculation procedure for combining the accuracy of their watt-node and current transducers based on power factor. For the RTU power measurements, which are predominantly inductive motor loads, the lagging power factor will range from 0.8 to 0.9 (www.ccontrolsys.com/w/Metering_System_Accuracy). Based on the on-site power factor measurement being above 0.85 for the power entering both RTUs, NREL stipulated the uncertainty of the power measurement was $3 \%$ based on the calculated combined watt-node and current transducer measurement accuracy.

\section{Sampling Uncertainty}

There are two types of sampling uncertainties. The first is the sampling uncertainty based on measuring across a large cross-section of RTU characteristics found at NAVFAC facilities, including make, model, size, and building type served. The sample size of this field demonstration is 1 . Because the scope of the study was to quantify the energy savings of one 10ton Rebel against one 10-ton baseline, this sampling uncertainty was not considered. While the savings numbers presented in this report can be indicative of energy savings realized on a larger sample set, these energy savings are by no means representative of a random sample set representing the entire RTU sample set at NAVFAC facilities. 
The second type of sample uncertainty deals with the fact the annual energy savings is based on a model that was calibrated against several months of field demonstration data (November 2013 through January 2014). The data samples are compared in "days" as NREL used daily total energy usage (kilowatt-hours) when calibrating the models. The baseline EnergyPlus model was calibrated against 36 days measured during the demonstration period. The Rebel EnergyPlus model was calibrated against 35 days measured during the demonstration period. The EnergyPlus calculation of annual energy usage is based on 260 days ( 5 days per week multiplied by 52 weeks). ${ }^{21}$

Equation $\mathrm{H}-2$ shows the calculation of this sampling uncertainty for the baseline and Rebel annual energy usage. This methodology is based on Equation 5.1 in ASHRAE Guideline $14 .^{22}$ Because the energy savings is the difference between the baseline and Rebel model energy outputs, the sampling uncertainty was calculated by combining both together. Therefore, the total number of data samples (Q) was 520 days (1 year at 260 days for the Rebel Model plus 1 year at 260 days for the baseline model). The number of measured samples (q) was 71 days (36 days for baseline plus 35 days for Rebel). The combined sampling uncertainty was $8 \%$.

$$
U_{s}=\frac{100}{\bar{y}} \times \sqrt{(1-q / Q)\left[\sum_{i=1}^{n}\left(y_{i}-\bar{y}\right)^{2} /(q-1)\right] / q}
$$

where

$\mathrm{U}_{\mathrm{s}}$ is sampling uncertainty (\%),

$\bar{y}$ is mean of the measured data ( $\mathrm{kWh} / \mathrm{day})$,

$\mathrm{q}$ is number of samples in the measured data,

$\mathrm{Q}$ is total number of data samples for both annual models (520 days), and

$y_{i}$ is measured data sample $(\mathrm{kWh} /$ day $)$.

\section{EnergyPlus Model Uncertainty}

During the calibration process, NREL compared the daily modeled energy usage (kilowatthours) versus the daily measured energy usage (kilowatt-hours). Equation $\mathrm{H}-3$ shows the calculation procedure for the coefficient of variation of the root mean squared error CVRMSE, based on the measured versus modeled daily energy usage. Similar to the sampling uncertainty calculation above, the CVRMSE was calculated combining the measured versus model with both baseline and Rebel RTU calibration data sets. The CVRMSE for the combined baseline and Rebel calibration periods was $10 \%$. When calculated separately, the CVRMSE of the Rebel model was $17 \%$ and $7 \%$ for the baseline model.

\footnotetext{
${ }^{21}$ NREL did not include holidays when running the annual models because typical thermostat controls can only handle a 7-day schedule, not incorporating holidays. Therefore, even though the buildings are empty on holidays, the RTUs will continue to run. However, the energy models did account for reduced building loads on 10 holidays across the year.

${ }^{22}$ ASHRAE. ASHRAE Guideline 14-2002. Measurement of Energy and Demand Savings. Atlanta, GA: American Society of Heating, Refrigerating and Air-Conditioning Engineers, 2012.
} 
$\mathrm{U}_{\mathrm{m}}=\operatorname{CVRMSE}=\frac{\sqrt{\sum_{i=1}^{n}\left(y_{i}-\tilde{y}\right)^{2} /(n-p)}}{\bar{y}}$

where

$y_{i}$ is the measured daily energy usage during the calibration period,

$\tilde{y}$ is the model daily energy usage during the calibration period,

$\mathrm{n}$ is the total days in the Baseline and Rebel calibration periods, and

$\mathrm{p}$ is equal to 1 ,

$\bar{y}$ is the average measured daily energy usage during the calibration period. 


\section{Appendix I: Naval Facilities Engineering Command Routine Rooftop Unit Maintenance Procedures}

The NAVFAC PAC HVAC shop provided its quarterly Job Plan and Task Report, which is shown in Figure H-1.

\section{Job Plan and Task Report}

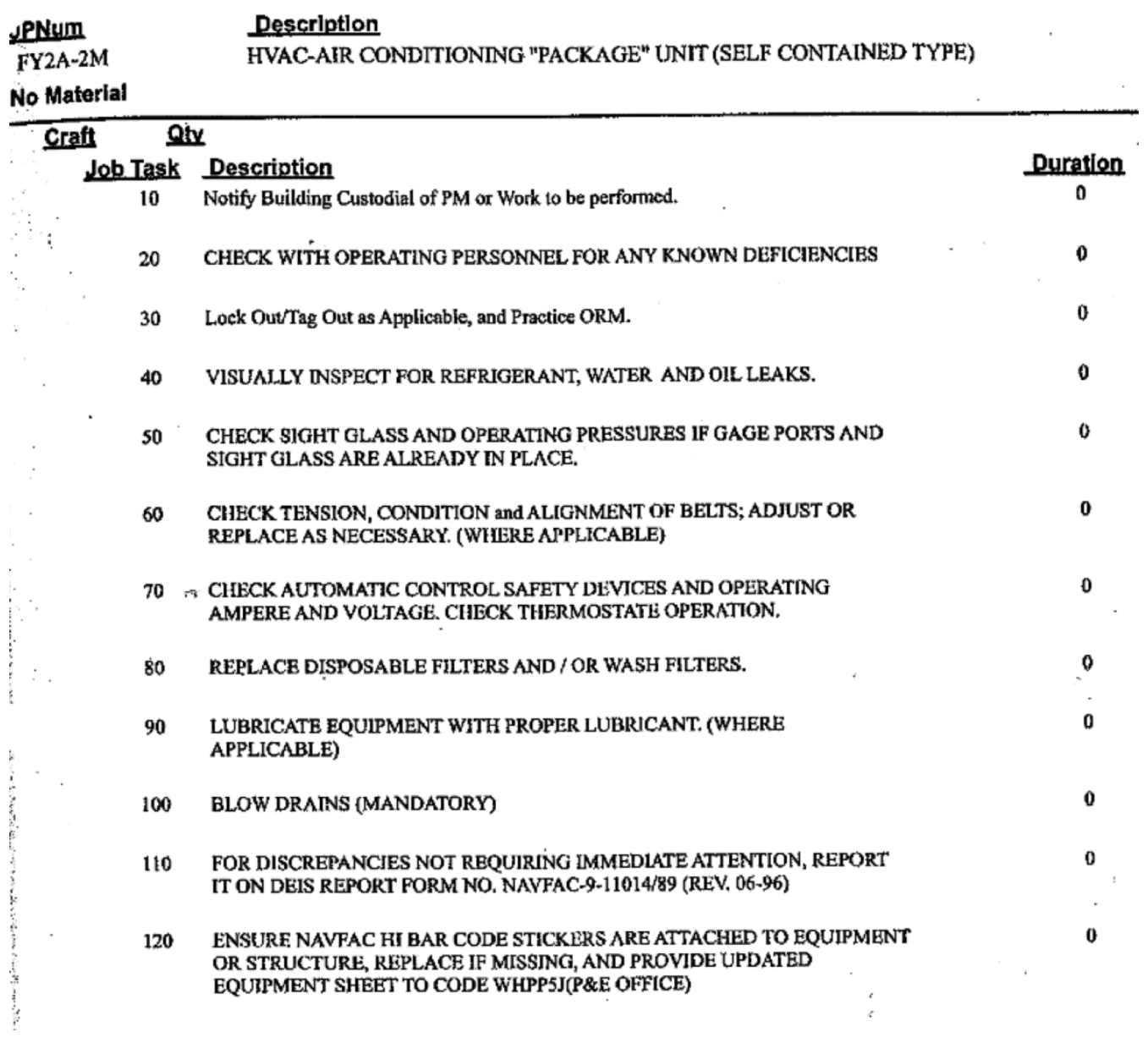

Figure H-1. NAVFAC quarterly RTU maintenance procedure 